\title{
The Society for Worldwide Interbank Financial Telecommunication (SWIFT)
}

This book traces the history and development of a mutual organization in the financial sector called SWIFT, the Society for Worldwide Interbank Financial Telecommunication. Over the last 40 years, SWIFT has served the financial services sector as proprietary communications platform, provider of products and services, standards developer, and conference organizer (Sibos). Founded to create efficiencies by replacing telegram and telex (or "wires") for international payments, SWIFT now forms a core part of the financial services infrastructure. It is widely regarded as the most secure trusted third-party network in the world serving 212 countries and over 10,000 banking organizations, securities institutions, and corporate customers. Through every phase of its development, SWIFT has maintained the status of industry cooperative, thus presenting an opportunity to study broader themes of globalization and governance in the financial services sector.

In this book the authors focus on how the design and current state of SWIFT were influenced by its historical origins, presenting a comprehensive account in a succinct form which provides an informative guide to the history, structure, activities, and future challenges of this key international organization.

This work will be of great interest to students and scholars in a wide range of fields including IPE, comparative political economy, international economics, business studies, and business history.

Susan V. Scott is a Reader in the Information Systems and Innovation Group, Department of Management, at The London School of Economics and Political Science. She received a Ph.D. from the Judge Business School at the University of Cambridge. Her research interests include information systems and risk management; electronic trading; post-trade services; organizational reputation risk management; rating, ranking and review mechanisms in social media; business transformation and global business management.

Markos Zachariadis is an Assistant Professor of Management and Information Systems at Warwick Business School, University of Warwick. He received a Ph.D. from the Information Systems and Innovation Group, Department of Management, at The London School of Economics and Political Science. His research interests include the history and economics of innovation, technology adoption, and the diffusion of data, information and knowledge across digital and social networks. 


\title{
Routledge Global Institutions Series
}

Edited by Thomas G. Weiss

The CUNY Graduate Center, New York, USA

and Rorden Wilkinson

University of Manchester, UK

\begin{abstract}
About the series
The Global Institutions Series has two "streams." Those with blue covers offer comprehensive, accessible, and informative guides to the history, structure, and activities of key international organizations, and introductions to topics of key importance in contemporary global governance. Recognized experts use a similar structure to address the general purpose and rationale for specific organizations along with historical developments, membership, structure, decision-making procedures, key functions, and an annotated bibliography and guide to electronic sources. Those with red covers consist of research monographs and edited collections that advance knowledge about one aspect of global governance; they reflect a wide variety of intellectual orientations, theoretical persuasions, and methodological approaches. Together the two streams provide a coherent and complementary portrait of the problems, prospects, and possibilities confronting global institutions today.

Related titles in the series include:
\end{abstract}

The International Organization for Standardization (2009) by Craig N. Murphy and JoAnne Yates

Global Think Tanks (2011)

by James G. McGann with Richard Sabatini

Corporate Social Responsibility (2013)

by Oliver F. Williams

Private Foundations and Development Partnerships (2014)

by Michael Moran

The UN Global Compact (forthcoming)

by Catia Gregoratti 


\section{The Society for Worldwide Interbank Financial Telecommunication (SWIFT)}

Cooperative governance for network innovation, standards, and community

Susan V. Scott and

Markos Zachariadis

Routledge

(2) 
First published 2014

by Routledge

2 Park Square, Milton Park, Abingdon, Oxon OX14 4RN

Simultaneously published in the USA and Canada

by Routledge

711 Third Avenue, New York, NY 10017

Routledge is an imprint of the Taylor \& Francis Group, an informa business.

(C) 2014 Susan V. Scott and Markos Zachariadis

The right of Susan V. Scott and Markos Zachariadis to be identified as authors of this work has been asserted by them in accordance with the Copyright, Designs and Patent Act 1988.

The Open Access version of this book, available at www.tandfebooks.com, has been made available under a Creative Commons Attribution-Non Commercial-No Derivatives 3.0 license.

Trademark notice: Product or corporate names may be trademarks or registered trademarks, and are used only for identification and explanation without intent to infringe.

British Library Cataloguing in Publication Data

A catalogue record for this book is available from the British Library.

Library of Congress Cataloging in Publication Data

A catalog record for this book has been requested

ISBN: 978-0-415-63164-8 (hbk)

ISBN: 978-1-315-84932-4 (ebk)

Typeset in Times New Roman

by Cenveo Publisher Services 


\section{Contents}

List of illustrations $\quad$ vi

Foreword ix

Acknowledgments xii

Abbreviations xiv

Introduction 1

1 Origins of the society $\quad 7$

2 How SWIFT works $\quad 27$

3 SWIFT standards $\quad 55$

4 Development of the SWIFT network 95

5 Current debates in historical perspective 119

6 Conclusion 151

$\begin{array}{ll}\text { Select bibliography } & 157\end{array}$

Index 159 


\section{Illustrations}

\section{Figures}

2.1 Board committees 31

2.2 V-shaped message flow structure $\quad 36$

2.3 Y-copy message flow via SWIFTNet 37

2.4 Evolution of security 42

3.1 Parsing of a user-to-user MT 62

3.2 A paper customer transfer instruction translated into a SWIFT MT 100 message $\quad 64$

3.3 Components of a SWIFT address (BIC) 67

3.4 Mapping a FIN MT 103 customer credit transfer on to an ISO 20022 XML-based message $\quad 76$

4.1 SWIFT network in $1977 \quad 97$

4.2 Cross-country diffusion of SWIFT (1977-2006) 101

4.3 SWIFT II network infrastructure 105

$\begin{array}{ll}4.4 & \text { SWIFTNet system configuration } \\ & 108\end{array}$

4.5 Diffusion of SWIFT 111

\section{Tables}

1.1 Chairpersons of SWIFT 16

1.2 CEOs of SWIFT 17

2.1 Description of payment system processes 34

2.2 Transaction Infrastructure Services activities 35

2.3 Sibos locations, themes, and numbers of participants
(1978-2013)

3.1 First SWIFT Message Types (MT) categories 63

$\begin{array}{ll}3.2 \mathrm{XML} \text { versus SWIFT proprietary syntax } & 71\end{array}$

3.3 Standards for securities trade lifecycle $\quad 78$

3.4 Key SWIFT standards-related documents $\quad 82$

4.1 SWIFT system traffic volumes (1977-1982) 103 
4.2 Benefits from the use of the SWIFT network in the early years

4.3 Growth of SWIFT connections, countries, and annual traffic (1977-2012)

\section{Boxes}

1.1 The Citi chimney sweep

2.1 SWIFT II and a new approach to operations

3.1 Standards, process innovation, and business transformation

3.2 XML

3.3 A Tale of Two Standards

4.1 SWIFT Interface Device

5.1 Heidi Miller's speech at Sibos 2004 



\section{Foreword}

The current volume is the 83rd title in a dynamic series on global institutions. These books provide readers with definitive guides to the most visible aspects of what many of us know as "global governance". Remarkable as it may seem, there exist relatively few books that offer in-depth treatments of prominent global bodies, processes, and associated issues, much less an entire series of concise and complementary volumes. Those that do exist are either out of date, inaccessible to the non-specialist reader, or seek to develop a specialized understanding of particular aspects of an institution or process rather than offer an overall account of its functioning and situate it within the increasingly dense global institutional network. Likewise, existing books have often been written in highly technical language or have been crafted "in-house" and are notoriously self-serving and narrow.

The advent of electronic media has undoubtedly helped research and teaching by making data and primary documents of international organizations more widely available, but it has complicated matters as well. The growing reliance on the internet and other electronic methods of finding information about key international organizations and processes has served, ironically, to limit the educational and analytical materials to which most readers have ready access - namely, books. Public relations documents, raw data, and loosely refereed websites do not make for intelligent analysis. Official publications compete with a vast amount of electronically available information, much of which is suspect because of its ideological or self-promoting slant. Paradoxically, a growing range of purportedly independent websites offering analyses of the activities of particular organizations has emerged, but one inadvertent consequence has been to frustrate access to basic, authoritative, readable, critical, and well-researched texts. The market for such has actually been reduced by the ready availability of varying quality electronic materials.

For those of us who teach, research, and operate in the area, such access to information and analyses has been frustrating. We were delighted several years ago when Routledge saw the value of a series that bucks this trend and 
provides key reference points to the most significant global institutions and issues. They were betting that serious students and professionals would want serious analyses, and they were right. We have assembled a first-rate team of authors to address that market, and the titles - in print and electronic form - are selling well. Our intention remains to provide one-stop shopping for all readers - students (both undergraduate and postgraduate), negotiators, diplomats, practitioners from non-governmental and intergovernmental organizations, and interested parties alike — seeking insights into the most prominent institutional aspects of global governance.

\section{The Society for Worldwide Interbank Financial Telecommunication (SWIFT)}

As we have argued elsewhere - as have many books in this series - the growing salience of non-state actors in world politics is one of the dominant explanations for the increased prominence and salience of the framework of global governance rather than of international organization. ${ }^{1}$ While nonstate actors have received a good deal of our analytical attention, non-state forms of regulation - and the agents behind their creation - have attracted far less. Nonetheless, as Craig Murphy and JoAnne Yates show in their book on the International Organization for Standardization (ISO), nonstate forms of regulation are often complex, extensive, and have a dramatic impact in shaping the world around us. ${ }^{2}$

The Society for Worldwide Interbank Financial Telecommunication (SWIFT) is both a non-state actor and the purveyor of one such form of regulation. SWIFT serves the financial services sector as a proprietary communications platform, a provider of products and services, a standards developer, and an organizer of conferences; and it has done so for the past four decades. Originally created to overcome the inefficiencies in, as well as to replace telegram and telex systems for international payments, SWIFT now forms a core part of the global financial services infrastructure. It serves some 212 countries and territories and provides services for over 10,000 banking organizations, securities institutions, and corporate customers.

Yet to construe SWIFT merely as a widely used provider of financial services would be incorrect. Moreover, it would provide an inadequate representation of the extent to which this non-state "society" has overseen the creation of an extensive and highly developed form of communication and regulation - the perfect instance of what we have called "creeping global

governance". ${ }^{3}$ SWIFT provides what Susan Scott and Markos Zachariadis call the "internet for financial services", overseeing the sending and receiving of more than 4.5 billion messages - astonishing given that very few outside the financial services sector have even heard of it. Indeed, SWIFT's own estimates put daily message traffic for 2013 at around 20 million. ${ }^{4}$ 
These messages deal with financial transactions, though as the authors, and SWIFT itself, point out, it is not a payment system but rather a transport network for virtually all major payment and securities infrastructures.

That actors like SWIFT have significant clout, or that the system that it has created has strong effects in shaping how global finance is conducted, is without doubt. What is less clear - particularly to those unfamiliar with bodies like SWIFT or indeed global finance - is the extent to which non-state forms of regulation and governance are advanced and continue to advance. This is reason alone to recommend that all those interested in global governance read this book. Our recommendation is made all the more easier by the strength of the pages that follow. Susan Scott and Markos Zachariadis' book on SWIFT is first-rate. It combines incisive analysis with factual data to offer the reader a compelling guide to one of the many forms of "creeping global governance" for which we have yet to find an adequate analytical handle. Susan is a Reader in the Information Systems and Innovation Group, Department of Management, at The London School of Economics; and Markos is an Assistant Professor in the Information Systems and Management Group at Warwick Business School. They make a formidable team.

We are pleased to publish their current book in the series, which should be especially useful for the classroom as well as to our understanding of non-state forms of regulation. We wholeheartedly recommend it and, as always, welcome comments from our readers.

Thomas G. Weiss, The CUNY Graduate Center, New York, USA Rorden Wilkinson, University of Manchester, UK

July 2013

\section{Notes}

1 Thomas G. Weiss and Rorden Wilkinson, eds., International Organization and Global Governance (London: Routledge, 2014); Thomas G. Weiss and Rorden Wilkinson, "Rethinking Global Governance: Complexity, Authority, Power, Change", International Studies Quarterly, 58, no. 2 (2014 forthcoming); Peter Willetts, Non-Governmental Organizations in World Politics: The Construction of Global Governance (London: Routledge, 2011); James G. McGann with Richard Sabatini, Global Think Tanks: Policy Networks and Governance (London: Routledge, 2011); Oliver F. Williams, Corporate Social Responsibility: The Role of Business in Sustainable Development (London: Routledge, 2013); and Catia Gregoratti, The UN Global Compact (London: Routledge, forthcoming).

2 Craig N. Murphy and JoAnne Yates, The International Organization for Standardization: Global Governance through Voluntary Consensus (London: Routledge, 2009).

3 Thomas G. Weiss and Rorden Wilkinson, "International Organization and Global Governance: What Matters and Why", International Organization and Global Governance.

4 www.swift.com/assets/swift_com/documents/about_swift/SIF_2013_04.pdf. 


\section{Acknowledgments}

This book was inspired by JoAnne Yates (MIT) who suggested that the material we had gathered about SWIFT might be of interest to this series. We are grateful to the series editors, Thomas G. Weiss and Rorden Wilkinson, for their support and interest in our research. Thanks also to Bernardo Bátiz-Lazo, Mark Billings, and the anonymous reviewers who provided feedback for our article about the origins of SWIFT published in the journal Business History. The Information Systems and Innovation Group (Department of Management) at The London School of Economics and Political Science (LSE) provided Susan Scott with the seed-corn funding that originally enabled her to initiate the research on SWIFT many years ago. This effort was extended in Markos Zachariadis' $\mathrm{PhD}$ research on the "History, economics, and diffusion of SWIFT" published at The London School of Economics (2011) and funded through work at the Centre for Economic Performance (CEP). We thank all those past and present financial services professionals who proved to be a constant source of information and inspiration.

Many thanks to Gottfried Leibbrandt at SWIFT who organized the modest amount of independent research funding which was essential in enabling the authors to consult archive data and conduct interviews at locations in Europe, including the SWIFT headquarters in La Hulpe, Belgium. We are most grateful to the staff and executives at SWIFT for their commitment to this project and for respecting our editorial control over the book contents. We would like to thank all those at SWIFT who found the time to give us feedback on our draft. Special thanks go to Peter Ware at the SWIFT Institute for his erstwhile support over the years and Maria-Eugenia Forcat for being a commensurate communications professional and our organizational genie. We are grateful to SWIFT's legal department who helped us identify and gain access to original historical documents; also to the professional archivists who helped us to find original documents at the Charles Babbage Institute (Center for the History of Information Technology), 
Bank of England, Stanford Research Institute, Guildhall Library, LSE Library, and Barclays Group archives.

This project has been an entirely collaborative effort by the two authors. If, however, for academic reasons, individual responsibility must be assigned for the composition of the book, Susan Scott led on the Introduction, and Chapters 1, 2, 5, and 6 while Markos Zachariadis led on Chapters 3 and 4. We would like to acknowledge the research assistance of Carolyn Paris and express our appreciation for her contribution to the preparation of our final manuscript. Susan Scott is grateful to Wanda Orlikowski (MIT) for her comments on draft chapters. Thanks to Natanya Paris for her help with interview transcription. Thanks also to our loyal colleagues for their patience with us while we worked on this project alongside our regular university duties, especially Chrisanthi Avgerou (LSE), Michael Barrett (University of Cambridge), and Joe Nandhakumar (Warwick Business School). Finally both of us would like to profoundly thank our respective families for constantly believing in us and our academic endeavours. 


\section{Abbreviations}

$\begin{array}{ll}\text { ABECOR } & \text { Associated Banks of Europe Corporation } \\ \text { ABN } & \text { Algemene Bank Nederland } \\ \text { AMRO } & \text { Amsterdamsche and Rotterdamsche Bank (became } \\ & \text { ABN AMRO after merging with Algemene Bank } \\ & \text { Nederland in 1991) } \\ \text { ANSI } & \text { American National Standards Institute } \\ \text { ATM } & \text { Automated Teller Machine } \\ \text { BBA } & \text { British Bankers' Association } \\ \text { BGA } & \text { Barclays Group Archives } \\ \text { BIC } & \text { Bank Identifier Code or Business Identifier Code } \\ \text { BINS } & \text { Barclays Integrated Network System } \\ \text { BIS } & \text { Bank of International Settlements } \\ \text { BP } & \text { Board Paper } \\ \text { BSC } & \text { Binary Synchronous Communication } \\ \text { CBI } & \text { Charles Babbage Institute } \\ \text { CBT } & \text { Computer-Based Terminal } \\ \text { CEDEL } & \text { Leading bank-owned securities and depository system } \\ & \text { in bond clearing (merged with Deutsche Börse } \\ \text { CEPT } & \text { Clearing in 2000 to form Clearstream) } \\ \text { CHAPS } & \text { Conference of European Post and Telecommunications } \\ \text { CISADA } & \text { Clearing House Automated Payment System } \\ & \text { US Comprehensive Iran Sanctions, Accountability, } \\ \text { CLS } & \text { and Divestment Act 2010 } \\ \text { CPSS } & \text { Continuous Linked Settlement } \\ \text { CSV } & \text { Committee on Payment and Settlement Systems of the } \\ \text { CUG } & \text { Bank of International Settlements } \\ & \text { Comma Separated Values } \\ & \text { Closed User Group }\end{array}$




\begin{tabular}{|c|c|}
\hline DFD & Data Field Dictionary \\
\hline DNS & Designated-time Net Settlement \\
\hline DTCC & Depository Trust \& Clearing Corporation \\
\hline DWG & Development Working Group \\
\hline EBIC & European Banks' International Company \\
\hline ebXML & E-Business XML \\
\hline ECB & European Central Bank \\
\hline EDIFACT & $\begin{array}{l}\text { Electronic Data Interchange For Administration, } \\
\text { Commerce, and Transport }\end{array}$ \\
\hline EMI & European Monetary Institute \\
\hline ER & Executive Report \\
\hline ETHZ & Swiss Federal Institute of Technology in Zurich \\
\hline FATF & Financial Action Task Force \\
\hline FAX & Facsimile \\
\hline FIN & FINancial \\
\hline FISD & Financial Information Services Division \\
\hline FIX & Financial Information eXchange \\
\hline FNCB & $\begin{array}{l}\text { First National City Bank of New York (was shortened } \\
\text { to "First National City Bank" in 1962, it then became } \\
\text { "Citibank" in 1976) }\end{array}$ \\
\hline FPL & FIX Protocol Ltd \\
\hline FpML & Financial products Markup Language \\
\hline GEISCO & General Electric Information Services CO. \\
\hline GLM & Guildhall Library Manuscripts \\
\hline HSM & Hardware Security Modules \\
\hline HTML & HyperText Markup Language \\
\hline HVPMI & High Values Payment Market Infrastructures \\
\hline IFT & Interbank File Transfers \\
\hline IMF & International Monetary Fund \\
\hline IP & Internet Protocol \\
\hline ISAE & International Standard on Assurance Engagements \\
\hline ISITC & $\begin{array}{l}\text { International Securities Association for Institutional } \\
\text { Trade Communication }\end{array}$ \\
\hline ISO & International Organization for Standardization \\
\hline LVFTS & Large-Value Funds Transfer Systems \\
\hline LVPS & Large-Value Payment Systems \\
\hline MAC & Message Authentication Code \\
\hline MA-CUG & Member Administered-Closed User Group \\
\hline MARTI & MAchine Readable Telegraphic Input \\
\hline
\end{tabular}




\begin{tabular}{|c|c|}
\hline MDDL & Market Data Definition Language \\
\hline MI & Market Infrastructures \\
\hline $\mathrm{MoU}$ & Memorandum of Understanding \\
\hline MSP & Message Switching Project \\
\hline MT & Message Type \\
\hline MWG & Maintenance Working Group \\
\hline MX & Message Type XML \\
\hline NASA & National Aeronautics and Space Administration \\
\hline NBB & Banque Nationale de Belgique \\
\hline $\mathrm{NCB}$ & National Central Banks \\
\hline NUG & National User Group \\
\hline OAGi & Open Applications Group, inc. \\
\hline OASIS & $\begin{array}{l}\text { Organization for the Advancement of Structured } \\
\text { Information Standards }\end{array}$ \\
\hline OECD & Organization for Economic Cooperation \\
\hline OTC & Over-The-Counter \\
\hline PKI & Public Key Infrastructure \\
\hline PTT & Post, Telegraph, and Telecom authorities \\
\hline RA & Registration Authority \\
\hline RIXML & Research Information eXchange Markup Language \\
\hline RMG & Registration Management Group \\
\hline RTGS & Real-Time Gross Settlement \\
\hline SA & Société Anonyme \\
\hline $\mathrm{SC}$ & Sub-Committee \\
\hline SEG & Standards Evaluation Group \\
\hline SEPA & Single Euro Payments Area \\
\hline SGB & Société Générale de Banque \\
\hline SGML & Standard Generalized Markup Language \\
\hline SIA & Securities Industry Association \\
\hline $\begin{array}{l}\text { Sibos (previously } \\
\text { SIBOS) }\end{array}$ & SWIFT International Banking Operations Seminar \\
\hline SID & SWIFT Interface Device \\
\hline SIIA & Software \& Information Industry Association \\
\hline SIPN & Secure Internet Protocol Network \\
\hline SIPS & Systemically Important Payment Systems \\
\hline SITA & $\begin{array}{l}\text { Société Internationale de Télécommunications } \\
\text { Aéronautiques }\end{array}$ \\
\hline SR & Special Recommendations \\
\hline SRI & Stanford Research Institute \\
\hline
\end{tabular}


SSCP

ST

STP

STS

SVFT

SVPS

SWG

SWIFT

TARGET2

TC

TCP/IP

TFTP

TNB

TWIST

UANI

UBS

UCLA

UGC

UML

UN/CEFACT

UNCITRAL

UNIFI

UNIVAC

VISA

W3C

WG

WPS

XBRL

XML
SWIFT Security Control Policy

SWIFT Terminal

Straight-Through Processing

SWIFT Terminal Services SA

Small-Value Funds Transfer

Small-Value Payment Systems

Standards Working Group

Society for Worldwide Interbank Financial

Telecommunication

Trans-European Automated Real-time Gross

Settlement Express Transfer system

Technical Committee

Transmission Control Protocol/Internet Protocol

Terrorist Finance Tracking Program

TransNational Banks

Treasury Workstation Integration Standards Team

United Against Nuclear Iran (New York-based advocacy group founded in 2008 by US Ambassador Mark D. Wallace, the late US Ambassador Richard Holbrooke, Former CIA Director Jim Woolsey, and Middle East expert Dennis Ross)

Union Bank of Switzerland

University of California Los Angeles

User Group Chairperson

Unified Modelling Language

United Nations Center for Trade Facilitation and

Electronic Business

United Nations Commission on International Trade Law

UNIversal Financial Industry message scheme

UNIVersal Automatic Computer

Visa International Service Association

World Wide Web Consortium

Working Group

Wholesale Payment Systems

eXtensible Business Reporting Language

eXtensible Markup Language 



\section{Introduction}

This book traces the history and development of a mutual organization in the financial sector called SWIFT, the Society for Worldwide Interbank Financial Telecommunication. Over the last 40 years, SWIFT has served the financial services sector as proprietary communications platform, provider of products and services, standards developer, and conference organizer ("Sibos"). Founded to create efficiencies by replacing telegram and telex (or "wires") 1 for international payments, SWIFT now forms a core part of the financial services infrastructure. It is widely regarded as the most secure trusted third-party network in the world, serving 212 countries and over 10,000 banking organizations, securities institutions, and corporate customers. ${ }^{2}$ Through every phase of its development, SWIFT has maintained the status of industry cooperative, thus presenting an opportunity to study broader themes of globalization and governance in the financial services sector.

SWIFT's primary role is that of a message carrier, an international network analogous to the "internet for financial services". In 2012, the SWIFT network was used to send and receive more than 4.5 billion messages ${ }^{3}$ ranging from traditional payments to securities confirmations. In 2013, message traffic grew to around 20 million financial transaction messages per day. ${ }^{4}$ It is important to clarify that SWIFT is not a payment system but serves as a transport network for a large number of major payment and securities infrastructures. This makes it the most significant provider of global financial messaging and processing services in the world today, a position that its cooperative status is designed to mitigate. ${ }^{5}$ SWIFT's Bylaws (2012) state that "the object of the Company is for the collective benefit of the Shareholders of the Company, the study, creation, utilization and operation of the means necessary for the telecommunication, transmission, and routing of private, confidential and proprietary financial messages". ${ }^{6}$ It is important to emphasize that SWIFT is not a bank or a clearing and settlement institution; it does not manage accounts on behalf of 
customers nor does it hold funds. The majority of financial institutions use SWIFT to send and receive information about financial transactions. However, SWIFT does not maintain financial information on an ongoing basis and data are only held for a limited period of time. Rather SWIFT is responsible for providing the network, standards, products, and services that allow member institutions to connect and exchange financial information. It distinguishes itself from public Internet Protocol networks by accepting limited liability for defined categories of loss resulting from transaction message delays that have arisen as a consequence of technical issues within SWIFT. ${ }^{7}$ Financial service professionals say that the most critical part of SWIFT's role is achieving the secure exchange of proprietary data - in other words: reliability, confidentiality, and integrity. While some practitioners recognize the SWIFT infrastructure as a key-operating asset, others simply regard it as the necessary but fundamentally uninteresting sector-wide "plumbing". The history of SWIFT, leading up to its current status as "essential but taken for granted", is a compelling account of institutionalization, codification of practice through standards, and industrialization of financial services. In this book, we chart SWIFT's evolution from an efficiency initiative driven by a closed "society" of banks to a network innovation of world-class standing whose standards continue to shape financial services.

As McKenney and Copeland note, "few firms have broken the mold of history and transformed their industries with a new dominant design for information processing". 8 SWIFT is one of those firms, and a historical analysis of SWIFT is justified from this perspective alone. However, as a mutual organization that has brought to bear a transformative influence in a competitive sector, SWIFT's story is especially provocative. Most accounts of sector change overlook the role of industry cooperatives, focusing instead on profit-seeking organizations and the entrepreneurial individuals within them. In such cases it is the few, not the many, who are credited with seeking out new and improved products, processes, and redesigning organizational structures which will reduce costs, better satisfy customer demands, and yield greater profits. These efforts are cast as part of in-house corporate strategy formulation, internal research, and development programs, or the result of informal "tinkering" or trial-and-error efforts by staff within commercial organizations. ${ }^{9}$ However, as this book bears witness, at particular junctures in the development of financial services, projects and initiatives have been taken out of organizational contexts dominated by profit-maximization imperatives, and been sequestered within a cooperative setting in order to achieve a step-change. The motivation, funding, organization, and effectiveness of such moves are integral to the existence of an organization like SWIFT. 
Organizational arrangements are not the only influence on processes of innovation; prior literature rightly emphasizes technological, management, organizational, and industrial conditions. ${ }^{10}$ For example, there is a level at which progress in computer-based advances like the SWIFT network and its standards are inseparable from specific national histories ${ }^{11}$ and also related to various degrees with changes in regulatory policy. ${ }^{12}$ As will become apparent, we suggest that understanding specific details of SWIFT's development over time, from its origins to current pressures, reveals insights into particular dynamics characterizing organizational change and business transformation in this economically critical sector. This is important because surprisingly little is known about innovation in financial services despite widespread acknowledgment that they play a crucial role as "a facilitator of virtually all production activity and much consumption activity". ${ }^{13}$ Lack of research in this area is thus a concern since we know that "improvements in the financial sector will have direct positive ramifications throughout an economy". 14

During the 1970s, when SWIFT was initiated, the dominant management literature portrayed organizations as the planned outcome of rational decisions made by senior management pursuing mission statements that reflected a grand design. For the most part the role ascribed to computerbased information and communication technologies was deterministic: whatever capabilities technology afforded, organizations would adopt. In practice, business development is a far more situated process: rarely technologically-led, usually historically contingent, and frequently politically entangled. Pausing for a moment to consider what research has already taught us about the nature of techno-innovation in this sector, we know that financial services organizations have tended toward "solution technologies [in response to] the perception of risks and opportunities in given circumstances". ${ }^{15}$ These have been based upon models and architectures that are "with relatively few exceptions not proprietary to this sector" ${ }^{16}$ Moreover, their status as "solutions" shifts; today's engine of innovation becomes folded into emergent strategies and over time sediments into an installed base, thus necessitating further calls for change. In the case of SWIFT, while its status as the trusted third-party infrastructure goes largely unchallenged, questions about its future do emerge and such challenges have to be proactively addressed. Indeed, we would argue that as globalization unfolds, the status of "global institution" carries with it positional vulnerabilities that require constant vigilance and management.

The prevailing strength of SWIFT is its capacity to provide opportunities for cooperation within a competitive sector. The way in which SWIFT has achieved its mandate to serve its member community in financial services over the last four decades reflects the extent to which influence can be 
achieved through consultation and committee: designing the rules that govern a core infrastructure and setting standards. SWIFT's remarkable sector-wide adoption and diffusion is an achievement that should not be downplayed. After all, this degree of institutionalization has eluded alternative initiatives which have aspired to similar status.

SWIFT's status as a core financial services infrastructure and its standing in the community as a "resilience assured" secure network has placed additional pressure on both its governance and design. In addition to demands for contingency planning and robustness that all major financial institutions have addressed since 9/11, SWIFT has found itself drawn into global affairs through its involvement in the Terrorist Finance Tracking Program and calls to exclude Iranian institutions. This has created a complicated outlook for SWIFT as a global institution and stimulated much debate.

We begin, in Chapter 1, by describing the origins of SWIFT in order to put its status as a cooperative society in historical perspective. Chapter 2 focuses on "how SWIFT works" and provides an overview of its organization, structure, operations, and management. Chapter 3 examines the development of SWIFT standards, giving a detailed description of what those standards are and how they reflect different interests in the financial services community. Defining standards goes hand-in-hand with network design and development, so in Chapter 4 we provide an account of the evolution of the SWIFT network and the cross-country diffusion that led it to become a global infrastructure. This brings us to a discussion of the challenges faced by SWIFT, particularly with regard to its cooperative governance. We also explore how and why SWIFT has been implicated in global affairs as well as its entanglement in ongoing processes of globalization. In the conclusion, we reflect on the central themes in the SWIFT study and consider key issues for further research.

\section{Notes}

1 "Wire" was originally used to refer to a cablegram (a message sent by a submarine telegraph cable). However, it eventually became the generic term for all payments made by either telegram or telex.

2 From http://www.swift.com/assets/swift_com/documents/about_swift/SIF_ 2013_04.pdf. See the following website for updated figures: http://www.swift. com/about_swift/company_information/swift_in_figures.

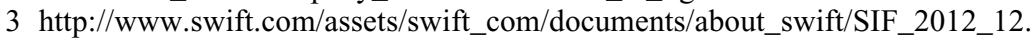
pdf.

4 http://www.swift.com/assets/swift_com/documents/about_swift/SIF_2013_04. pdf.

5 Dominique Rambure and Alec Nacamuli, Payment Systems: From the Salt Mines to the Board Room (Houndsmill: Palgrave Macmillan, 2008): 48. 
6 SWIFT 2012, SWIFT Bylaws, 2012, June, Article 3: 4 (https://www2.swift. com/uhbonline/books/public/en_uk/swift_by_laws/swift_by_laws.pdf).

7 Responsibility and liability for SWIFT's core ('FIN') is defined in their User Handbook. SWIFT accepts liability for direct loss. Direct loss is defined as: "A non-recoverable loss of funds representing the principal amount of authenticated payments or transfers, whatever the category or type of message sent through the FIN service." SWIFT liability for direct loss is EUR 150,000,000 in the aggregate for each annual period.

8 James McKenney, Duncan G. Copeland, and Richard Omason, Waves of Change: Business Evolution through Information Technology (Boston, MA: Harvard Business School Press, 1995): 1.

9 W. Scott Frame and Lawrence J. White, "Empirical studies of financial innovation: lots of talk, little action?" Journal of Economic Literature, 42 (2) (2004): 118.

10 JoAnne Yates, Structuring the Information Age: Life Insurance and Technology in the Twentieth Century (Baltimore, MD: Johns Hopkins University Press, 2005); Craig N. Murphy and JoAnne Yates, The International Organization for Standardization (ISO): Global Governance through Voluntary Consensus (London: Routledge, 2008).

11 Alfred D. Chandler Jr. and James W. Cortada, A Nation Transformed by Information (Oxford: Oxford University Press, 2000).

12 See Alexandros-Andreas Kyrtsis, ed., Financial Markets and Organizational Technologies: Systems Architectures, Practices and Risks in the Era of Deregulation (Houndsmill: Palgrave Macmillan, 2010).

13 Frame and White, "Empirical studies:" 118.

14 Ibid.

15 Kyrtsis, ed., Financial Markets: 14.

16 Ibid., 9. 



\section{Origins of the society}

- Correspondent banking and expanding international trade

- Information communications and globalizing bank services

- Network projects and governance

- Achieving critical mass and global usage

- Co-opetition

SWIFT is among a select few organizations that established the core operational foundations for international trade, increasing interaction across boundaries and contributing to our experience of a global world. This has made it subject to both external pressures from groups conscious of the privileged access that it offers and internal calls from its own membership to continuously improve its performance. Understanding its organizational response to current and future demands necessitates understanding its past. The purpose of this chapter is to take a historical perspective on the development of SWIFT. This helps establish a context for better understanding its defining characteristics: the choice of a cooperative legal form, reinforced by a set of rules and responsibilities that support the position of SWIFT as it negotiates programmes of action (such as standards development) among organizations engaged in financial activities.

We begin by briefly reviewing how the convergence of pressures in three areas, international trade, telecommunications technology, and banking services, led to the founding of SWIFT. While it was apparent that existing market practices needed to be surpassed if banks were to meet growing demand for international services, there were many potential ways to organize a response. In this chapter, we consider the conditions that enabled this major, self-organized inter-bank initiative to emerge. ${ }^{1}$ SWIFT currently occupies such an established position in the sector that the circumstances surrounding its founding and the precarious days of network growth seem distant. We provide a close examination of events leading up to the launch 
of the society and show that in part it succeeded because it offered a negotiated compromise at a competitively tense time.

SWIFT was one of many options being cultivated by a small group of transnational banks (TNBs) keen to capture new business opportunities arising from the expansion of international trade. The decision to adopt a cooperative governance structure proved pivotal and ensured that when SWIFT jockeyed for position with competitive alternatives, it became the banks' preferred choice. As a consequence, competitive tensions were superseded by an era of collective effort that cumulated in an unprecedented network effect, landmark standards, and knowledge exchange.

The success rate of large-scale information systems projects in the 1970s was low. In the next part of our discussion, we show that SWIFT's progress depended on the willingness of a critical mass to share existing practices, define common standards, develop interfaces, adopt security protocols, and adapt their back-office systems. This challenge was further heightened by unwritten international trade agreements, shortfalls in multi-jurisdiction regulation, and protectionism by incumbent state-owned Postal, Telephone, and Telegraph authorities (PTTs).

If SWIFT's initial achievement was connectivity, its lasting contribution to financial services has been the development and diffusion of standards. This has enabled automation of international services on a scale that is best regarded as the "industrialization" of global financial services. Providing a secure and reliable basis for realizing extraordinary growth in financial transactions has given SWIFT its standing as the most significant network innovation in the history of international banking.

\section{Correspondent banking and expanding international trade}

SWIFT's early history is indivisible from the rising importance of correspondent banking, the term used when a financial institution acts as an agent for another - conducting business transactions, accepting deposits, or gathering documents. In the early 1970s, unprecedented levels of international trade highlighted discrepancies between correspondent banking services and the communication systems that supported them. In this section, we will place the race to provide systems able to cope with the growth in correspondent banking services in the context of developments in international trade in order to show that the emergence of SWIFT took place at a particular juncture in the history of globalization.

The starting point for our discussion is Roland Robertson's definition of globalization as "the compression of the world and the intensification of consciousness of the world as a whole." 2 From our current vantage point, globalization may appear inevitable but for those living in nations 
experiencing colonial legacies and post-world war recovery, it was far from obvious that if trade and transactions increased we would see the emergence of a global economy that takes into account all the economies of the world accompanied by flows of national and cultural resources. The trajectory of international trade has been uneven, marked out by phases of acceleration and deceleration. During the gold standard period (c. 1870-1914), capital movements were free and flows reached new highs. Despite measures taken to reconstruct international finance in the intervening years, ${ }^{3}$ the two world wars truncated financial services, firmly retrenching and bounding capital markets within the borders of nations.

Immediately post-World War II, international finance was restricted to national policy arenas in order to contain them within a controlled framework of social purpose. ${ }^{4}$ As Rawi Abdelal puts it: "At that time members of the international financial community collectively shared a set of beliefs about the destabilizing consequences of short-term, speculative capital flows, or 'hot money,' and the need for government autonomy from international financial markets." 5 Subsequently, keystone agreements were put in place to regulate international trade which was then further boosted in the 1950s by the emergence of London as the centre of the euro-dollar market and the development of business within the British Commonwealth. However, far from assuming that a process of globalization was afoot, it was generally assumed that each country would flourish but within its own version of capitalism. ${ }^{6}$

So what drove the expansion in international business with which SWIFT is associated? It has been argued that the quickening of international trade during this era was consumer-led, rather than policy-led. In other words, commercial organizations outgrew domestic markets and searched for opportunities to expand. It was further fuelled by the need to raise capital for major multinational projects that were emerging, such as the European Airbus which was founded in 1970 and whose production was contingent on raising an estimated $\$ 1$ billion. This is indicative of the way in which finance internationalized on an ad-hoc basis during this period, without the proactive establishment of a global regulatory framework of multilateral rules. ${ }^{7}$

European banks were under greater pressure during this period than their North America competitors who benefited from a federal trade region and network arrangements that had improved the speed and accuracy of payments. ${ }^{8}$ In contrast, many commercial activities in Europe were necessarily both cross-border and, prior to the euro, cross-currency. European banks attempted to mitigate this through greater cooperation, forming "clubs" such as the EBIC (European Banks' International Company)..$^{10}$ This served as a stepping stone for banks, enabling them to engage in international 
business; by joining EBIC, a bank could become a shareholder in consortium banks established within the EBIC framework, thus avoiding the cost of setting up branches in overseas countries. ${ }^{11}$

Although there was notable concern in Europe about "the challenge of American banking penetration", 12 internationalization put pressure on all the TNBs to act regardless of their shareholding or headquarters. The sector was compelled to innovate because within a relatively short timeframe the existing telex infrastructure would have been overwhelmed. This ultimately motivated banks to organize private initiatives to establish communication network projects.

Thus, we place the founding of SWIFT within what historian Geoffrey Jones has termed the "Second Globalization", ${ }^{13}$ a period that witnessed the restarting of internationalism after a period of profound disruption. During this period corporations would be called upon to answer distinctive pressures to converge: rationalizing processes, codifying professional practices, harmonizing rules, and clarifying governance. Organizations such as SWIFT played an important role in this by drawing together key knowledge resources and developing standards which simultaneously acted as carrier, flow, and source for best practice. In so doing, they drew back-office professionals together and stimulated new support industries.

In our conclusions, we will return to this discussion of globalization and consider how SWIFT is positioned in relation to current trends ${ }^{14}$ such as the resurgence of anxiety about cross-border movement activities; a renaissance in regulation; and the persistence of geopolitics. Next, we turn to a phenomenon widely recognized as being entangled with the past, present, and future of globalization: communications technology. If we are to understand the legacy of SWIFT's original technological footprint and its achievement of global usage, we need to explore the on-going interdependency of information and communication technologies and international banking practices.

\section{Information communications and globalizing bank services}

Telecommunications in banking can be traced back to the late 1840s when the electrical telegraph was introduced to improve the speed of inter-market communications and reduced differences in securities prices between remote stock exchanges in the United States. ${ }^{15}$ The introduction of the first trans-Atlantic submarine cable in 1866 greatly facilitated the integration of securities trading between New York and London. ${ }^{16}$ Further advances in telegraphy and cable technology subsequently gave rise to domestic pointto-point networks ${ }^{17}$ capable of transmitting signals representing alphanumeric characters, thus enhancing communications between head offices 
and branches in internal bank networks. By the end of the century, international communications technology was thus in its "early adoption period"18 as individual banks began to carry out international transactions with correspondent banks.

Once advances in message routing and switched-network technology were combined with the use of the typewriter keyboard, the foundations for the first teleprinter exchange - or telex - networks were laid. During the 1920 s, Germany led the field in research and development, producing an operational teleprinter service in 1933. Automatic dial subscriber-tosubscriber services were first introduced in Germany before the Second World War using a switching system from Siemens and Halske. Soon after, the United Kingdom, France, the United States, and Canada followed. ${ }^{19}$ Serving as a privileged teleprinter network, the telex was initially based on the use of the existing telephone and telegraph networks that allowed speech and teleprinter signals on the same connection. ${ }^{20}$

Telex soon surpassed the telegram for business subscribers ${ }^{21}$ and by 1957 it connected 19 European and 18 Latin-American, African, and transPacific countries with the United States and Canada, giving access to more than 30,000 separate subscribers over international communications. Using "wires" (the colloquialism for transactions between banks by telegram and telex) dominated international payment for the next fifteen years. The participant base of telex grew fast and grew to an estimated one million users worldwide. ${ }^{22}$

Telex provided the banking sector with a basic communications platform for international business and an operational means through which they could begin to expand. It marked a considerable improvement on courier services. However, some fundamental limitations remained. A cross-border transaction would often require the exchange of more than ten telex messages, which made the process costly and time consuming. Authentication procedures needed to ensure the necessary level of security for fund transfers were based upon a system of manually calculated sequential test keys which increased labour intensity. ${ }^{23}$ Banker, Eric Sepkes, describes his experience of international payments practices in the London office of Citibank during the 1960s as follows:

[On] a telex machine you had two sets of tables, like logarithmic tables... the telex sender would perform calculations based on the value, currency, and amount. They would then use tables to work out the keys and come up with a tested telex result... For every single telex that was sent you had to manually calculate what this telex test key was... When you received the tested telex you had to do the reverse calculation to make sure that the telex hadn't been tampered with 
during transmit and receive cycles. So you can imagine, there were hundreds - if not thousands - of these messages being sent every day from some of these banks. It was incredibly labour intensive, it was incredibly prone to human error... imagine the costs. ${ }^{24}$

To make things even more complicated, payment instructions received by phone or telex would arrive in free text using various formats depending on the originator. The clerk had to interpret these handwritten details and pass them to a secretary who typed them into a form which would then be sent to the authorization/confirmation section. This manual payments process had considerable potential for system breakdown and error (see Box 1.1).

Thus, despite its widespread use, the limitations of telex had a significant impact on banking operations:

- Capacity: this was a major drawback as the number of the transactions was increasing and the international telex network was congested. The telex network was running on a speed of 50 Baud or approximately 8 bytes per second. The scope for improving performance was limited.

- Free format: telex messages had a free format that allowed users to enter any information that they thought was necessary to process a transaction, and this meant that this data had to be manually processed

\section{Box 1.1 The Citi chimney sweep}

During the 1960s, at Citibank London, handwritten payment instructions were typed on a form which was then folded, put in a canister, and sent via a vacuum tube to the authorization/confirmation section on the floor above. After a particularly busy morning, staff in the payment section found themselves without the confirmation necessary to complete transactions. A staff member went to the second floor to investigate, to be met by a bemused confirmation section who had been waiting for payment instructions. The vacuum tube between the two floors had become jammed and remained so until staff enlisted the services of a chimney sweep who cleared the blockage and restored payment processing in Europe that day. ${ }^{1}$

\section{Note}

1. Anecdote shared by Eric Sepkes (interviewed by Susan Scott and Markos Zachariadis [in person], London, 13 November 2008). 
in order to complete any transaction. It was error prone which kept costs high and acted as a barrier to further process automation.

- Lack of security: telex transmissions used public lines and banks did not have full control over access or security. Telex authentication procedures (test keys) between corresponding banks were complex and time consuming, and this created costly inefficiencies.

As the volume of transactions increased, it became apparent that manual telex practices were a constraint on expanding business and a number of banks began exploring options. In the next subsection, we discuss the competitive dynamics at work during this formative period and consider the motivation that a competitor project, MARTI, provided for joining SWIFT.

\section{Network projects and governance}

The idea of a private communications network between multinational banks for international payments had been circulating since the late 1960s..$^{25}$ The use of public networks was rejected because banks needed assurance that messages would be secure and that there would be capacity for traffic volumes to rise. There were also concerns that the PTTs would impose volume-driven rates which would act as a potential constraint on future growth in banking activity. ${ }^{26}$ As a consequence, major banks found themselves in the role of pioneers developing proprietary private networks using circuits and satellite facilities leased from PTTs. In addition to developing private, secure international communication networks, a structured format for the message body of international financial transactions had to be agreed upon and supported. The design of this common messaging system had to be capable of increasing volumes of international payments and reducing their operational risk (e.g. the reduction of error rates, increased security, and reliability).

At the forefront of such strategic developments were The First National City Bank, Bank of America, and Chase Manhattan in the United States, and Barclays, Lloyds, and Midland Bank in Europe. In anticipation of business expansion and cost savings arising from the automation of international payments, banks made resources available and multiple network projects were launched. Using strategic speculation as an approach to techno-innovation was common among banks during the late 1960s until the early 1990s. Major financial organizations built up tactical portfolios of concurrently funded, competing projects in prospect of at least one proving useful, if not profitable. ${ }^{27}$

Finalizing sourcing decisions on internal IT projects involves setting and assessing both technical and organizational criteria. This is often problematic 
and can be contentious. Such issues are amplified when alternative infrastructure projects are dependent upon sector-wide diffusion and adoption. In this regard, the achievement of critical mass and global usage has historical distinction that warrants close study.

During this period, a relatively small number of TNBs competed in foreign markets which concentrated cross-currency transactions between organizations. This meant that a few banks with high volumes of transactions could achieve an economy of scale with attractive cost benefits and, as a consequence, the TNBs were in active consultation with each other. Consortium banking and joint ventures provided not only an opportunity to access overseas markets but also drew together resources for projects.

In Europe, consortiums such as, EBIC and ABECOR ${ }^{28}$ (Associated Banks of Europe Corporation founded in 1970), determined to "initiate innovations in banking", ${ }^{29}$ rallied 68 banks from the United States and ten European countries for "The Banks' International Message Switching Project" (MSP). ${ }^{30}$ The purpose of the project was:

- To examine the feasibility of an international communications network for the transfer of international payment and related messages between participating banks;

- To examine the costs of such a network and to provide suitable information to allow individual banks to decide whether to participate in the project;

- To prepare outline functional specifications on which detailed tender documents for issue to system suppliers could be based;

- To provide the basis for determining the form of organisation and methods of funding required if the project were to be implemented. ${ }^{31}$

Although the MSP was the product of a consortium effort, particular emphasis has been placed on the role played by a Dutch banker from ABN called Johannes Kraa (known as Jan) and the support that he received from a French banker from Banque de l'Union Parisienne called François Dentz. European bankers may have led the way, however, there was a fundamental requirement for this to be an international project which took considerable political effort to consolidate:

Johannes Kraa was very instrumental in trying to convince his European partners that instead of trying to compete on a technical basis by adding network to network, creating something together was the best thing. A few key people were really convinced at first that Europe must act. But they were persuaded that it would never be workable if they could not get the Americans on board. And they succeeded in convincing them to 
join; I'm not sure that the Americans were entirely sure that they should do it, but they said: "Let's go and see, let's wait and see. We'll put our nose in the door, and we will see how it works. If it works, we'll see how we can benefit from it. If it does not work, we are not losing too much." 32

Not only did Kraa enthusiastically advocate that banks should selforganize on an international basis and create a "within sector" network capable of replacing the public telex using their own standards, he envisioned a bank-owned host organization that would maintain a balance between control, verification, openness, and mutual benefit. ${ }^{33}$ However, the degree of openness that should characterize the governance of this network project was the subject of debate. While Kraa is reputed to have broadly favoured the concept of a utility, this was not necessarily shared by some banks around the table, such as First National City Bank (FNCB), who signed up to the MSP but continued to develop competitive private network options and explore the use of standards for market dominance. ${ }^{34}$

In a bid to move forward, in 1971, it was decided that the MSP should contract consultants to explore different governance models and technological designs. This was divided into two studies: the technical project was assigned to the Logica consultancy in London while the legal and organizational study was undertaken by the non-profit Stanford Research Institute (SRI). For the SRI Organization and Legal Sub-Committee, ${ }^{35}$ the choice of legal form went hand-in-hand with discussions on the appropriate location of headquarters since liability and profit-sharing were configured differently in each jurisdiction. Diplomacy dictated that a third option was needed to circumvent the intense rivalry between New York and London. Initial recommendations centred on Amsterdam but Brussels prevailed due to its stable "social climate" and its regulatory, legal, and fiscal advantages. ${ }^{36}$ When SRI produced their findings in 1972, the findings endorsed Jan Kraa's community-centred vision.

Having decided on establishing an organizational entity within Belgium, SRI's Legal Working Group faced two options: an international association or a cooperative society. ${ }^{37}$ The international association appeared to be the less costly choice. But after considering the nature of SWIFT's operations in the commercial field and the obvious charitable character of international associations, the committee opted for the cooperative society. An international association would pose difficulties as it was subject to severe legal profit restrictions whereas the regulation for cooperatives was more flexible. Not only did SRI find the call for a European payments network feasible, they confirmed that it should have a global remit and emphasized the 
importance of standardizing payments between institutions as well as enabling communications between them.

On Thursday, May 3 1973, the Society for Worldwide Inter-bank Financial Telecommunication (SWIFT) ${ }^{38}$ was founded as a cooperative society under Belgian law. Having been the chairman of the MSP Steering Committee and a key figure in the founding of SWIFT, Jan Kraa was elected as the first Chairman of the SWIFT Board. ${ }^{39}$ By October 1973, Carl (Charlie) Reuterskiöld was appointed SWIFT General Manager (equivalent of the CEO today). The founding executive core consisted of Jacques Cerveau (Operations), Bessel Kok (Finance), Joel (Jack) Tilley (Facilities), and Harold (Harry) Steele (Services) (see Tables 1.1 and 1.2 for complete lists of all the CEOs and chairpersons since SWIFT's foundation). ${ }^{40}$ SWIFT's organizational and technological signature had been established. Siting its headquarters in Brussels not only influenced its legal form but also normalized the practice of appointing multilingual staff capable of interacting with a thoroughly international membership. At the time of its founding, SWIFT membership amounted to a total of 239 banks from 15 countries. A global technological terrain was also in the process of being mapped out and, by the end of 1974, the initial network design was complete. After a request for a proposal that elicited bids from four vendors Philips, ITT, Collins Radio, and Burroughs Corporation - the latter was chosen to supply the computer equipment and install the system. Although the Burroughs technology may not have been the most technically sophisticated option, it offered the most scope to upgrade and increase capacity which was critical for a network whose mission was to grow rapidly and achieve a critical mass of global usage. ${ }^{41}$ SWIFT had made a major move forward in taking control of the technological development for a communications network out of the hands of PTTs but the more profound benefits depended upon achieving critical mass.

Table 1.1 Chairpersons of SWIFT

\begin{tabular}{lll}
\hline Date & Chairperson & Country \\
\hline $1973-1974$ & Johannes Kraa & Netherlands \\
$1974-1976$ & François Dentz & France \\
$1976-1984$ & Helmer Hasselblad & Sweden \\
$1984-1989$ & W. Robert Moore & USA \\
$1989-1992$ & Richard Fröhlich & Austria \\
$1992-1996$ & Eric C. Chilton & UK \\
$1996-2000$ & Jean-Marie Weydert & France \\
$2000-2006$ & Jaap Kamp & Netherlands \\
$2006-$ & Yawar Shah & USA \\
\hline
\end{tabular}


Table 1.2 CEOs of SWIFT

\begin{tabular}{ll}
\hline Date & CEO \\
\hline $1973-1983$ & Carl Reuterskiöld \\
$1983-1991$ & Bessel Kok \\
1991 & Interim CEO Jacques Cerveau \\
$1992-2007$ & Leonard H. Schrank \\
$2007-2012$ & Lázaro Campos \\
$2012-$ & Gottfried Leibbrandt \\
\hline
\end{tabular}

\section{Achieving worldwide critical mass and global usage}

Retrospection tells us that in the forty years that followed its founding, SWIFT developed landmark standards and connected thousands of users worldwide, so one might imagine that if banks accepted the outcome of the MSP, they would have cooperated from this point forward. But in practice, if we pause to consider the historical conditions surrounding the MSP, we find many reasons why SWIFT might not have succeeded, among the most important of which was navigating a terrain affected by bank rivalry and the challenge of achieving critical mass.

Then and now, banks have tended to resist change and as traditional organizations they are highly invested in their practices at both firm and national level. This had become apparent in the user groups and international working parties set up by Logica to coordinate input from the member banks on messaging formats, security, and network technology as part of the MSP prior to the founding of SWIFT. For example, on a presentation given at Barclays Computer Conference in June 1975, the SWIFT project team representative recalled: "Not surprisingly, the recommendations of these groups met with much international discussion and disagreement. Each country tried to impose their national standards on the rest. Even within countries there was considerable disagreement." 42

The momentum that finally galvanized the adoption of SWIFT by international banks eventually came from an unexpected ally. As discussed above, FNCB had invested in the MSP but continued to explore other strategic options. Effectively, they decided to "parlay"43 multiple initiatives to ensure that they were positioned to best advantage. In 1973, the same year that SWIFT was founded, Transaction Technology Inc., ${ }^{44}$ a subsidiary of The First National City Bank (FNCB), developed a proprietary messaging standard known as MARTI (Machine Readable Telegraphic Input). By mid-1974, FNCB's private MARTI network was in place and a pilot implementation had been conducted with one of their correspondent banks, Wilmington Trust. ${ }^{45}$ 
In what would eventually prove to be a pivotal move, the international banking group within FNCB opted for an "either/or" strategy for the adoption of MARTI, announcing that the deadline for compliance would be 31 March 1975. ${ }^{46}$ Many correspondent banks, particularly in Europe, balked at the imposition of a proprietary standard. Banker, Renato Polo recalled:

They told us: "We advise you to use MARTI from now on. If you don't use it, we will not execute your instructions. If your instructions are non-MARTI and come via telex, we will return the telex. If we receive them by mail, we will put them into an envelope and send it back to you." Another bank could have come with a totally different solution... I mean either you make yourself captive to one correspondent, which no one in his right mind would ever do, or you say no. ${ }^{47}$

The MARTI ultimatum created a crisis in the international banking relationship which became a powerful ally in SWIFT's bid to establish critical mass: a "burning platform", the business euphemism commonly used to communicate a need for immediate and radical change due to dire circumstances. Whereas FNCB was imposing standards developed by a private company for commercial purposes on to correspondents, SWIFT offered membership of a network through shared cooperative ownership and standards collectively designed by private companies for community purposes. The result was a decisive landslide in SWIFT adoption; the 68 banks that had funded the MSP were joined by many more and by the end of 1975 , there were 270 member banks located in 15 countries. Renato Polo put it like this:

[T] he beauty of SWIFT, is that it identified a compromise situation: the sender cannot prevail over the receiver and the receiver cannot prevail over the sender. Necessarily both sender and receiver modify their own internal output and, conversely, input procedure into a standard format. ${ }^{48}$

Although the foundations were laid, much network and standard development still lay ahead before SWIFT could go live. One of the most common flaws in IT projects during the 1970s was the imposition of an overengineered model of business practices springing from lack of knowledge about context which would manifest as inadequate business analysis and a mismatch with user requirements. The strength of SWIFT's information systems development was clarity of purpose and close user involvement because members of the SWIFT industry cooperative had "the same vision, the same needs, the same requirements" 49 around a highly focused end: 
replace telex and facilitate the end-to-end automated processing of international financial transactions.

Despite the tensions, those involved in the early history of SWIFT characterize it as a time of optimism in which members on both sides of the Atlantic showed considerable willingness to engage in the cooperative effort needed to ensure that the system ran smoothly. Back-office professionals, widely regarded as second-class citizens in the banking sector, were given the opportunity to travel, gather, build a professional network, and extend their expertise into areas of innovation:

We would take any opportunity to meet up and swap ideas and give each other hints... If there was an issue they would pick up the phone to their counterpart in what would have been a competitor bank and say look I'm setting up SWIFT and I am having these problems and they would help them out - gratis - which marks a pretty extraordinary period of developmental history for the sector. ${ }^{50}$

As coordinators and beneficiaries of this collective action, SWIFT became the repository for the standards and network developments that emerged, enabling them to move forward where other projects might have failed. On 9 May 1977, Prince Albert (now King of Belgium) sent the first SWIFT message. ${ }^{51}$ In that same year FNCB's MARTI network was closed down.

\section{Co-opetition}

Throughout the history of banking, the boundary between competition and cooperation has had to be navigated. We regard SWIFT as an exemplar of "co-opetition", 52 the simultaneous cooperation and competition between firms. The development of SWIFT is not about relationships between customers and suppliers but one of correspondent banking and counterparties or "complementors". ${ }^{33}$ This marks the practice of creating and capturing organizational value at the same time. The organizations involved simultaneously maintain multiple roles, competing in some areas, cooperating and complementing each other elsewhere.

In other words, although the banks were competing for business as international trade expanded, they realized that their customers would value their services more if they had access to another company's services than if their services stood alone. Co-opetition entails sharing knowledge which might in other contexts be regarded as a potential source of competitive advantage, recognizing that more is achieved when resources are shared than when they are hoarded. In the case of SWIFT, banks had more to gain 
from sharing technical details of their business processes than not. This ethos of collaborative innovation and co-creation is echoed in SWIFT's current company information:

SWIFT is a member-owned cooperative through which the financial world conducts its business operations with speed, certainty and confidence. More than 10,000 financial institutions and corporations in 212 countries trust us every day to exchange millions of standardised financial messages. This activity involves the secure exchange of proprietary data while ensuring its confidentiality and integrity.

Our role is twofold. We provide the proprietary communications platform, products, and services that allow our customers to connect and exchange financial information securely and reliably. We also act as the catalyst that brings the financial community together to work collaboratively to shape market practice, define standards, and consider solutions to issues of mutual interest.

SWIFT enables its customers to automate and standardize financial transactions, thereby lowering costs, reducing operational risk, and eliminating inefficiencies from their operations. By using SWIFT, customers can also create new business opportunities and revenue streams..$^{54}$

In the next chapter we focus on the development of standards and illustrate their role in the "industrialization" of financial services. Standardization is a prerequisite for automation. As we go on to discuss, while efficiencies from straight-through-processing (STP) are an important part of this because they enable increases in capacity and speed at lower costs, further benefits are also realized as different parts of the financial value chain are connected. Ultimately, co-opetition is not only a modus operandi but rather focuses on creating value by opening up opportunities to create "a bigger pie" 55 and then putting companies in a position in which they are both creating and capturing that "pie".

\section{Conclusion}

SWIFT emerged in response to a shared need among correspondent banks to replace largely manual banking practices using low-speed public telex with automated payments services on a secure private communications network capable of accommodating rapidly expanding international trade in the 1970s. SWIFT standards were then used to progressively re-engineer backoffice processes creating efficiencies that enabled bank performance and contributed to cost reduction. During the next four decades, SWIFT membership 
expanded to securities, market infrastructures, ${ }^{56}$ and corporate treasuries, thus creating a network phenomenon with global standing at the core of the global financial services infrastructure. It has become the world's most trusted third-party network, dominating international payments, serving as an agent for the International Standards Organization (ISO), hosting the premier transaction banking conference (Sibos), as well as developing additional services and offering training for the financial services community. As a community hub, SWIFT has always engaged in debate and, as we will go on to discuss, some of these achievements have not been won without controversy. In the following chapter, we describe how SWIFT works and provide an overview of its organizational structure, operations, and management.

\section{Notes}

1 Alec Nacamuli describes SWIFT as "the last major inter-bank initiative that was not regulation led" (interviewed by Susan Scott and Markos Zachariadis [in person], London, 17 February 2012). Some formal discussions were taking place: for example, on 28 October, 1974, Congress established the EFT Commission to enable it to understand better the rapidly expanding EFT industry. It instructed the 26-member commission to study "the possible development of public or private electronic fund transfer systems" and to recommend appropriate Congressional action. However, it is clear that the decisive momentum to organize SWIFT came from within the banking community, not from regulators.

2 Roland Robertson, Globalization (Thousand Oaks, CA: Sage, 1992): 8.

3 The Bretton Woods conference in 1944; the General Agreement on Tariffs and Trade in 1947; the establishment of the European Economic Community in 1958; and the formation of the European Free Trade Association in 1960.

4 See Rawi Abdelal, Capital Rules: The Construction of Global Finance (Boston, MA: Harvard University Press, 2007).

5 Ibid., 1-2. Abdelal goes on to note that "The origins of the expression 'hot money' can be traced to a speech President Franklin D. Roosevelt gave in November 1936, the first time the phrase was used to describe financial flows" (ibid.): 231.

6 Ibid.

7 See Eric Helleiner, States and the Reemergence of Global Finance: From Bretton Woods to the 1990s (Ithaca, NY: Cornell University Press, 1996).

8 Such as Bankwire, Fedwire, CHIPS, and a small number of intra-bank networks. For comparison, the most significant EFT in the UK was the Bankers' Automated Clearing Services (BACS), a "not-for-profit, membership based, industry body" responsible for the clearing and settlement of automated payments. Owned by 15 of the leading UK and European banks and building societies, BACS began operations in 1968.

9 Richard Tilly notes the following: "In the 1960s, there was growing interest in international alliances with a view to promoting foreign business. In 1963, Deutsche Bank was the first German bank to enter into a loose cooperation, in the form of a European Advisory Committee, with three other banks - the Dutch Amsterdamsche Bank N.V. (later Amsterdam-Rotterdam Bank N.V., Amrobank) Amsterdam, the British Midland Bank Ltd, London, and the Belgian 
Banque de la Société Générale de Belgique S.A. (later Société Générale de Banque S.A.) Brussels. A management company, European Banks' International Company S.A. (EBIC), was set up in Brussels as the institutional framework, in October 1970, with a capital of \$2 million. The Austrian Creditanstalt-Bankverein (Vienna) and the French Société Générale (Paris) joined in 1971, followed in 1973 by the Italian Banca Commerciale Italiana (Milan)" ("A short history of the German banking system", in Handbook on the History of European Banks, ed. Manfred Pohl and Sabine Freitag (Aldershot: Edward Elgar, 1994)): 385-6.

10 Membership of EBIC was reported to be as follows: Amsterdam-Rotterdam Bank; Banca Commerciale Italiana; Creditanstalt-Bankverein; Deutsche Bank; Midland Bank; Société Générale de Banque (Belgium); Société Générale (France) (Jenny Ireland, "Groups overtaken by international banking," The Financial Times, 10 May 1982). During the 1970s, EBIC was involved in the formation of the Banque Européenne de Crédit à Moyen Terme (Brussels), the European-American Banking Corporation, the Euro-Pacific Finance Corporation, the European Banks International Company, the European-Asian Co. London, and the European-Asian Bank (see Philip L. Cottrell, "The historical development of modern banking within the United Kingdom," in Handbook on the History of European Banks, ed. Manfred Pohl and Sabine Freitag (Aldershot: Edward Elgar, 1994): 1158). Contemporaries sometimes referred to EBIC as "the Bachelors Club because of their already existing joint ventures in a state of independence" (see Clyde H. Farnsworth, "European financial groupings: banks join forces to meet need for capital", The New York Times, 8 November 1970).

11 Ibid.; Cottrell notes that ultimately these collaborations broke down "as members of the group each opened their own offices in one another's domestic territory... Nonetheless cooperative international banking was an immediate way forward."

12 This expression comes from Clyde H. Farnsworth, "European financial groupings". Rawi Abdelal argues that during this period international financial architecture was European-led in terms of "leadership and deliberate design" (Capital Rules): 3.

13 Jones builds on the widely held view that while there was international trade in earlier times, the "first global economy" formed during the second half of the nineteenth century with world capital, commodity, and labour markets becoming closely integrated by 1914 . He further proposes that a second wave of globalization began during the 1950s and intensified after 1979. During this period, global networks developed and multinational banking assumed a new importance (Geoffrey Jones, "Globalization," in The Oxford Handbook of Business History, ed. Geoffrey Jones and Jonathan Zeitlin (Oxford: Oxford University Press, 2007)): 141-68.

14 See, for example, Anon, "The great unravelling: bank supervisors are quietly forcing a deglobalization of finance," The Economist, 20 April 2013.

15 Kenneth D. Garbade and William L. Silber, "Technology, communication and the performance of financial markets: 1840-1975", Journal of Finance, 33 (1978): 819-32.

16 Garbade and Silber ("Technology, communication") uncover statistically significant evidence illustrating that the introduction of innovations in communications technology - specifically domestic telegraph and the trans-Atlantic cable - led to the significant narrowing of inter-market price differences. 
17 Electronic Funds Transfer (EFT) began in 1915 when the Federal Reserve Board used the telegraph systems of Western Union and Postal Telegraph to transmit its financial data (http://www.newyorkfed.org/aboutthefed/fedpoint/fed43.html).

18 Bernardo Batiz-Lazo and Douglas Wood, "An historical appraisal of information technology in commercial banking”, Electronic Markets, 12 (2002): 192205.

19 For a detailed review of the technological advances that led to the development of the telex, see Patrice A. Carré, "From the telegraph to the telex: a history of technology, early networks and issues in France in the 19th and 20th centuries", Flux, 9 (11) (1993): 17-31 (retrieved April 252013 from http://www.persee.fr/ web/revues/home/prescript/revue/flux).

20 Ken Beauchamp, A History of Telegraphy: Its Technology and Application (London: Institution of Engineering and Technology, 2008).

21 Jill Hills, "Regulation, innovation and market structure in international telecommunications: the case of the 1956 TAT1 Submarine Cable", Business History, 49 (2007): 868-85.

22 Although banks, stock exchanges, and other financial institutions were the first and most numerous users of the telex, there was a notable increase in subscribers from other industries particularly towards the end of the 1960s. Among the most intense users were the air carriers who needed a means to communicate flight and passenger information. Telex usage continued to increase and reached a peak in 1987 after which it began to be superseded by TCP/IP technology from commercial internet providers (see Gottfried Leibbrandt, "The role of the installed base in payment system adoption," Journal of Payments Strategy and Systems, 4 (1) (2010): 6-16. Also see Gottfried Leibbrandt, "Establishing compatibility between Europe's payment systems," International Journal of Industrial Organization, 28 (1) (January): 69-73). Data on the number of telex subscribers are held by the International Telecommunication Union (ITU).

23 Alec Nacamuli, "Cross-currency payments and SWIFT," in Payment Systems: From the Salt Mines to the Board Room, ed. Dominique Rambure and Alec Nacamuli (Houndsmill: Palgrave Macmillan, 2008): 43-51.

24 Eric Sepkes (interviewed by Susan Scott and Markos Zachariadis [in person], London, 13 November 2008). Sepkes went on to say that former military signalmen were often employed as authentication key clerks. This was further confirmed by Jacques Cerveau (interviewed by Susan Scott [in person], Paris, 13 February 2012).

25 See Batiz-Lazo and Woods, "An historical appraisal". There is also reference to other projects in the transcript of a speech delivered by A.E. White, R.E.W. Hazel, and D.S. Warman at the Barclays Computer Conference in June 1975. The Barclays SWIFT Project Team were based at Friggell House in Poole, Dorset (information retrieved from Barclays Group Archives, 80-4134).

26 See further discussion of the legal case between SWIFT and the PTTs in Chapter 5 of this book.

27 Elsewhere we have referred to this tactic of funding multiple options as "strategic risk positioning" (see Susan V. Scott and Michael I. Barrett, "Strategic risk positioning as sensemaking in crisis: the adoption of electronic trading at the London International Financial Futures and Options Exchange", Journal of Strategic Information Systems, 14 (1) (2005): 45-68. See also Susan V. Scott, "Understanding the characteristics of techno-innovation in an era of selfregulated financial services", in Financial Markets and Organizational Technologies: 
Systems Architectures, Practices and Risks in the Era of Deregulation, ed. Alexandros-Andreas Kyrtsis (London: Palgrave Macmillan Studies in Banking and Financial Institutions, 2010)): 166-88.

28 Membership of ABECOR was reported to be as follows: Algemene Bank Nederland; Banca Nazionale de Lavoro; Banque Bruxelles Lambert; Banque Internationale à Luxembourg; Banque Nationale de Paris; Banque de la Société Financière Européenne; Barclays Bank; Bayerische Hypotheken und Wechsel Bank; Dresdner Bank; Österreicheische Läenderbank. This list is from an article by Ireland ("Groups overtaken by international banking"). For an example of the kind of strategy pursued by consortium banks, see Barclays Bank International, "Abecor: Europe's biggest bankers offer you a complete international banking service", The Financial Times, 31 May 1977. An extract from this source reads: "The skill and experience of seven major European banks which form Abecor, the Associated Banks of Europe Corporation, combine to make this Europe's leading international banking group, just as much as the combined assets of almost 200 billion dollars. Barclays is the Abecor bank in Britain... Abecor has branches, representative offices and associates in 118 countries across 5 continents. What could be more international than that?... Service is not just the provision of facilities, it's an attitude of mind as well. Abecor's attitude is that everything should be as simple and swift as possible. Whatever you want from Abecor, you usually need to contact only one man. In the U.K. that man is Mr. B. Bartlett, International Division, Barclays Bank International, 168 Fenchurch Street, London EC3P 3HP." For a historical analysis of the "clubs", see Duncan M. Ross, "European banking clubs in the 1960s: a flawed strategy", Business and Economic History, 27 (2) (1998).

29 Johan de Vries, "The Netherlands financial empire", in Handbook on the History of European Banks, ed. Manfred Pohl and Sabine Freitag (Aldershot: Edward Elgar, 1994): 752.

30 Logica Final Report: The Banks' International Message Switching Project, Logica Ltd (31-36 Foley Street, London W1P 7LB), Part 1 (15 March 1972): 2. We are most grateful to Eileen Chiles (former SWIFT Board Secretary) for giving us access to her personal bound copy of the MSP reports.

31 Ibid.

32 Jacques Cerveau (interviewed by Susan Scott [in person], Paris, 13 February 2012).

33 Alec Nacamuli (interviewed by Susan Scott and Markos Zachariadis [in person], London, 17 February 2012). Many of the meetings where these ideas were broached took place at the ABN building on 32 Vijzelstraat, Amsterdam.

34 Not only would the winner of a standards war benefit from a dominant network position and cost-efficient automated processes, they would also shift the cost of using their proprietary standard on to counterparties who would then have to absorb the cost of adapting their systems to that standard.

35 The Organization and Legal Sub-committee consisted of Mr H. Bruckert (Crédit Industriel et Commercial, Paris (Chairman)); Mr Charles Read, Inter-bank Research Organization, London (Co-chairman); $\mathrm{Mr}$ E. Trolle-Schultz, Kjøbenhavns Handelsbank (Co-chairman); Mr R.W. Freud, First National City Bank, New York; Mr D.C. Fiske, Stanford Research Institute, London; Mr M. Martin, Banque Nationale de Paris (Legal Working Group); Dr H.J. Pabbruwe, Algemene Bank Nederland N.V., Amsterdam (Legal Working 
Group); DrM. Schaudwet, Dresdner Bank A.G., Frankfurt (Legal Working Group); Mr L. Vekeman, Kredietbank, N.V., Brussels (Legal Working Group). Details taken from Organisation Recommendations for Proposed Society for Worldwide Interbank Financial Telecommunication (SWIFT), Stanford Research Institute, SRI-Europe, Head Office, London, England, 20 March 1972. According to Blanche Petre, Luc Vekeman went on to draft the original SWIFT bylaws and rules (Blanche Petre, interviewed by Susan Scott and Markos Zachariadis [in person], La Hulpe, Belgium 22 December 2011).

36 "The Legal Committee has come to this conclusion after a comparative law study of the possible legal forms in several European countries. Some of these have various suitable legal forms which would have made it well worth considering the inception of SWIFT in one of these countries, other than Belgium, had there not been attendant objections which apply to a far less degree to Belgium, if at all. These objections are mainly in the financial field and are amongst the others concerned with: social premiums to be paid by SWIFT for its employees. These premiums have to be paid in every European country. The level of the amount does not differ very much from one country to another; Taxes to be paid by SWIFT, specially the Value Added Tax (VAT). The VAT is the most important tax of all taxes which have to be paid by SWIFT. With regard to the VAT in Belgium telecommunication services are charged at a rate of 14 percent. However, in the case of international telecommunication services the rate is reduced to 0 percent; Taxes to be paid by employees of SWIFT, the main one being income tax. Belgium income tax is one of the lowest in Europe. At the same time the Legal Committee has taken into consideration the "social climate" in the countries which have formed part of the comparative law stay, which is very stable in Belgium." Organisation Recommendations, 5-6.

37 Ibid.

38 According to Bessel Kok, the original company acronym was "SWIT", the Society for Worldwide Interbank Telecommunication. Legend had it that they were persuaded to add the word "Financial" by Carl (Charlie) Reuterskiöld's wife, who was also credited for the design of SWIFT's logo.

39 Johannes (Jan) Kraa remained as Chairman of SWIFT until 1 April 1974.

40 SRI was involved with staff recruitment, assisting with key executive appointments. As of March 1975 SWIFT had hired a total of 53 people distributed in four divisions: Services, Operations, Finance, and Administration. The staff slowly took over responsibilities from Logica's consultants who remained involved until the end of September 1974. For more information, see SWIFT Annual Report, 1974.

41 Details of the technological options are from Jacques Cerveau (interviewed by Susan Scott [in person], Paris, 13 February 2012).

42 See pages $2-3$ in the transcript of a speech given by A.E. White, R.E.W. Hazel, and D.S. Warman at the Barclays Computer Conference in June 1975 (retrieved from Barclays Group Archives, 80-4134).

43 This is the expression used by Jacques Cerveau (interviewed by Susan Scott [in person], Paris, 13 February 2012).

44 Transaction Technology Incorporated (TTI) was headquartered in Santa Monica, CA. This unit went on to develop Citibank's first automatic teller machine. In 1974, entrepreneur and inventor Jack Scantlin became president of TTI. Having established a track record of innovation in financial services (e.g. the stock market system Quotron) he led TTI in the development of a range of technologies that contributed to the reengineering of the sector. 
45 I am grateful to Malcolm Hamer (Improved Systems Factors, New York) for clarifying details of the MARTI project (personal communication, 24 April 2013). See also an account of MARTI in Malcolm Hamer, "An introduction to structured transactional messages", Improved Systems Factors, New York (http://www.isf-us.com/Structured-Transactional-Message-Standards.pdf).

46 Ibid.

47 Renato Polo (interviewed by Susan Scott [by telephone], 20 November 2009).

48 Ibid.

49 Blanche Petre (interviewed by Susan Scott and Markos Zachariadis [in person], La Hulpe, Belgium, 22 December 2011).

50 Chris Norton (interviewed by Susan Scott and Markos Zachariadis [in person], London 22 July 2010).

51 For further information about this royal event, see SWIFT 2013, SWIFT History (http://www.swift.com/about_swift/company_information/swift_history).

52 Barry J. Nalebuff and Adam M. Brandenburger, Co-opetition (London: HarperCollinsBusiness, 1996).

53 Ibid.

54 SWIFT's company information can be found at http://www.swift.com/about_ swift/company_information/company_information

55 See Nalebuff and Brandenburger, Co-opetition.

56 The term "market infrastructures" is industry terminology for payment systems, exchanges, and depositories. 


\section{How SWIFT works}

- Governance

- SWIFT as a cooperative society

- Payment infrastructures and financial telecommunication: putting SWIFT in context

- Operations and security: oversight, reliance, and robustness

- Community engagement: Sibos

In this chapter, we draw together an account of how this multifaceted cooperative organization works. In the first part of the chapter we relate what SWIFT does to its cooperative society status and consider how the principles of that model manifest in its governance of multiple stakeholder groups. In the next section we take a second, more detailed look at SWIFT, putting it in context alongside payment systems and analyzing the role of telecommunication technology in the transmission of standardized messages across the network. This deeper foray into the business landscape will help the reader understand more about the significance of payment infrastructures and place SWIFT within its field of business. This is particularly important because in order to understand how SWIFT works we need to distinguish its role from that of a traditional payment system. In so doing we draw out its distinctive status as a message carrier and highlight its unique contribution in the payment process. Having clarified SWIFT's position in the business world, we then discuss how it has achieved and upheld its most significant attribute: secure operations. Finally, we consider how SWIFT's cooperative principles manifest through practitioner community outreach at Sibos (SWIFT's International Banking Operations Seminar).

\section{Governance}

After the detailed historical analysis of SWIFT's origins in Chapter 1, we bring our description of how SWIFT works up to date by explaining its current 
organizational structure and membership arrangements. Before we do so, let's briefly review what SWIFT does. In the present day a significant proportion of organizations involved in transaction banking and the securities business use the private, member-owned SWIFT communication network as a message carrier. ${ }^{1}$ The reach of this network is extended through interface-enabled connectivity between a large number of other payment and securities infrastructures. The most widely used SWIFT messaging service is SWIFTNet FIN, which allows the exchange of messages formatted with the traditional SWIFT MT standards. As indicative, in April 2013, 49.3 percent of SWIFTNet FIN message traffic was related to payments, and 44.0 percent to securities. ${ }^{2}$ SWIFTNet FIN and a range of other products and messaging services are delivered using SWIFTNet, an IP-based messaging platform which acts as a "single window environment" for the messaging needs of SWIFT users. ${ }^{3}$

Standards are an integral part of making any network franchise work and so when SWIFT committed to the implementation of a global messaging system it became a de facto standards developer because, as we will go on to discuss in Chapter 3, few relevant standards existed at the time. Standardizing one area of a business tends to have a "domino effect" and before long the standards team at SWIFT became a significant hub for an advancing agenda of process redesign for transaction banking and other financial services processes. The quality of standards not only rests upon the expertise that can be brought to bear but also involves negotiations during which one group must compromise their existing practices in order to institute (or migrate to) another way of doing things. For this reason, SWIFT's organizational structure centres around consultative forums and working groups.

With the network established and standardization underway, SWIFT began collaborating with its members to develop a range of products and services that "build out" from its platform. Whereas sector-wide technology and standards are designed to be relatively "open" so that a critical mass will adopt them, custom projects demand detailed knowledge of a SWIFT user's business in its local context. As we will see below, this specific focus falls to SWIFT's marketing group, but lines of communication with users are distributed throughout the organizational structure. Indeed, the organizational chart is generally configured to enable dynamic communication at multiple levels.

A walk around SWIFT headquarters in La Hulpe, near Brussels, brings all this vividly to life. The boardroom has a 30 -seat circular desk in the style of the United Nations Assembly. A wooden bench has recently been set along the inside edge of the desk offering the potential to sit and talk to the person in the chair positioned on the outside. Some of the executives that have presented in this room maintain that while the concept is evocative, it 
is not always the most practical layout in terms of audience contact or acoustics. From a historian's perspective, it freezes a particular ideological notion of how SWIFT's cooperative model should work in material form. Continuing our tour, we find that during the recent building refurbishment in which SWIFT staff chose themes and provided input, a quotation from the telecoms innovator Alexander Graham Bell has a prominent place on the wall in one of the hot-desk open spaces. It reads, "Great discoveries and improvements invariably involve the cooperation of many minds". In common with other mutual organizations, SWIFT and its advocates emphasize its core cultural characteristics of community and cooperation.

\section{SWIFT as a cooperative society}

As discussed in Chapter 1, the founders of SWIFT conducted a study to investigate various options for its governance. ${ }^{4}$ The findings supported the position held by many of the founding bankers that it should be established as a mutual organization. To recap, the subsequent decision to make Brussels their registered headquarters influenced the precise organizational form that would be adopted at its incorporation. In the early 1970s, under Belgian law, there were two relevant mutual entities: an international association or a cooperative society. Initially, the international association seemed the logical choice but in the local context this term was primarily used for charitable missions. Early indications suggested that the Belgian government would be willing for SWIFT to use the category of international association but the study's legal working group advised that the entity's commercial operations might cause difficulties in the longer term, and status as a memberowned cooperative society was applied for instead. Commercial interests in the local agricultural community already set precedent in this area and a Belgian member-owned cooperative offered more flexibility than the international association in terms of membership expansion and options for profit distribution. So, SWIFT was founded as a member-owned cooperative society under Belgian law which means it is owned and controlled by its shareholders. It also implies that those responsible for this core part of the financial services infrastructure are charged with providing particular facilities within a specific set of governance principles.

The cooperative structure has a number of implications in terms of finance. ${ }^{5}$ SWIFT received start-up equity funding from its founding bank members, extended to include loans as SWIFT could not go to the credit markets for funding until it had become operational and established a proven business model in terms of revenues. SWIFT also took advantage of lease financing to avoid upfront capital costs for some infrastructure. Operations moved into a positive earning position one year after SWIFT 
went "live". A few years later leases were converted to purchases and by 1982 they were able to repay the initial loans. SWIFT generated a positive earnings position or surplus shortly thereafter and has been loss-making in very few years since. Subsequent to this, it has entered into major financings only for working capital management and specific capital expenditures. The steady positive earnings from operations means that SWIFT has generally been in the position of being able to offer discounts and rebates as a way of returning surplus to members consistent with its status as a cooperative. Although sometimes referred to as not for profit, SWIFT is more accurately committed to being a "not-for-profit maximization"6 organization. Over the last ten years, SWIFT management have prioritized a reduction in per message costs, from US\$0.26 after rebate in 2001 to US\$0.04 after rebate in 2012. The cooperative status also imposes certain obligations on members to support SWIFT in kind, through contribution of relevant expertise and an undertaking to route a substantial portion of messaging through SWIFT.

Alongside SWIFT's foundational status as a private network owned by a cooperative of financial institutions, it draws from other sources of authority in relation to the market and market participants - for example, its role as ISO registration authority and developer of proprietary standards; its status as subject to regulatory oversight by central banks and other national and international banking authorities; its role as accredited market infrastructure; and as the central forum for a worldwide community of practitioners. The governance structure of SWIFT has evolved over the years to address this multifaceted portfolio of responsibilities, but SWIFT's initial brief and its cooperative status continue to be reflected in share allocation and the constitution of the board.

The shareholding structure of SWIFT is central to the present and future of the cooperative: the more a member uses SWIFT, the more shares they are allocated, and the more influence they gain. In addition to shareholder (or member) influence over the election of the board of directors, they also have the power to modify the bylaws and influence strategy through votes at a general meeting. The basic principle of shareholding is that "the number of shares held by a Shareholder in the capital of the Company shall be proportional to the annual financial contribution paid to the Company by such Shareholder for the network-based services provided to it by the Company" (SWIFT Bylaws, Article 10). That means, consistent with SWIFT's status as a cooperative, that ownership and control of the organization are proportional to usage of SWIFT's basic services. There is a reallocation of shareholding every three years. For the purposes of share allocation, affiliated companies may be grouped and their usage aggregated. Not all organizations that use the SWIFT network are eligible to be shareholders. Under SWIFT's Bylaws 
(Article 8), shareholders must be "involved in the same type of business as the other Shareholders, and ... involved in financial message transmission", as determined by the board of directors. These include banks, eligible securities broker-dealers, and regulated investment management institutions. ${ }^{7}$

The shareholders elect a board of 25 independent directors which governs SWIFT and oversees its management (SWIFT Bylaws, Article 16), with directors serving for a term of three years. One third of the board is subject to election each year. A director must be an employee of a shareholder (SWIFT Bylaws, Article 16), and there is no remuneration to directors apart from expense reimbursement (SWIFT Bylaws, Article 27). ${ }^{8}$ The overall composition of the board of directors is determined by reference to a formula which aggregates shareholding by country as follows: the six largest countries by shareholding each nominate two directors; the next ten largest countries by shareholding nominate one director each; and all the other countries nominate the remaining three directors. ${ }^{9}$ The board then appoints a chairman and a deputy chairman from among its members (SWIFT Bylaws, Article 19). There are six committees in which members of the board actively participate in order to provide strategic guidance to SWIFT management. These are the audit and finance committee, the human resources committee, the risk committee, the banking and payments committee, the securities committee, and a technology and production committee. Consistent with the purpose for which SWIFT was created as stated in its Bylaws and the cooperative principle more generally, the current Chairman of the Board, Yawar Shah, emphasizes that the board not only approves strategy, market entry, and alliances but also approves new products and services, major extensions of existing offerings, and key third-party vendors. In his view, it is this reservation of powers to the board that makes SWIFT distinctive among global cooperatives and other global institutions (see Figure 2.1).

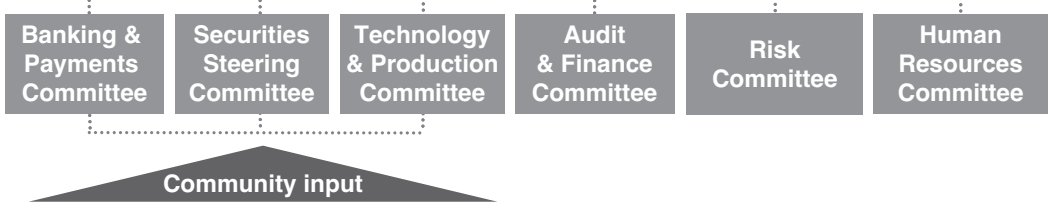

Figure 2.1 Board committees.

Source: SWIFT. 
SWIFT users are grouped into three categories, each of which has access to different levels of service from SWIFT: supervised financial institutions can send and receive all types of messages; non-supervised entities active in the financial industry can send all type of messages to supervised financial institutions but cannot send or receive payment messages to or from other non-supervised entities; and closed user groups and corporate entities have access to services as defined by the administrator of the closed user group or, for corporate entities, according to criteria defined in the relevant service. Only members of the first category - who are banks, securities brokerdealers, and regulated investment management institutions - would be eligible to be shareholders of SWIFT. ${ }^{10}$ A closed user group is a group that connects users in order to exchange a specific set of message types that facilitates a particular business requirement. The administrator of the closed user group has responsibility for defining the rules, the type of service, and the admissions criteria for all the members in the group.

The concept of a national or country-level voice is threaded through SWIFT's governance structure as an organizing principle. It can be seen in the voting formula for directors, and is formalized for shareholders in national member groups. For SWIFT users more generally, SWIFT has organized national user groups. These groups "help ensure a coherent global focus by ensuring a timely and accurate two-way flow of information between SWIFT and its users." 11

Management of SWIFT is organized among three groups (marketing, IT operations, and finance and administration) and two functions (legal and human resources), across three regions (Americas, Asia-Pacific, and EMEA (Europe, Middle East and Africa)). Marketing has a broad brief encompassing product portfolio management, global communication, innovation, and standards. IT operations is not only responsible for the day-to-day running of the SWIFT network but also product development and security control. ${ }^{12}$ Finance and administration is responsible for financial management, corporate planning, and pricing of products as well as all internal support functions such as procurement, internal IT, and office management.

This bare description does not give full expression to how the cooperative spirit that governs the day-to-day running of SWIFT manifests in practice. It is charged with balancing multiple responsibilities: as a cooperative for the benefit of members; an arguably broader remit and responsibility by virtue of compliance obligations vis-à-vis regulators; producer of public goods through standards-setting activities (see Chapter 3); contractual obligations to its users; and its role and authority in the financial services industry as a secure trusted third party in the core industry infrastructure. The notion of a "cooperative" imbues SWIFT's service standards, standardsetting agenda, relationships, projects, and communications strategies with 
a particular, almost quasi-governmental or public service orientation. Inwardly its organizational culture still retains the almost family-like quality established by former CEO Bessel Kok in the early years, while outwardly interactions are informed by its overarching goal to maintain its reputation as trusted third party. This orientation is in evidence across the organization, but perhaps in no respect more so than in SWIFT's approach to operations and security and in its annual practitioner community conference, Sibos. We turn to these subjects in more detail later in this chapter but in the next section we place SWIFT in context by reviewing financial telecommunication in relation to payment infrastructures.

\section{Payment infrastructures and financial telecommunication: putting SWIFT in context}

Payment infrastructures or payment systems are considered by both banking professionals and research scholars to be the backbone of the financial system, often referred to as the "financial plumbing" of an economy. ${ }^{13}$ According to Alan Greenspan, a "payment system is a mechanism - actually many mechanisms - which, when coupled with rules and procedures, provides an infrastructure for transferring money from one entity in the economy to another". ${ }^{14}$ However, payments between counterparties are not generally processed instantly, which means that payment systems, or "payment mechanisms," will often process payments and monetary claims on the basis of "promises to pay", rather than actual transfer of funds. To facilitate this exchange and guarantee as much as possible the completion of the transaction, payment systems initiate a sequence of events that involves a number of financial institutions and technologies such as banks, clearinghouses, data transmission links, and electronic accounting systems. ${ }^{15}$ There are generally three basic stages or processes which are triggered each time a payment needs to be executed (see Table 2.1).

At each step of the payment lifecycle, the payment system must be efficient and reliable in order to avoid any operational and financial risks ${ }^{16}$ and ultimately ensure the exchange of funds. Clearly, the larger the value of payments a system carries, the more significant the risks for the overall financial stability of an economy if the payment system were to fail. As a result, it is imperative for payment infrastructures, especially those that deal with large values, to settle their transactions as soon as these enter the system. Such time-sensitive, systemically important payment systems (SIPS), often referred to as Large-Value Payment Systems (LVPS), ${ }^{17}$ usually incorporate real-time gross settlement (RTGS) as part of their payment process. ${ }^{18}$ Since the attributes of SIPS, and the risks associated, are of great interest to central banks, it is common that they will be actively involved in 
Table 2.1 Description of payment system processes ${ }^{1}$

\begin{tabular}{|c|c|}
\hline Payment stage & Description \\
\hline $\begin{array}{l}\text { 1. Authorization and initiation of the } \\
\text { payment }\end{array}$ & $\begin{array}{l}\text { This stage involves the submission of } \\
\text { the payment order by the payer in } \\
\text { order for the funds to be transferred. }\end{array}$ \\
\hline $\begin{array}{l}\text { 2. Transmission and exchange of the } \\
\text { payment instructions }\end{array}$ & $\begin{array}{l}\text { This involves the transmission and } \\
\text { exchange of obligations between the } \\
\text { parties involved in the transaction. } \\
\text { This process may also include the } \\
\text { netting (or offsetting) of the } \\
\text { obligations where necessary. }\end{array}$ \\
\hline 3. Settlement of the payment & $\begin{array}{l}\text { This final stage entails the compensation } \\
\text { sent from the payer's bank to the } \\
\text { payee's bank. A third-party } \\
\text { settlement agent is usually involved } \\
\text { in this process. }\end{array}$ \\
\hline
\end{tabular}

Note

1. These steps are also often referred to as the life cycle of the payment. See BIS 2005, New Developments in Large-Value Payment Systems: 1-90; Sheppard, "Payment systems in global perspectives:" 6.

the governance and decision-making that control these. Quite often central banks will own the domestic LVPSs and operate the various payment and settlement services, though when this is not the case they will monitor operations and oversee any developments while ensuring that the payment systems generally comply with the core principles identified by BIS (the Bank for International Settlements). ${ }^{19}$ Typically, when central banks do not own the system themselves they act as settlement agents within the payment process. $^{20}$

The above criteria apply equally in the case of domestic and international payments since "the settlement of payments in a given currency takes place at the central bank which issues it." 21 Nevertheless, what changes is the infrastructure used to facilitate the payments. Returning to the basic stages of the payment process, it can be inferred that payment systems rely on a core infrastructure, the main settlement engine, and on a secondary one "that is needed to support the system and its participants." 22 The main infrastructure comprises the hardware and software that operate the system in a narrow sense. This is usually owned and controlled by the settlement agent (e.g. central bank) but can also be outsourced to a thirdparty service provider. The complementary infrastructure or "transaction infrastructure" is also a significant component of the system since it connects the participants with the core settlement mechanism in order to 
"create, validate and transmit payment instructions." 23 This process involves the use of telecommunication to provide a set of necessary services which are known as "transaction infrastructure services" and usually refers to the activities listed in Table 2.2.24

As in the case of the core infrastructure, the secondary engine can also be owned by the settlement agent or it can be provided by a local or distant network operator. The choice of the communication network, especially for large value systems, will depend on the characteristics of the system and the context of its operation..$^{25}$

Whereas interbank payments at the national level often utilize wellestablished formalized (core and secondary) infrastructures typically owned and operated by central banks, the process is more complicated for crossborder payments. Lack of formalized cross-border payment systems often means that "payment arrangements are traditionally based upon bilateral correspondent banking relationships." 26 In addition, the payment initiated by the sending bank needs to pass through the domestic payment system of the local currency before reaching its ultimate destination. This implies that settlement in the local currency also needs to be arranged.

As discussed in Chapter 1, up until the 1970s, transnational banks (TNBs) used to communicate payment instructions using telex (teleprinters connected through the telephone lines). With the successful launch of SWIFT in 1977, most of the big international banks moved their crossborder operations on to the SWIFT network. Henceforth, it was, and still is, SWIFT's primary role to carry the messages containing the payment instructions between financial institutions involved in a transaction. Looking back at Table 2.1, this "secondary" function largely corresponds to stages 1 and 2 of the payment lifecycle. However, since SWIFT is not a clearing or settlement institution and does not operate a core payment infrastructure, the need to communicate the details of the transaction with a clearing house (where applicable) and a settlement institution remains. Depending on the payment system architecture, the routing of the messages can take many different forms. The simplest and most popular structure of message flows

\section{Table 2.2 Transaction Infrastructure Services activities}

Transaction Infrastructure Services

Authentication and identification of the agents that take part in the transaction process by using encryption technologies

Validation of the payment means against the system

Verification of the ability the payer has to pay

Authorization for the transfer of funds between the parties involved

Processing and recording payment instructions

The communication of the information between the financial institutions 


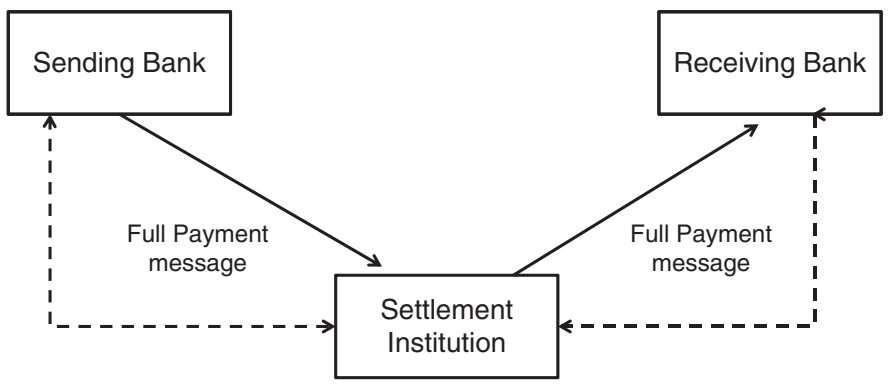

Figure 2.2 V-shaped message flow structure.

used by the majority of RTGS systems around the world is the V-shaped structure depicted in Figure 2.2. According to this, when a payment is initiated, the sending bank transmits a message to the core infrastructure of the settlement institution. Once the settlement process has finished, another message is generated from the core infrastructure with a settlement confirmation and is forwarded to the receiving bank.

A number of LVPS rely upon the telecommunication network and message standards offered by SWIFT in order to transmit instructions to and from settlement institutions. Especially for Market Infrastructures (MIs), SWIFT has designed and operates the Y-copy routing, a sophisticated message flow arrangement currently used by more than 70 domestic and global RTGS systems around the world such as CHAPS in the UK and TARGET2 ${ }^{27}$ in Europe. As shown in Figure 2.3,

...the sending bank [Bank A] addresses a payment message directly to the receiving bank [Bank B], for instance, by an MT103 message. SWIFT intercepts this message, copies the entire content (or a subset) of the message, and sends this copy to the settlement institution. Once the SWIFT network receives a respective approval and settlement message from the settlement institution, it forwards the original payment message to the receiving institution..$^{28}$

SWIFT complements the process with a number of query and reporting features that provide users with information useful for their payment operations (e.g. better liquidity management and to achieve reconciliation in case of system outages). ${ }^{29}$ Ensuring the integrity of the message is one of the key roles of SWIFT as transport network and leading international provider of financial messaging and processing services. ${ }^{30}$

Going back to the definition of a payment system, part of the aforementioned "payment mechanism" refers to the technological infrastructure 


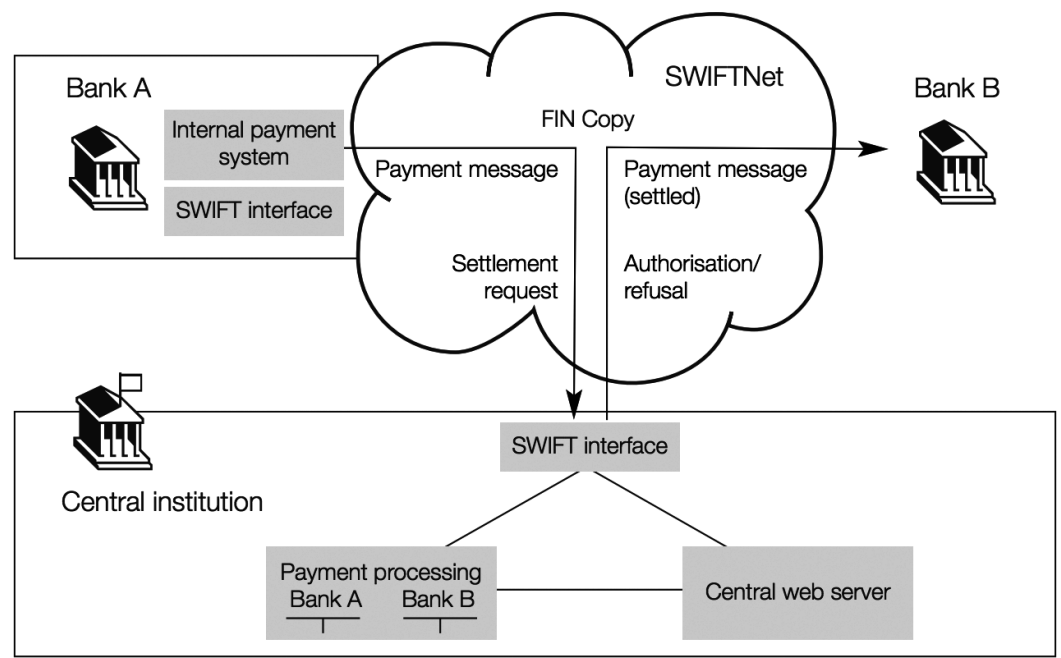

FIN Copy transaction flow

Figure 2.3 Y-copy message flow via SWIFTNet. ${ }^{31}$

behind the scenes on which the whole payment process "sits". These "technological mechanisms" not only facilitate the value exchanges, but also tend to make them more efficient and secure. In that respect the role of technology in payments is vital and helps to address the risk that payments will go astray or transactions will otherwise not settle. On these grounds, member institutions and/or central banks tend to invest a lot of money in technologies that would make payment systems more efficient ${ }^{32}-$ that is, to process payments with as little cost and risk as possible. Nevertheless, in order to arrive at this calculation, one needs to take into account the cost versus benefit. For example, it wouldn't be cost-effective to make a major investment in a small-value payment system that involves little settlement risk. In contrast, it makes much more sense to invest in technological resources that would eliminate the settlement risk of LVPS and SIPS. ${ }^{33}$ In general, payment system innovations provide an important platform for funds to be transferred between participants, hence forming a financial network that consists of a set of institutions connected to each other. The configuration of these kinds of networks has influence on - but is also considerably influenced by - the market structure, the number and diversity of the participants, and their relationship. ${ }^{34}$ In spite of the systemic risks that emerge from the existence of these networks there are also significant benefits from the reduction of transaction costs that arises from connectivity among users and the economies of scale ${ }^{35}$ being created. ${ }^{36}$ 
Economies of scale are reported to be substantial, notwithstanding the expenses incurred by adding a financial institution to the network and the investments in technology needed to resize the infrastructure in order to avoid congestion in the network. ${ }^{37}$

During its time of service, SWIFT's network infrastructure has addressed many of the communication needs of banks and other financial institutions. By taking advantage of technological advances SWIFT helps to reduce operational risk by producing a marked decrease in human errors and other technical failures. In the next section we examine the operational management of the SWIFT network and its security protocol, from its initial operation in 1977 to the current day. SWIFT's reputation as the most secure trusted third party has been critical in achieving the status of de facto provider for connectivity and messaging services, establishing it as a core infrastructure for the global finance industry.

\section{Operations and security: oversight, reliance, and robustness}

Many accounts of operations and technological infrastructure in organizations overlook the way in which current systems are subject to organizational and technical legacies. These legacies often weigh upon the conditions and possibilities of the present in terms of culture and capability. For this reason, we propose understanding today's operations by pausing to study the material history and genealogy of SWIFT systems. ${ }^{38}$ The original operations team at SWIFT was led by Jacques Cerveau ${ }^{39}$ and, when designing the first system, he brought to bear prior experience with hotel and airline systems developed during an earlier phase of his career in the travel sector, which at that time was leading the way in the business use of network technology. ${ }^{40}$ A further contribution to the "conceptual workbench" came from the vendor's (Burroughs) experience with special message switching systems developed for the Canadian Army. SWIFT's systems heritage is thus set side-by-side upon a timeline of projects where reliability and timeliness of communications were a design priority.

Its "family history" also confirms that the underlying systems engineering used was not ground-breaking but built upon existing developments. This is consistent with our earlier observation that financial services tend to borrow technological and operations solutions from other sectors rather than innovate bespoke information and communication systems for themselves. Acknowledging this, Jacques Cerveau describes the original system as "message switching + plus" 41 - in other words, his team drew on triedand-tested technology but added value to meet the requirements of financial services content (for example, checking the integrity of messages, security rules, logging, and access permissions). In so doing, they raised the standard 
and level of reliability found in existing network technology. Reflecting on this he says:

We had to increase reliability because when we signed banks up they said, "Fine, but if we put all our eggs in your basket, SWIFT, we don't want outages." And these issues have been on-going. The reliability of the service is still, I believe, key.

There was one further area where the SWIFT team wanted to push their systems development beyond the limits of prior networks and that was security. If banks were to trust SWIFT to reliably communicate their financial messages they had to design and develop a secure architecture. As Jacques Cerveau says, "The text keys that were put in the telex were not something that could be used. So we had to reinvent completely something to protect privacy and integrity of messages." The SWIFT team set to work developing matching algorithms as the foundation for a new approach to test keys and authentication. Computers were not yet powerful enough to produce encrypted messages but SWIFT worked out a way of taking selected message fields and converting them to make sure that if one character changed (e.g. an amount or the beneficiary's name) the system would know. So, while the core system used proven network technology, its secure protocol originated in-house and was tempered only by the need to avoid too much complexity so that it did not overwhelm the constraints of their 1970s' computer resources which were modest in comparison with those of today.

If the first part of this chapter identifies how the specifics of its cooperative form structure, SWIFT's "organizational DNA", then here we have found the second strand of the double helix in its genetic make-up: reliability and security. Throughout most of its history, this has been treated as essential but largely taken for granted. As the current Chief Information Officer (Head of Information Technology and Operations), Mike Fish puts it:

We integrate off-the-shelf components and manage them in a way that provides "Five Nines" [99.999 percent] availability and security... SWIFT is viewed as rock solid in technology terms. If we innovate in operational terms it usually goes unseen. But we are extremely innovative in the level of security and reliability we provide in our services. The problem is that we never call it innovation. We tell customers that we will give them "an improved service level with better security than you have ever had before." But we don't frame it as "innovation". At the end of the day we are just here to serve the customer so we often don't get recognition for "pushing the envelope". 
The term "Five Nines" refers to a critical shift made in the quality of service provision during the 1990s after upgrading from the original SWIFT system to "SWIFT II" (see Box 2.1).

In the aftermath of the SWIFT II outage, the operations team began consolidating and extending their already distinctive approach to robustness in

\section{Box 2.1 SWIFT II and a new approach to operations}

One of the most challenging phases in SWIFT's operations history involved two network disruptions in June and September 1991 during an upgrade and migration project from SWIFT's original technological infrastructure, using Burroughs' proprietary protocol, with central switches and national concentrators, to a more distributed network architecture using packet switching (see Chapter 4). "SWIFT II" was a second-generation system that would bring significant advances in SWIFT's FIN messaging application. It represented a major change not only in the technological basis of the SWIFT network but also new applications and protocols. Indeed, The Financial Times heralded it as the "the largest IT project in the world."

At around 3:00 on 4 June 1991, SWIFT II regional processors 1, 2, 3 , and 4 went offline and the SWIFT system was disrupted for four hours. As a result, user banks across Europe were unable to log on to the network and use its services. The financial press reported the incident as follows:

Back-up processors could not be successfully activated. Finally, at about 07:30, there was a partial recovery allowing continental European banks back onto the network ... but banks in the U.K., Ireland, the Channel Islands and Iceland remained cut off until nearly 16:00 in the afternoon. Several SWIFT II users missed CHAPS (Clearing House Automated Payments System) clearing deadlines as a result. ${ }^{2}$

About three months later, on 16 September 1991, a day before the opening of SWIFT's Sibos conference:

a software change input over the weekend resulted in a sevenhour SWIFT II network disruption. The cause was a bug in the software governing undelivered message reporting. An innocent request for a review of undelivered messages created a bottleneck 
in the queue holding confirmation messages for transactions flagged as "urgent". ${ }^{3}$

These two events not only flung SWIFT into crisis management mode but sent shock waves through the organization that would eventually result in a significant shift in its culture, culminating in profound changes not only in their approach to future system upgrades but to the 360-degree management of its security and reliability. This was summed up by the maxim "Failure is Not An Option" (FNAO) inspired by the NASA Apollo 13 mission. ${ }^{4}$

\section{Notes}

1. Samantha Laurie, "SWIFT faces problems: the burning issue of supervision," The Financial Times, 12 November 1991.

2. "Cracks in SWIFT coalition appear at Hong Kong Sibos," Waterstechnology, 7 October 1991.

3. Ibid.

4. These incidents coincided with Bessel Kok's departure (Sibos 1991 would be the last he addressed as CEO) and Lenny Schrank's arrival in July 1992. Jacques Cerveau served as an interim CEO after Bessel Kok took up an executive position at the Belgacom PTT in 1991.

an internally-driven initiative supported by incoming CEO Leonard Schrank. The difference between 99.99 percent reliability and 99.999 percent may seem very small but the investment in technology and advanced level of process management protocols needed to achieve this places SWIFT in an unusual category of "high-reliability organizations".

The SWIFT architecture is designed around layers of resilience and "gold plate" with regularly tested redundant systems capable of providing potential back-up resources if needed. Data centres are distributed in different countries around the world and data are handled on a "zonal basis" 42 as operations management "follows the sun", 24 hours a day, seven days per week. While these centres all have physical security measures in place in their grounds and building architecture, the guiding principle of SWIFT ops is that "operational excellence is achieved by people not hardware, software, or high fences around properties." 43 For example, critical changes to the system have to be reviewed and signed off by (at least) two members of staff, in compliance with their "Four Eyes" rule. This is backed up by highly developed migration and fallback scenarios. 
The ethos guiding SWIFT's "care-oriented assurance" is "Learn, Prevent, Plan, Manage" with an emphasis on team communication practices designed to put experience and practice behind each principle. At their "watchdog" management stations they use both preventative and detective systems including traffic charts to track the "heartbeat" of the message traffic flows. This alerts them to any variation from usual baseline activity and is further supported by component-level monitoring. Tiger teams ${ }^{44}$ are used to test the system and access to the buildings. This feeds into a process of critical event reporting and post-mortem discussions at their regular "round robin" 45 style meetings. As Lenny Schrank put it in one of his adages: "It is no accident that we have no accidents."

As Figure 2.4 shows, SWIFT has implemented many generations of security; indeed it is a case study for the evolution of operations security. Because they implement leading-edge security on a larger scale "ahead of the curve", other financial services organizations and market infrastructures follow, learning from SWIFT's experience. For example, they were an early adopter of Public Key Infrastructure (PKI) on a large scale and among the first to employ Hardware Security Modules (HSM), a special device that is tamper-resistant, rolled out throughout SWIFT's customer sites to digitally sign or encrypt messages.

With security issues and resilience now high on the agenda for financial organizations and their regulators, SWIFT has gradually risen in regard. As Mike Fish puts it "where other people try to stay one or two steps ahead, we try to stay two or three steps ahead of the bad guys." They work closely with

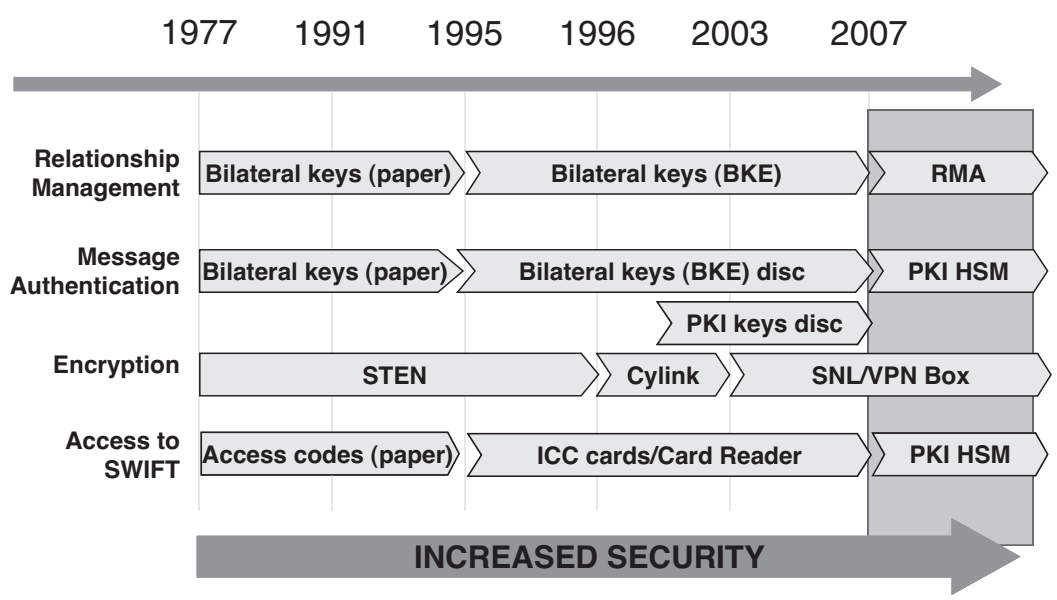

Figure 2.4 Evolution of security.

Source: SWIFT Operations Centre presentation. 
vendors as a benchmark customer for security controls and pass on their area of security expertise to member organizations. This means that when SWIFT implements further security measures " $\ldots$ the protection tide rises for everyone."

In terms of oversight, SWIFT represents an interesting case because being neither a settlement institution nor a payment system it is not directly regulated by central banks or bank supervisors. However, since a significant number of Systematically Important Payment Systems (SIPS) ${ }^{46}$ have become dependent on the network, SWIFT became a critical infrastructure and acquired a "systemic character." 47 Since 1998, the Group of Ten countries (G-10) central banks ${ }^{48}$ have been acting as joint overseers and maintain an open dialogue with SWIFT. In 2012, the oversight framework was reviewed and a SWIFT Oversight Forum was established, through which information sharing on SWIFT oversight activities was expanded to a larger group of central banks. ${ }^{49}$ Since the society is incorporated in Belgium, the NBB (Banque Nationale de Belgique) has kept its position as the lead overseer and it continues to monitor SWIFT on an ongoing basis. ${ }^{50}$ The oversight of SWIFT by banking authorities focuses primarily on systemic risk, confidentiality, integrity (level of security in the infrastructure), and availability (business continuity).

The operational processes of SWIFT are overseen by the audit and finance committee of the board of directors. As security is central to SWIFT operations, the committee mandates an external auditor to conduct an annual independent security report in accordance with International Standard on Assurance Engagements (ISAE) 3402 "Assurance Reports on Controls at a Service Organization", issued by the International Auditing and Assurance Standards Board. ${ }^{51}$ This security report includes the auditors' tests (observations and inspections) based on a set of controls that relate to the SWIFT Security Control Policy (SSCP) and are structured along the areas of: governance, confidentiality, integrity, availability, and change management. The results are used to mitigate risks that would prevent the achievements of the company's objectives.

Disseminating expert operations "know-how" is regarded as part of SWIFT's responsibility as an industry cooperative. In the next section, we provide an overview of a further way in which SWIFT supports community engagement through the organization of a major annual conference called Sibos.

\section{Community engagement: Sibos}

Starting in 1978, one year after operations commenced, SWIFT has provided a prominent forum for transaction banking in the form of "Sibos", SWIFT's International Banking Operations Seminar (see Table 2.3). 
Table 2.3 Sibos locations, theme, and numbers of participants (1978-2013) ${ }^{1}$

\begin{tabular}{|c|c|c|c|}
\hline \multicolumn{2}{|l|}{ Location } & \multirow[t]{2}{*}{ Theme } & \multirow{2}{*}{$\begin{array}{l}\text { Number of } \\
\text { participants } \\
\text { (approx.) }\end{array}$} \\
\hline Year & & & \\
\hline 1978 & Brussels & $\mathrm{n} / \mathrm{a}$ & 300 \\
\hline 1979 & Amsterdam & $\mathrm{n} / \mathrm{a}$ & not known \\
\hline 1980 & Copenhagen & $\begin{array}{l}\text { "Developments in operational } \\
\text { banking"”* }\end{array}$ & 1,000 \\
\hline 1981 & Düsseldorf & $\begin{array}{l}\text { "SWIFT's role in international } \\
\text { banking",* }\end{array}$ & not known \\
\hline 1982 & $\begin{array}{l}\text { Washington, } \\
\text { DC }\end{array}$ & $\mathrm{n} / \mathrm{a}$ & not known \\
\hline 1983 & Montreux & "International electronic banking" & not known \\
\hline 1984 & Barcelona & "Costs, risks, and profits" & not known \\
\hline 1985 & Brighton & "The management of change" & not known \\
\hline 1986 & Nice & "The competitive edge" & 1,200 \\
\hline 1987 & Montreal & "Operations: the strategic choice" & not known \\
\hline 1988 & Vienna & "The quality commitment" & not known \\
\hline 1989 & Stockholm & "Innovation and risk" & not known \\
\hline 1990 & Berlin & "The service equation" & not known \\
\hline 1991 & Hong Kong & $\mathrm{n} / \mathrm{a}$ & not known \\
\hline 1992 & Brussels & $\mathrm{n} / \mathrm{a}$ & not known \\
\hline 1993 & Geneva & $\mathrm{n} / \mathrm{a}$ & not known \\
\hline 1994 & Boston & "Opportunities in changing times" & not known \\
\hline 1995 & Copenhagen & $\begin{array}{l}\text { "Sharing the vision, shaping the } \\
\text { future" }\end{array}$ & 3,195 \\
\hline 1996 & Florence & "Entering a new era" & 3,568 \\
\hline 1997 & Sydney & $\begin{array}{l}\text { "Doing business in a borderless } \\
\text { world" }\end{array}$ & 3,054 \\
\hline 1998 & Helsinki & $\mathrm{n} / \mathrm{a}$ & 3,523 \\
\hline 1999 & Munich & $\begin{array}{l}\text { "Harnessing business and IT } \\
\text { strategies",* }\end{array}$ & 5,275 \\
\hline 2000 & San Francisco & "The e-vision debate" & not known \\
\hline 2001 & - & - & - \\
\hline 2002 & Geneva & "Resilience and value" & 6,000 \\
\hline 2003 & Singapore & "New realities" & not known \\
\hline 2004 & Atlanta & "Time for growth" & 5,250 \\
\hline 2005 & Copenhagen & $\begin{array}{l}\text { "Transformation: towards SWIFT } \\
2010 "\end{array}$ & 6,850 \\
\hline 2006 & Sydney & "Raising ambitions" & 5,700 \\
\hline 2007 & Boston & "Gaining momentum" & 7,200 \\
\hline 2008 & Vienna & "Enough talk; more action"” & 8,114 \\
\hline 2009 & Hong Kong & $\begin{array}{l}\text { "Collaboration and innovation } \\
\text { dominate" }\end{array}$ & 5,782 \\
\hline 2010 & Amsterdam & "Light at the end of the tunnel? & 8,900 \\
\hline
\end{tabular}


Table 2.3 (Continued)

\begin{tabular}{llll}
\hline Yocation & Theme & $\begin{array}{l}\text { Number of } \\
\text { participants } \\
\text { (approx.) }\end{array}$ \\
\hline 2011 & Toronto & $\begin{array}{c}\text { "Regulation, future of money, } \\
\text { changing technology, } \\
\text { worldwide shifts" } \\
\text { "Regulation, changing technology, } \\
\text { worldwide shifts" }\end{array}$ & 7,600 \\
2012 & Osaka & $\begin{array}{c}\text { "Regulation, operational } \\
\text { excellence, worldwide shifts" }\end{array}$ & TBA \\
\hline
\end{tabular}

Notes

1. Updated version of Table 3 in our earlier journal article: Susan V. Scott and Markos Zachariadis, "Origins and development of SWIFT, 1973-2009", Business History, 52 (3) (2012): 462-83.

2. Sibos does not have a byline per se. This table assumes a thematic priority based upon our analysis of Sibos conference programs kept onsite at SWIFT headquarters in La Hulpe, Belgium. If marked with * we have based this theme on the title of the first plenary seminar because it was regarded as indicative.

The Sibos annual conference is held in a different city each year and takes place over at least three days with supplementary activities taking up to a week.

Celebrating its 35th anniversary in 2013, Sibos has evolved considerably since its beginnings. Sibos was initially thought of as providing an opportunity for SWIFT to solicit the views and insights from back-office personnel at banks, focused on technical aspects of operations - in effect, a user group forum. But early on SWIFT recognized the potential of Sibos as a way to build community and share knowledge among its constituencies, ${ }^{52}$ and the Sibos annual conference has evolved into a see-and-be-seen networking event, attended by executives with a range of responsibilities including strategy and compliance. It provides an opportunity to air concerns and issues as well as a place for exhibitors (financial institutions, IT vendors, and other service providers) to promote leading-edge products and services. ${ }^{53}$ As Lenny Schrank commented: "We turned it into a professionally managed annual conference... you would cut random conferences, but Sibos you would never cut, because you would do in three days what you could do in four months. Everybody's there." 54 To give a sense of the breadth of issues coverage, Sibos 2013 had tracks for technology, market infrastructures, corporate, compliance, Innotribe, and standards, with a special day allotted to Africa and the Middle East. 
From the 1990s onward, an important principle guiding the development of Sibos as "a premier business forum for the global financial community to debate and collaborate in the areas of payments, securities, cash management and trade" 55 was that Sibos should be a place for "critical dialogue". Speakers have occasionally used the opportunity to challenge SWIFT and the financial institutions community - one example being a speech given by Heidi Miller of JP Morgan in 2004, discussed in Chapter 5. Former Director of Communications, Rosie Halfhead, regarded debate as part of her ethic for Sibos:

SWIFT aims to achieve a spread which is representative of the event and the audience, but there is absolutely no sense in which it tries to suppress debate and controversy. Quite the contrary, SWIFT wants to provoke debate and discussion and controversy.

This is not spin. In Stockholm in 1989, delegates were shocked to find themselves being addressed by a German computer hacker who had agreed to explain to the men in suits how he and his ilk could break into their systems. The effect can be likened to the organizers of a conference of postmasters and mistresses inviting Ronnie Biggs to talk about the intellectual challenges of the Great Train Robbery. Similarly, at Brussels in 1992, star guest Nigel Lawson - the Euro-sceptical former British Chancellor of the Exchequer who agreed to make the closing address managed to insult his largely Europhile audience with some disparaging remarks about the idea of a single European currency. However, the only clear instance of a genuinely controversial speech that anyone can remember was made by Vivian Banta Eversole at Boston in 1994 during her Chase days. The timing of this now-famous speech ("stick to your knitting") was no coincidence. SWIFT had chosen Sibos 1994 to launch SWIFTAsset Reconciliation, and custodians were keen to discourage any custodial pretensions. ${ }^{56}$

Though the registration fee is high (3,200 euros in 2013), the event is oversubscribed, and financial institutions are eager to put forward their representatives as speakers and to be allocated attractive exhibition space. Over the years, Sibos event management has been increasingly professionalized, with reporting including social media coverage during the conference and video recordings made available after the event. SWIFT assigns personnel to work on Sibos year-round, and the conference sites are selected several years in advance because of the complexity of logistics.

Notwithstanding the extensive planning, the annual Sibos convention has not been unaffected by external events. In 1985, Sibos was due to be held in Brighton at The Grand Hotel when an IRA bomb destroyed it. Five 
years later, Sibos was in Berlin in time for the one-year anniversary of German reunification. Delegates were distracted in 2008 by the bankruptcy of Lehman Brothers. But the only time the event has been cancelled was in in 2001 after the $9 / 11$ terrorist attacks.

Although revenues from Sibos exceed $\$ 10$ million, SWIFT runs the conference on a break-even basis. So what does SWIFT sponsorship mean for Sibos and what does Sibos mean for SWIFT? Sibos is described as SWIFT's flagship event for bringing "the financial community together to work collaboratively to shape market practice, define standards and debate issues of mutual interest." ${ }^{57}$ That is, Sibos supports a community of practice ${ }^{58}$ in the financial services industry, where competing businesses can come to share knowledge and practices to advance those areas of cooperation, such as in the area of standards, or to mobilize an industry view vis-à-vis compliance issues, that will benefit them all. Jessica Parser, a central figure in the organization of Sibos over a number of years, commented in 2012: "Sibos stood for "SWIFT International Banking Operations Seminar." In 1994, Lenny [Schrank] and Rosie [Halfhead] made a strategic decision. The "Operations Seminar" no longer rang true so it was decided it would be named "Sibos" as though it were one word ... as though it were a brand ... and to give it a separate visual identity. ${ }^{59}$

Though some have mooted the idea that Sibos might be spun off as a stand-alone concept and enterprise, SWIFT management believes that as a second brand there is symbiosis with SWIFT - without Sibos, SWIFT would lose something vital to its value proposition as a nexus for the financial services community and without SWIFT's credibility as a trusted third party, Sibos would be just another commercial conference. ${ }^{60}$

\section{Conclusion}

Why should we bother to find out how SWIFT works? Because most discussions of global financial services tend to focus on the hierarchy of multinational corporations and functionality of markets with relatively little attention given to how these are supported. Yet market economies would cease to work and business would be ungovernable without a particular genre of organizations whose agency lies "in between". SWIFT is an interesting instance of this genre because it draws upon an international cooperative membership to resource a secure network, standards, working groups, and an industry conference.

In this chapter we have provided details of the organization and operations that enable the cooperative to work. Cooperative organizational models vary considerably and arguably their translation into organizational 
form differs still further because they evolve over time. SWIFT's current culture of governance rests upon many distinctive sources of organizational authority through which it is able to draw upon a diverse but considerable resource base. When we use the term "authority" in this context, we are referring not only to sets of rules but also to the wisdom or experience of individuals and institutional resources rather than any powers of coercion or enforcement. ${ }^{61}$ These resources are realized through both internally generated revenue streams and calls for "in kind" community participation with which SWIFT is able to pursue its mission to support market practices and promote standardization.

While the mechanisms through which this industry cooperative is run may have changed, its organizational structure is still arranged around a community ethos supported by the logic and practice of consultation and collaboration. We would argue that this owes much to the profession of standards development. The second part of the Alexander Graham Bell quotation with which we began this chapter reads: “... I may be given credit for having blazed the trail, but when I look at the subsequent developments I feel the credit is due to others rather than to myself." In the next chapter we provide a detailed examination of standards as well as the practices that have matured around standards design, development and, critically, their adoption by a community of users.

\section{Notes}

1 SWIFT is sometimes referred to as a communication network and was founded to replace telex systems owned and run by post, telegraph, and telecom (PTT) companies. However, although SWIFT's history overlaps with the evolution of the telecoms sector, important distinctions need to be made. Mike Fish, Chief Operating Officer at SWIFT, makes the following clarification: "We are not a telecommunications company. We are a messaging company. Our value added is really the software and services that we put on top of the network. We assemble our network from providers, it is a necessity to have the worldwide connections but we outsource all our telecom work to telecom providers and we focus on providing the value added on top of that." (Interview with Mike Fish (2012), interviewed by Susan Scott and Markos Zachariadis [in person], European Operations Centre, 16 February 2012.)

2 SWIFT website, SWIFT in Figures (April 2013): http:/www.swift.com/assets/ swift_com/documents/about_swift/SIF_2013_04.pdf.

3 Another important messaging service is InterAct. InterAct enables the exchange of SWIFT MX messages based on XML (see Chapter 3 for more details on SWIFT Standards) and apart from the traditional store-and-forward mode it also supports real-time messaging. Both FIN and InterAct work on a message-per-message basis. Two other messaging services that "sit" on SWIFTNet are FileAct, for the secure transfer of important files, and Browse for accessing securely financial websites (see "SWIFT messaging services", SWIFT 2011). 
4 See Timothy J. Sinclair, Global Governance (Cambridge: Polity Press, 2012), 28.

5 Details of SWIFT finances are based upon internal documents kindly provided by Francis VanBever (interviewed by Susan Scott and Markos Zachariadis [in person], La Hulpe, Belgium, 22 December 2011). Also thanks to Bessel Kok who describes the original financing for SWIFT in his interview with Susan Scott [in person], Prague, 24 April 2012.

6 Francis VanBever (interviewed by Susan Scott and Markos Zachariadis [in person], La Hulpe, Belgium, 22 December 2011).

7 SWIFT, SWIFT User Categories: http://www.swift.com/about_swift/community/ swift_user_categories.

8 SWIFT reimburses the employer of the chairman of the board for the share of the chairman's payroll and related costs representing the portion of the time dedicated by the chairman to SWIFT (SWIFT Annual Review, 2012: 32).

9 In 2013, the countries with two board members were as follows: United States, United Kingdom, Germany, France, Switzerland, and the Netherlands. Countries with one board member were Belgium, Japan, Italy, Canada, Sweden, Spain, Luxembourg, Hong Kong, Australia, and China.

10 See generally SWIFT, SWIFT User Categories: http://www.swift.com/about_ swift/community/swift_user_categories. The closed user groups and corporate category include the following categories of SWIFT users: Corporate, Financial Market Regulator, Payment System Participant, Securities Market Data Provider, Securities Market Infrastructure System Participant, Service Participant within Member Administered Closed User Group, and Treasury Counterparty (ibid.). For more about user eligibility, see SWIFT, User and Shareholder Eligibility Criteria: http://www.swift.com/assets/swift_com/ documents/about_swift/User_eligibility_criteria_v5.pdf

11 SWIFT, Governance at SWIFT: http://www.swift.com/about_swift/company_ information/governance_at_swift?lang=

12 SWIFT, Organizational Structure: http://www.swift.com/about_swift/company_information/leadership_council?lang=

13 David Sheppard, "Payment systems in global perspectives: some views from the central banks", in Proceedings of the Central Bank Governors' Symposium (London: Bank of England, 1998): 28-32.

14 See Alan Greenspan, "Remarks on evolving payment system issues", Journal of Money, Credit, and Banking, 28 (4) (1996): 690. Generally, definitions of payment systems can vary according to the context. The Bank of International Settlements (BIS) defines a payment system as "a set of instruments, procedures and rules for the transfer of funds among system participants" (see BIS 2001, Core Principles for Systemically Important Payment Systems: 83). Other definitions describe payment systems as social relations and technological mechanisms that enable funds or other assets to be transferred, thus highlighting their diversified and "sociotechnical" features (see the work of David Humphrey and others). In some cases the meaning is narrowed down to the actual infrastructure that processes the payments. All these definitions are useful in explaining the role of SWIFT and how this compares to other payment infrastructures.

15 See Greenspan, "Remarks"; Allen Berger, Diana Hancock, and Jeffrey Marquardt, "A framework for analyzing efficiency, risks, costs, and innovations in the payments system", Journal of Money, Credit, and Banking, 28 (4) (1996): 696-732. 
16 Financial risk concerns the fiscal part of the payment process and describes issues around the inability of the parties to fulfill their obligations (credit or settlement risk), system liquidity, systemic threats, etc.; on the other hand, operational risk refers to factors like technical failures, human mistakes, and legal issues (regulatory ambiguities and poor guidelines) that can cause disruption to a payment system (see Berger, Hancock, and Marquardt, "A framework for analyzing").

17 In the payment systems literature LVPSs, also known as Wholesale Payment Systems (WPS) or Large-Value Funds Transfer Systems (LVFTS/LVTS), usually refers to payment mechanisms that transfer payments of more than 1 million US\$ (see Berger, Hancock, and Marquardt, "A framework for analyzing”). The volumes reflected in those systems are much less than those of the Small-Value Payment Systems (SVPS or SVFTS/SVTS) which represent payment methods such as cheques, credits cards, debit cards, etc., also known as Retail Payment Systems (RPS), and whose values are significantly smaller. For examples of the US payment instruments including statistics on their volumes or values, see David Humphrey, Lawrence Pulley, and Jukka Vesala, "Cash, paper, and electronic payments: a cross-country analysis", Journal of Money, Credit, and Banking, 28, (4) (1996): 914-39; BIS 2002 (Statistics on Payment Systems in the Group of Ten Countries); BIS 2003 (Payment and Settlement Systems in Selected Countries); BIS 2005 (New Developments in Large-Value Payment Systems).

18 On the contrary, less important systems such as Small-Value Payment Systems (SVPS) typically settle their transactions on a deferred basis at a pre-designated time, usually at the end of the day. Net settlement arrangements, often know as Deferred Net Settlement or Designated-time Net Settlement (DNS) systems, settle their transactions at the end of the day, whereas RTGS deliver payments instantly and irrevocably (see Berger, Hancock, and Marquardt, "A framework for analyzing").

19 The Committee on Payment and Settlement Systems (CPSS) at the BIS provides a number of core principles that should be met by SIPS in order to ensure stability in the financial system and the economy in general; these can be found at BIS 2001 (Core Principles for Systemically Important Payment Systems): $57-67$.

20 In practice, this means that central banks manage the settlement accounts of various banks and transfer funds between them to achieve finality (BIS 1997, Real-Time Gross Settlement Systems).

21 Dominique Rambure and Alec Nacamuli, Payment Systems: From the Salt Mines to the Board Room (Houndsmill: Palgrave Macmillan, 2008): 43.

22 BIS 2005, New Developments in Large-Value Payment Systems.

23 BIS 2006, General Guidance for National Payment System Development: 42.

24 These "payment infrastructure services" are defined in the consultative BIS report (BIS 2006, General Guidance for National Payment System Development).

25 For example, a local SVPS will have different networking requirements compared to a LVPS which may engage in cross-border payment activities. In the latter case, compatibility among alternative networks is also essential in order to guarantee transmission between networks. Furthermore, the structure of the market under which the system performs can influence the choice of the network. In any case, core and complementary infrastructures need to be reliable and secure in order to avoid operational nuisances and ensure financial stability in the economy (BIS 2005, New Developments in Large-Value Payment Systems). 
26 See David Sheppard, "Payment Systems," Bank of England Discussion Papers (1996): 49.

27 TARGET2 is a RTGS system for the euro provided by the European Central Bank (ECB) and the National Central Banks (NCBs) of all the countries that have adopted the euro currency. This is used to settle central bank operations, large-value interbank transfers, and euro payments. For more information, see www.ecb.int.

28 BIS 2005 (New Developments in Large-Value Payment Systems): 19.

29 SWIFT also provides services for other message-routing arrangements like T-copy and L-shaped architectures. For more information, see BIS 1997 (Real-Time Gross Settlement Systems); Rambure and Nacamuli, Payment Systems.

30 Rambure and Nacamuli, Payment Systems: 48.

31 Source: SWIFT report on "High values payment market infrastructures (HVP MI)", February 2009.

32 Competition among payment infrastructures is another factor that also drives investments in technology and communication networks. Various private or non-privately owned establishments race to provide new products and services to their users and raise the standards of their payment processes by investing in the latest payment technologies. Such examples are well-known payment-card systems like VISA, MasterCard, and American Express, but more examples can be found in the LVPS arena and especially between clearing houses in the financial securities industry.

33 Berger, Hancock, and Marquardt, "A framework for analyzing"; Mark Flannery, "Technology and payments: déjà vu all over again?" Journal of Money, Credit, and Banking, 28 (4) (1996): 965-70; Jean-Charles Rochet and Jean Tirole, "Controlling risk in payment systems", Journal of Money, Credit, and Banking, 28 (4) (1996): 832; Jean-Charles Rochet and Jean Tirole, "Interbank lending and systemic risk", Journal of Money, Credit, and Banking, 28 (4) (1996): 733.

34 Mark Casson, "Networks in economic and business history: a theoretical perspective", in Innovation and Entrepreneurial Networks in Europe, eds. Paloma Fernandez-Perez and Mary B. Rose (London: Routledge, 2010): 14-40.

35 There is a substantial literature on network effects and the economies of scale created from the growth of networks (also referred to as network economics) driven largely by the work of Economides, Saloner, Farrell, Katz, Shapiro, Liebowitz, Margolis, and others. For an empirical econometric analysis on the network effects of SWIFT, see Markos Zachariadis, "Diffusion and use of financial telecommunication: an empirical analysis of SWIFT adoption", NET Institute Working Paper 11-10 (2011): 1-44.

36 Ian Domowitz, "Liquidity, transaction costs, and re-intermediation in electronic markets", Journal of Financial Services Research, 22 (1-2) (2002): 141-57; Diana Hancock, David Humphrey, and James Wilcox, "Cost reductions in electronic payments: the roles of consolidation, economies of scale, and technical change", Journal of Banking and Finance, 23 (2-4) (1999): 391-421.

37 Diana Hancock and David Humphrey, "Payment transactions, instruments, and systems: a survey", Journal of Banking and Finance, 21 (11-12) (1998): $1573-624$.

38 There has been very little academic or practitioner literature on SWIFT operations. While we undertook fieldwork at the operating centres, we have been necessarily selective in our description of them. A notable exception is Jan Van Auseloos, "Responsibilities of TTPs in trusted networks", Information Security 
Technical Report, 1 (1) (1996): 52-6. There have been two fictional accounts of operations and security at SWIFT: Marc Cave, Vals Goed (Antwerpen: Manteau, 2007) and James Follett, SWIFT (London: Methuen/Mandarin, 1986/1994). Follett (SWIFT: 1) begins with the chilling line: "We're interested in your knowledge of SWIFT, doctor."

39 Jacques Cerveau joined SWIFT and became their first Director of Operations in January 1974 and assumed overall technical responsibility for the development and implementation of the system. His responsibilities included the selection, negotiation, and management of hardware and software contracts, the major one being a turnkey contract with Burroughs (now Unisys) for the delivery of the first SWIFT System (30 MUSD); the design of a security architecture and negotiation with vendors of security products; the design and development of mini-computerbased terminals to be installed in the banks to interface to the SWIFT system; negotiations with PTTs and Carriers for the provision of international circuits; the construction and installation of two major computer centres, and of regional centres in each country of operation; planning the organization of the Operations Division and resourcing it with a multinational team; and the operational launch of the SWIFT system in May 1977. His background includes a degree in engineering from École Centrale de Paris (Jacques Cerveau, interviewed by Susan Scott [in person], Paris, 13 February 2012).

40 During this phase of his career, working alongside experts on leading-edge communication technologies and networks, Jacques Cerveau learned about interconnecting systems (notably a reservation system for hotels in Europe with seat reservation systems for the BOAC airline). He said that as part of the in-house research conducted when developing the SWIFT system his team closely studied travel sector networks (as well as principles from military message switching systems). The Brussels based "Société Internationale de Télécommunications Aéronautiques", known as SITA, was the first worldwide packet switching network dedicated to business traffic and proved particularly important in this regard (Jacques Cerveau, interviewed by Susan Scott [in person], Paris, 13 February 2012). In light of its role as a reference point in the technical history of SWIFT's network, some further detail on SITA may be useful: Founded in 1949 as a member-owned cooperative society to provide a worldwide message switching network for international air carriers, "Initially the network consisted of manual (torn-tape) centres, interconnected by low speed circuits (50, 75 Bauds, 60, 30, 15 words per minute, asynchronous). The Airline terminal equipment (teleprinters and telex) was connected to the SITA manual centres, thus enabling airline messages to be exchanged via nodes of the SITA network, with consequent reduction in costs to the airlines by their sharing of communications facilities. With the rapid development of the Air Transport Industry, the airline communications needs became increasingly important and thus the SITA network expanded very quickly, by 1963 covering the world" (G.J. Chretien, W.M. Konig, and J.H. Rech "The SITA Network", in Proceedings of the NATO Advanced Study Institute on Computer Communication Networks (Leyden: Noordhoff International Publishing, 1975): 373-96 [accessible from http:// rogerdmoore.ca/PS/SITAB.html]). During the 1960s, SITA began replacing telex with computer systems and established a communication data network to carry safety-critical messages (see Chretien et al., "The SITA Network"). They go on to note: "By mid-1973, the SITA network comprised 150 centres including 8 high level centres and 21 satellite processors." SITA currently has 450 
co-owners from members of the ATI. The company provides services to over 2,800 customers in 1,000 airports located in 200 countries and territories, which represents over 95 percent of all international destinations (see http://www.sita. aero/about-sita/what-we-do/sita-history; http:/www.sita.aero/about-sita/what-wedo/facts-and-figures).

41 This phrase and his further comments included in this section of the chapter are from Jacques Cerveau (interviewed by Susan Scott [in person], Paris, 13 February 2012).

42 See Chapter 5 for further discussion. The messaging infrastructure is split into two different data zones, one for intra-European activity, located at European operating centres, and one for trans-Atlantic or global activity located at operating centres in Europe and the US. This approach was instituted to address concerns about data governance and ensures that purely intra-European messaging activity does not enter US jurisdiction.

43 This quotation and other details in this paragraph are based upon notes from presentations given by the operations team during a one-day tour of SWIFT's operating centres in Europe, 16 February 2012.

44 In security terms, a tiger team is a specialized group that tests an organization's ability to protect its assets by attempting to circumvent, defeat, or otherwise compromise that organization's internal and external security.

45 The term "round robin" refers to a meeting protocol in which the team responsible for operations management on one shift will share details during a hand-over meeting to the next shift. This is one of the methods used in SWIFT operations to reinforce team communication.

46 A payment system is defined as systemically important when "a disruption within it could trigger or transmit further disruptions amongst participants or systemic disruptions in the financial area more widely" (see BIS 2001, Core Principles for Systemically Important Payment Systems: 3-5).

47 This has been recognized both by SWIFT and other bodies like the Bank of International Settlements (BIS) and a number of central banks in Europe and elsewhere (SWIFT Annual Report, 2009; BIS 2003, "International payment arrangements:" 1-24).

48 These are the Bank of Canada, Deutsche Bundesbank, European Central Bank, Banque de France, Banca d'Italia, Bank of Japan, De Nederlandsche Bank, Sveriges Riksbank, Swiss National Bank, Bank of England, and the Federal Reserve System (USA) The last is represented by the Federal Reserve Bank of New York and the Board of Governors of the Federal Reserve System (see SWIFT Annual Review, 2013: 34).

49 The National Bank of Belgium is lead overseer in cooperation with the other G-10 central banks. In the SWIFT Oversight Forum, these central banks are joined by other central banks from major economies: Reserve Bank of Australia, People's Bank of China, Hong Kong Monetary Authority, Reserve Bank of India, Bank of Korea, Bank of Russia, Saudi Arabian Monetary Agency, Monetary Authority of Singapore, South African Reserve Bank, and the Central Bank of the Republic of Turkey (SWIFT Annual Review, 2013: 34).

50 Further details on the role of the NBB in overseeing SWIFT can be found in the Financial Stability Review published by the National Bank of Belgium (2010).

51 Ibid.

52 Interview with Jessica Kuborn [Parser], reported in Dominic Hobson, "A brief history of Sibos", Global Custodian, August 2001: "We had a three day event, 
with plenary sessions and three parallel sessions entitled "Our Solutions" in one of the biggest hotels in Brussels, but we still could not fit everyone in", recalls Jessica Kuborn [Parser], a former head of corporate communications at SWIFT who helped organize that first Sibos. "It was an extraordinary success. We thought we would get about 100 people, and ended up turning 200 away. So the need to share ideas, discuss things with each other, and hear from SWIFT was obviously considerably larger than we had anticipated. It made us realize that we needed to think the thing through more carefully, and run it again" (http://www. globalcustodian.com/magazine/magazine_article.aspx?id=40201).

53 Sources for this section: Sibos 2013 website (http://www.sibos.com/); Hobson, "A brief history of Sibos"; Jessica Parser (2012) interviewed by Susan Scott and Markos Zachariadis [in person], La Hulpe, Belgium, 14 February 2012; Rosie Halfhead, interviewed by Susan Scott [by telephone], 29 February 2012; Lenny Schrank (2012), interviewed by Susan Scott and Markos Zachariadis [in person], La Hulpe, Belgium, 19 April 2012.

54 Lenny Schrank (interviewed by Susan Scott and Markos Zachariadis [in person], La Hulpe, Belgium, 19 April 2012).

55 Sibos, “Whatis Sibos?"(http://www.sibos.com/what_is_sibos.page?navtab=tab1).

56 Hobson, "A brief history of Sibos".

57 Sibos, "What is Sibos?"

58 Jean Lave and Etienne Wenger, Situated Learning: Legitimate Peripheral Participation (Cambridge: University of Cambridge Press, 1991).

59 Jessica Parser (interviewed by Susan Scott and Markos Zachariadis [in person], La Hulpe, Belgium, 14 February 2012).

60 Rosie Halfhead (interviewed by Susan Scott [by telephone], 29 February 2012).

61 Sinclair, Global Governance: 27. 


\section{SWIFT standards}

- Financial messaging standards and the need for voluntary consensus

- Proprietary SWIFT standards

- Message types (MT) and structure

- The evolution of SWIFT standards and SWIFT's relationship with ISO

- Making ISO 20022 a universal standard

- Standards convergence and the need for interoperability

- SWIFT's standards development and maintenance process

- MT standards development and maintenance

- MX standards development and maintenance

As summarized by Chairman of the Board Yawar Shah, SWIFT comprises a "unique combination of secure financial messaging platform, the ability to shape industry-wide financial standardization and related market practices, and its worldwide community." In Chapter 2, we highlighted how SWIFT's commitment to secure and reliable messaging operations works alongside multiple channels of communication with its global practitioner constituency, including an annual conference called Sibos. In this chapter, we focus on the role of SWIFT as a standards-setting body and its mission to bring the financial community together in order to achieve convergence to common standards and practices in the sector.

We first discuss the role of financial messaging standards in payment systems, pointing out the need for voluntary consensus on standards in order to allow financial institutions around the world to communicate directly using a common language and to facilitate automated handling and straight-through processing of financial transactions. We then return to the history of SWIFT and identify technological and other contextual factors that influenced the development of financial messaging standards during the 1970s and 1980s - for example, pointing out that SWIFT standard messages were initially computer-readable versions of the telexes they replaced.

Then we describe the evolution of SWIFT standards and examine how its relationship with ISO allowed SWIFT to increase its ability to shape 
sector-wide standardization and further systematize its standards-setting procedures. We explore the challenges of messaging standards implementation and coexistence - allowing for multiple standards in the sector - as well as the future industry trends in light of ISO 20022. The chapter concludes with a discussion of the development and maintenance process of the SWIFT messaging standards.

\section{Financial messaging standards and the need for voluntary consensus}

The private network initiatives discussed in Chapter 1 depended upon the automation of transactions between market participants. Automating transactions required process re-engineering, including formatting financial messages to make sure they contained all the information necessary to effect the transaction and could be "read" by both parties of a transaction. Computers can't interpret meaning with the same complexity or contextual understanding as us, so if our strategy depends upon using them to replace humans we have to develop an "unambiguous form of communication" - or standards. Thus, to ensure the flow of financial transactions between financial organizations, standardized financial messaging formats - known as message standards - emerged.

More formally, a standard is "a set of technical specifications" 3 or the objectification of a business process adhered to by a number of organizations or people in a specific sector (either tacitly or as a result of a formal agreement), thus forming a "market practice" which is commonly accepted. In the case of transactional messages, ${ }^{4}$ a standardized message is usually a structured message, ${ }^{5}$ one that is "machine readable" and can be sent, interpreted, and processed. This means that all the information from the message can be extracted by a machine or computer and used to automatically execute the transaction on a peer-to-peer basis. As a result, the standardization of a structured financial message entails not only the characteristics of the message that will help with the delivery of the instruction but, perhaps most importantly, the specific format of the message that will facilitate the processing of the information transferred without any human intervention. In his historical review of structured transactional messaging, Malcolm Hamer describes the emergence of a two-stage approach toward messaging standards: first, standardizing the message header containing message routing information associating it with the correspondent; secondly, standardizing the body of the message to enable automation and speed in communication. ${ }^{6}$ It is these fully structured messages that effectively "industrialized" transaction processing and transformed correspondent banking.

The fundamental objective of transactional message standards, then, is to provide information enabling the uninterrupted flow of transactional data 
from the one end of the business process to the other. This concept of transaction automation, known as straight-through processing (STP), ${ }^{7}$ has been described as "a strategic operating principle focusing on optimizing process design and technology to improve customer service and reduce operational costs." " STP aligns separate and perhaps previously disconnected components in the payment or trade process from across different systems, legacy technologies, and practices (see Box 3.1).

Research on the economics of standards in information processing has shown that the benefits of adoption are manifold. ${ }^{9}$ Groups of standard developers can share the fixed costs of the technical effort as well as lowering their ongoing transaction costs. In addition, any initiative that reduces manual intervention and thus the likelihood of human error will improve efficiency. When combined with new ICTs and gateway innovations, standards eliminate the need to manually re-key information from system to system and instructions are transferred directly. This increases the quality of the data, improves transaction-processing speed, and lowers operating costs as well as reducing operational risks. ${ }^{10}$ The potential benefit of standards in the financial services sector lies well beyond the narrow scope of STP. Standards-setting can facilitate the establishment of a technical infrastructure for a modern economy, as well as shape competition and enable innovation..$^{11}$ If the benefits of increased standardization are so wide reaching, what are the obstacles to widespread voluntary consensus for common "industry standards"?

First, competing standards can emerge where different stakeholder groups are (or become) invested in different standards, perhaps seeking competitive advantage. Alternatively, there may be situations where the needs of specific groups are not met by existing standards. For example, a standard can de facto be imposed by a single agent or organization promoting a proprietary product or service as a standard or with an embedded standard. Then again, standards can be established spontaneously via an undirected competitive process where individuals or organizations are able to choose between alternatives. ${ }^{12}$

Depending on the mechanism that initiates the standardization process, the literature generally distinguishes between unsponsored standards, sponsored standards, standards agreements, and mandated standards..$^{13}$ Unsponsored standards are not represented by an identified originator but have a specific and well-documented form among their users. These "open," publicly available standards often require a certain threshold of early adopters in order to be widely diffused in the market. A classic example of an unsponsored standard is the facsimile (FAX) machine, the adoption of which grew exponentially during the $1980 \mathrm{~s} .{ }^{14}$ On the other hand, sponsored or "proprietary" standards are commonly supported by one or more sponsoring entities - either a supplier, a user, or a private cooperative venture - who hold 


\section{Box 3.1 Standards, process innovation, and business transformation}

Although sector-wide standardization has proved transformative, adopting SWIFT standards has never been regarded as a strategic concern which makes the globalizing changes achieved all the more distinctive and points to continuing issues in this area. Top management have rarely grasped the implications of standards work. Reflecting on the pioneering efforts undertaken during the 1970s-1990s, Jacques Cerveau says:

At that time, this was coming from middle management - the back office - and I do not believe that they realized how to take advantage, the maximum advantage of what they were creating. The focus was not on broader programmes of change but on projects, it went project by project. ${ }^{1}$

Looking back at firm-level project-by-project plans from the 1970s helps us to appreciate how much work lay ahead and the business transformations that would be necessary to implement them at scale within the sector. For example, in a Barclays SWIFT briefing called Future Development of SWIFT2 from 1975 they detail plans to develop further message types. The ambitions of early adopters such as Barclays are clearly in evidence as they announce their intention to embark on projects to develop standards in a widereaching range of areas: credit card operations; documentary credits; securities; and letters of credit. Alongside this they note their current "to do" list ${ }^{3}$ in which they use the momentum of SWIFT adoption to follow through with internal Barclays developments, including:

- Getting the inward payment order system ready for the launch of SWIFT.

- Improving payments to other banks in the City (they were still walking payments).

- Developing Barclays Integrated Network System (BINS) to make direct automated payments to accounts in Barclays branches (cutting printed bankers payments by 50 percent and realizing same-day credits). 
- As a result of BINS, they were investigating the possibility of inputting the payment instructions from the originating branch, thus reducing processing.

- Connecting to CHAPS (the replacement for Town Clearing) which would enable them to output 85 percent of Town Clearing payments from the inward payment order department automatically.

- SWIFT adoption and the process innovation that it entailed instigated an onward march toward STP both within and beyond the firm creating significant increases in performance.

There is evidence of this throughout the banking world, as Erik Sepkes (former Citbank) recalls:

[Our bank] had its own standard ... then we suddenly realized, why do we have to have our own internal standard? If you're using one standard externally why don't we use that same standard internally?... We basically took the SWIFT message and put our internal wrap around it and used SWIFT standard internally from that point and on. We suddenly realized it's not only good for dealing with everyone else. ${ }^{4}$

Summing up, Renato Polo (former Banca Commerciale Italiana) said: "I got the feeling that there was a higher heaven to be reached, not only bank-to-bank or financial institution to financial institution communication but an end-to-end in the whole market." 5 The potential for this "domino effect" continues today.

\section{Notes}

1. Jacques, Cerveau, interviewed by Susan Scott [in person], Paris, 13 February 2012.

2. Information retrieved from Barclays Group Archives (BGA), HOC 138-77.

3. Retired back-office bank professional Chris Norton described the most common first wave of SWIFT-related automation projects as follows: "firstly, payments MT100; dealing confirmation; reconciliation; statements. This might continue with inward nostro, confirmation, and generating nostro statements." Norton (interviewed by Susan Scott and Markos Zachariadis [in person], London, 22 July 2010).

4. Eric Sepkes (interviewed by Susan Scott and Markos Zachariadis [in person], London, 13 November 2008).

5. Renato Polo (interviewed by Susan Scott [by telephone], 20 November 2009). 
a direct interest and are motivated by the potential to translate the benefits of adoption and diffusion into network externalities. ${ }^{15}$ In this case, however, there is a trade-off between the value users get from the increased size of the network and sharing profits with competitor firms that join the scheme. ${ }^{16}$ Standards agreements or voluntary user coalitions are commonly formed by voluntary standards-setting organizations like ANSI (the American National Standards Institute) and ISO (the International Organization for Standardization) - a process known as "standardization-by-committee" - and are often considered to be superior to other standard-setting mechanisms. ${ }^{17}$

Different combinations of these mechanisms can exist simultaneously in any given context, resulting in many different outcomes and competing standards irrespective of their superiority. ${ }^{18}$ The financial services world offers various interesting examples ${ }^{19}$ of standard-setting. For example, during the 1980s Citibank's proprietary ATM network competed against national networks such as Cirrus and Plus, but made their network interoperable and joined them in $1991 .{ }^{20}$ In 1992, a group of securities trading firms developed a series of messaging specifications to support STP in equity trading and to speed up communication with their clients. While they claimed there were no suitable message standards to carry out their trading operations, the resulting FIX protocol competed directly with existing standard-setting bodies such as SWIFT and ISO. ${ }^{21}$ The route to standards convergence can be a long one, full of twists and turns. In the next two sections, we examine how SWIFT's standardization efforts originated and evolved to serve the interests of its community.

\section{Proprietary SWIFT standards}

Creating a common language that would provide the basis for the automation of transaction processes was at the top of the SWIFT agenda from the beginning. In the company's first Annual Report, François Dentz, who replaced Jan Kraa as Chairman of the Board, characterizes the cooperation and participation of member banks in reaching consensus on message text standards as a "major achievement" and predicts that the increase of productivity will be more important than "any possible savings in transmission costs". ${ }^{22}$ Despite his comment, when SWIFT was conceived, it was primarily thought of as an application service provider that operates its own proprietary network rather than as a standardization body. The importance of standards was overshadowed by the emphasis on technology development - rolling out SWIFT's infrastructure internationally, achieving critical mass, and global usage. ${ }^{23}$ Except for the travel sector, which was developing the SITA network, ${ }^{24}$ no other sector had succeeded in designing and developing a private global network. 
With operational efficiency of the network a priority, the initial standards work focused on providing configurability, so that banks could easily adapt their existing practices and legacy technologies to SWIFT requirements. The new SWIFT language was heavily influenced by telex (teleprinters communicating over a telephone line), at the time the dominant telecommunication standard in the banking industry. SWIFT messages were designed so that they overcame many of the limitations of telex ${ }^{25}$ but nonetheless were still able to be used alongside it. Frank Vandamme puts it as follows:

much effort was spent to ensure compatibility between existing telex information flows and the new SWIFT electronic information flows ... [which] meant that the printed version of a SWIFT message looked very similar to its corresponding telex version [but somewhat more structured]. ${ }^{26}$

As a result, the same outgoing message could be sent via telex or the SWIFT network depending on the destination. This was of critical importance in the early stages of SWIFT adoption, when many banks were still using the older technology. But it limited opportunities for innovation and the development of more flexible messaging solutions.

\section{Message types (MT) and structure}

Despite the limitations of the telex-based format, SWIFT's efforts to standardize information flows established the foundation for a generation of messaging standards that would become the de facto standards for many segments of the financial services sector. A key person behind this effort was Max Engeli, a professor at the Swiss Federal Institute of Technology in Zurich (ETHZ) who is widely considered to be the technical architect of the first SWIFT standard. ${ }^{27}$ Engeli, being an "outsider [with] no banking experience at all" 28 had a firm belief in standards and maintained that "at SWIFT the network is of major significance for the banks; however, the standards are of the utmost importance." 29 A physicist by background, with a special interest in computing and applied mathematics, ${ }^{30}$ he defined the original proprietary ${ }^{31}$ SWIFT message structure and categorized the various fields to be used. Erik Wennerholm (Head of Standards) and Alec Nacamuli (then a Marketing Manager) played key roles traveling around the world visiting future SWIFT user communities promoting new standards to banks in their respective roles. Indeed, they came to be regarded by some as "the two apostles of message standardization". ${ }^{32}$ Since realizing the benefits of standardization depend upon both design and adoption, the practice of enrolling banks into an agenda of standardization is vitally important. 
Standards work is often portrayed by those who are not interested in it as a peculiar form of pedantry whereas those engaged in it regard it as "a passionate business" 33 that demands an uncommon combination of skills. Fascination with detail has to fuse with strategic vision, both of which must be enacted with diplomatic prowess in order to sign others up to a cause. Along the way those involved must be able to identify where and when to "change the problem". ${ }^{34}$ Despite remaining intensely committed to their cause, standards people must retain the capacity for compromise because they know that ultimately effectiveness depends upon the adoption of a universal outcome. Although there are standards "professionals", many practitioners voluntarily commit time and effort because they see beyond the need to realize short-term efficiencies associated with an immediate business case to what Renato Polo referred to as "a higher heaven". These individuals are part of what might be thought of as a "standards movement" which, as previously discussed, is a phenomenon widely regarded as fuelling processes of globalization. It is important to remember this as we embark on an analysis of the minutiae characterizing the generations of standards that have been developed.

We begin with a description of the first generation of financial messages developed by SWIFT which were organized into "Message Types" based on the different transactions they fulfilled. Each message type (MT) was codified using a three-digit number. Since the Society was founded by banks, the initial messages were confined to banking transactions. The most common message category was Category 1 , which provided instructions for customer fund transfers. Apart from the first digit of each MT that signified the category range, the second and the third digits also represented the group and the type of message respectively (see Figure 3.1). ${ }^{35}$

The initial categorization of message types is provided in Table 3.1. Additional message type categories where reserved to accommodate the need for new services and more automation in different segments of the financial services sector: Category 3 included money markets and derivatives; Category 4 collections and cash letters; Category 5 securities markets; Category 6 precious metals and syndications; Category 7 documentary credits and guarantees; and Category 8 travellers checks. ${ }^{37}$ Figure 3.2 illustrates how a paper-based payment instruction was translated into an MT 100 SWIFT message in the 1980s.

\section{MT 100}

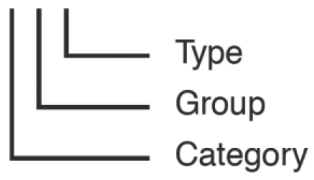

Figure 3.1 Parsing of a user-to-user MT. ${ }^{36}$ 
Table 3.1 First SWIFT Message Types (MT) categories ${ }^{1}$

\begin{tabular}{ll}
\hline Category & Message type \\
\hline 1 & Customer transfers \\
2 & Bank transfers \\
3 & Foreign exchange and loans/deposits \\
4 & Statement messages \\
Common group messages & Queries/answers/free formats \\
\hline
\end{tabular}

Source: This table is largely based on Barclays Group Archives (BGA) document: 80-4134, June 1975.

Note

1. Common group messages retained the first number of the category to which the message referred or belonged and used the last two digits to describe the relevant use. For example, a query message was MT n95, so a query for a customer transfer would be MT 195 and for a query for a statement MT 995.

The actual structure of each message consists of "fields" and "subfields" which have a distinct business meaning and represent the unique proprietary SWIFT message syntax, or "FIN" language. ${ }^{39}$ Each field or data element has a unique tag or "field identifier code" presented by a two-digit number (often followed by a letter) which tells the receiving system or individual what piece of information the field contains. ${ }^{40}$ For example, in the MT 100 format specification, tag ":20:" contains the transaction reference number, and tag ":50:" contains information about the ordering customer. The syntax of the message represents the actual format according to which the information included in the message is structured - it is the physical representation of the data. ${ }^{41}$ Understanding a particular syntax is necessary in order to understand the message content when a message is exchanged. While the structure of the message had largely stayed the same throughout its lifecycle, "clusters" of data fields were introduced when the ISO 15022 standard was implemented in 1999.42 These were applied to indicate a repeated or related sequence of fields, thus allowing particular information in the message to be reused. Overall the structure for all the SWIFT proprietary FIN messages consisted of five separate parts (or blocks) each one containing important information and serving a different purpose:

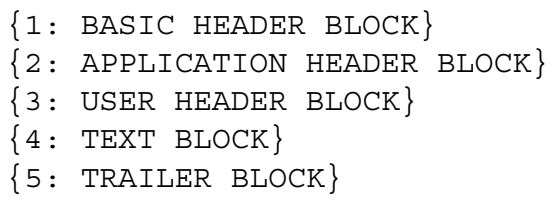

Blocks 1 to 3 are known as the "header" of the message and contain information including the location of the destination system, the address of the 
sending system, unique identification number of the instruction, and the time and date the message was transmitted. Block 4, also known as the "body," contains the actual text message with the instructions in the form of fields and subfields. Finally, Block 5 is commonly described as the message trailer or message terminator. ${ }^{43}$ While the trailer is nowadays an optional block (based on the type of the message and on the application through

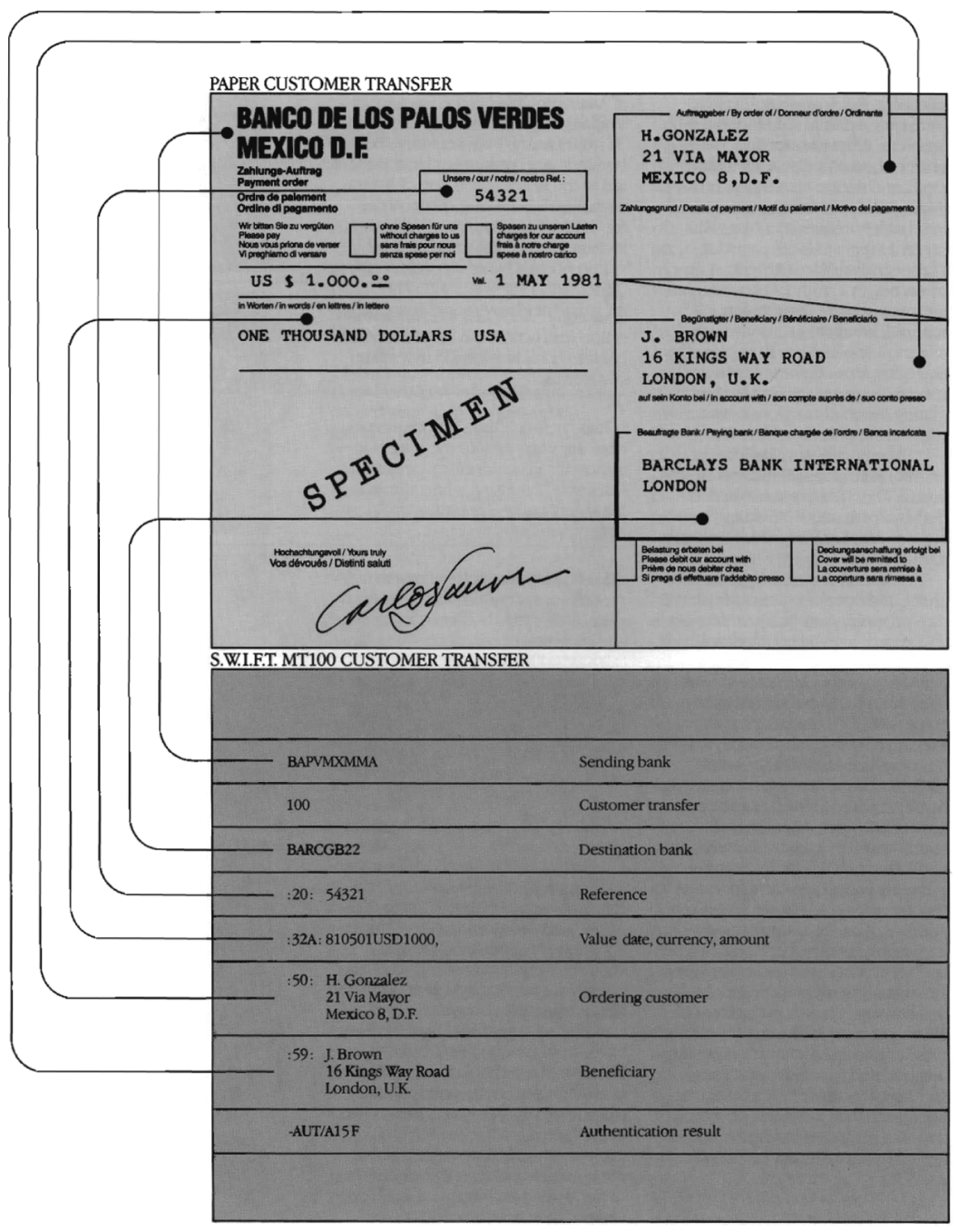

Figure 3.2 A paper customer transfer instruction translated into a SWIFT MT 100 message. ${ }^{38}$ 
which it is being sent or received) the information it contains used to be of considerable value in the era of telex in order to mark the end of message transmission and thus reassure the receiver that they received the complete instruction. The trailer also included other security-related information such as the message authentication code (MAC) to ensure the integrity of the message.

In more detail a full MT 100 message would have the following structure ${ }^{44}$

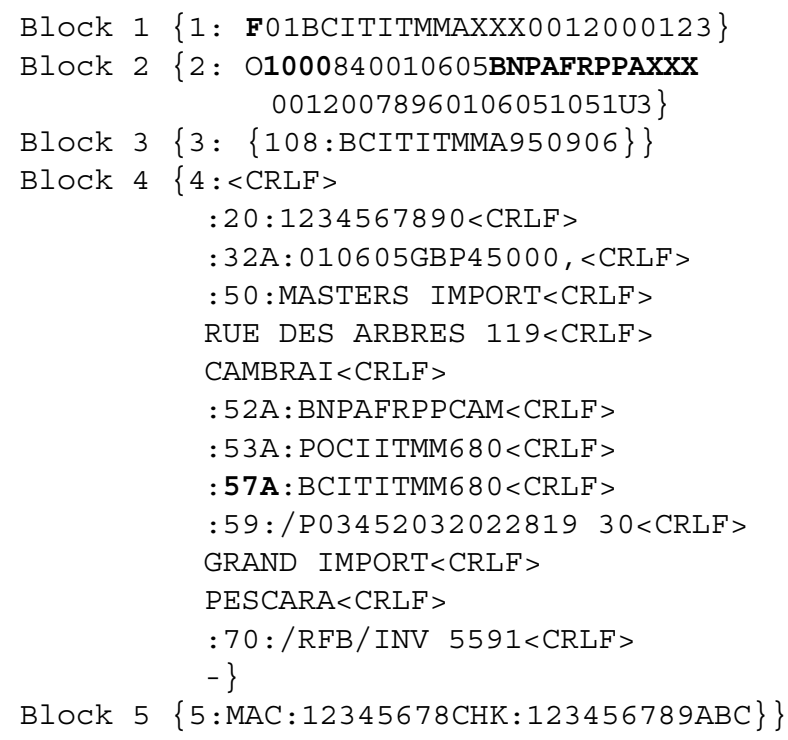

Highlighted in bold above are some examples of useful information that can be extracted by looking at the message, such as the application identifier in Block 1: "F" refers to a message sent from the FIN service, the MT in Block 2: "100" refers to a customer funds transfer, and the 12-character receiver's SWIFT address in Block 2: "BNPAFRPPAXXX". In Block 4, field "57A" is used to define the bank or financial institution that services an account for the beneficiary of this payment. Option "A" means that this financial institution is characterized by its unique Identifier Code, thus achieving a higher level of automation.

These seemingly dull details brought previously unachievable levels of accuracy to transaction banking processes and led to significant reductions in errors. Jamie Shay, a former banker who went on to become Head of SWIFT Standards, says:

I can remember standing by the printer on September 26th 1977 waiting for those first messages to be printed. We were thrilled that the field 
names made the message so superior to the telex messages we still received (for a great many years) and sometimes misinterpreted due to both the language and lack of structure. SWIFT messages obviated this problem.

A crucial step toward leveraging the network and connecting up the content of a transaction with the parties involved was the development of a universal Bank Identifier Code, or BIC. Since ISO was intimately involved in the BIC, this prompts us to explore how SWIFT related to other standards setting organizations such as ISO and the expansion of standardization more broadly across financial services.

\section{The evolution of SWIFT standards and SWIFT's relationship with ISO}

Defining the elements and structure of a universal Bank Identifier Code, or BIC (later renamed to Business Identifier Code to include non-banking institutions) was recognized as a key part of the effort to standardize financial messages necessary to "facilitate automated processing of telecommunication messages in banking and related financial transaction environments." 45 Once again it was apparent that universal adoption and critical mass were essential, a cause taken up by bankers who managed to maintain concurrent involvement with SWIFT and the International Organization for Standardization. In 1986, during an ISO T68/5/3 meeting Nicolas de Sèze (Banque de France) and Renato Polo (Banca Commerciale Italiana) jointly proposed that "a generalised assignment of machine-readable codes" 46 should be assigned to financial institutions to facilitate automated processing. This ISO standard was subsequently adopted by SWIFT who collaborated with ISO to produce ISO 9362 (first published in 1987), with SWIFT as the designated ISO registration authority (RA). The BIC, which came to be known as the SWIFT address or the "SWIFT code", consists of 12 characters (see Figure 3.3).

The primary four characters compose a unique identification code for each financial institution worldwide known as the Business (or Bank) Code. The next two alphabetic characters represent the Country Code and are based on the alpha-2 ISO 3166-1 standard (e.g. GR= Greece). Alphanumeric characters 7 and 8 refer to the Location Code and identify the region, the geographical territory, or the city where the user is located. The next character in sequence represents the Logical Terminal Code, and finally, the last three alphanumeric characters characterize the Branch Code. ${ }^{47}$ SWIFT publishes all the registered SWIFT addresses in the BIC Directory, though the Logical Terminal Code is not included in this list and the Branch Code is 


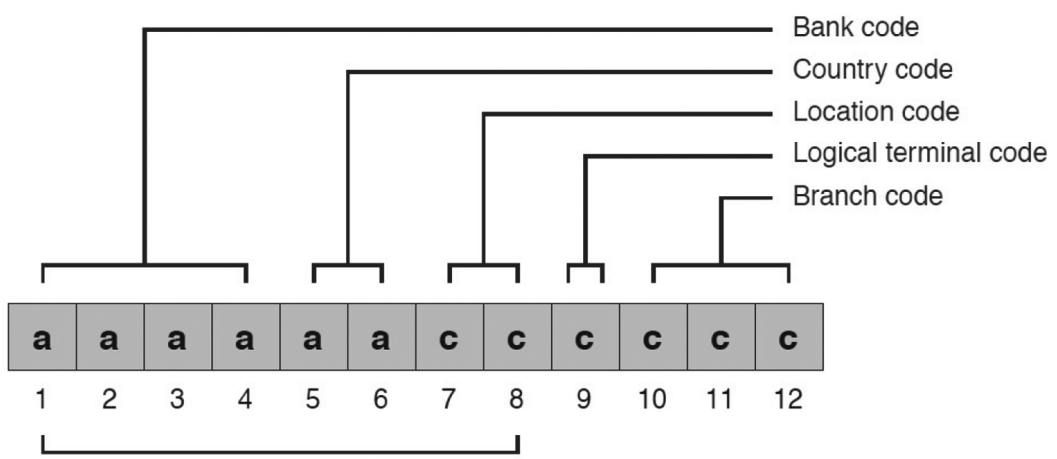

S.W.I.F.T. Destination

Logical Terminal Identifier (LTID)

Figure 3.3 Components of a SWIFT address (BIC).

Source: SWIFT User Handbook, Standards General Information, November 2001 Standards Release.

Notes

"a" = letters only, and "c" = letters and digits only.

also optional. The short, 8-character version of BIC, also known as BIC8, would generally have the following format: "BNPAFRPP."

When SWIFT launched its network operations all banks with a BIC were able to use the network. However, not all entities with a BIC are users of SWIFT. For that reason, BICs are categorized as SWIFT BICs and NonSWIFT BICs to distinguish between institutions that have a BIC but are not part of the SWIFT network. BIC is an example of where global standards can connect networks of financial institutions and this raises interesting questions about when and how organizations should or could collaborate on standards work. The additional purchase achieved by SWIFT's decision to base its message standards on the telex legacy ${ }^{48}$ illustrates that establishing a standard does not necessarily depend on advanced technical characteristics but instead on "the number of users that [it can] claim at the beginning of the period of competition". ${ }^{49}$ The timing of standards releases and adoption campaigns is crucial as is the process of encouraging distributed interest groups to work together. As discussed above, SWIFT benefited from the "installed base" of telex users who had an incentive to support the network. Apart from FNCB's effort to enforce its rival proprietary messaging standard (MARTI; see Chapter 1), there is evidence of a parallel standardization initiative that posed a serious threat to the development of SWIFT. However, correspondence between the Swiss Bankers' Association and The British Bankers' Association 
(BBA) reveals that on 19 September 1977, ANSI, in its capacity as Secretariat of TC68 (technical committee on banking, securities and other related services) of ISO, submitted a proposal to the members of ISO to establish standards for the exchange of daily "Nostro Accounts Reconciliation" statements. ${ }^{50}$ After consulting the BBA, the Swiss body replied to ANSI:

The Swiss banks favour a harmonisation of standards for daily statements of account of Nostro accounts but only on the basis of the standards established for the SWIFT system (MT 950). A Swiss working group of SWIFT is currently re-examining the present SWIFT standards. It will subsequently submit them to an international standards group of SWIFT for decision... Consequently it is not the members of ISO who should take part in the discussions individually but in the first instance SWIFT in Brussels, in order to avoid two different standards being set up. ${ }^{51}$

This is one example of how members safeguarded SWIFT standards and were generally anxious to consolidate efforts in the sector. ${ }^{52}$ Attempts to reproduce SWIFT payment standards under the aegis of ISO did not receive general support from member banks because the costs to maintain and replicate changes (made by SWIFT) in the corresponding messages at ISO were significant, and there seemed to be little value in the ISO documenting a standard that was already documented by SWIFT. ${ }^{53}$

However, ISO did provide a forum for standards development in areas of the financial services that fell outside SWIFT membership. For example, driven by a surge in equity trading during the early 1980s, the securities community proactively organized itself under ISO, more specifically in the subcommittee SC4 (securities and related financial instruments) of the technical committee TC68 (banking, securities and other related services). ${ }^{54}$ During that period, the Working Group 2 (WG2) of ISO/TC68/ SC4 designed a series of securities messages (MT 500s) under the ISO standard 7775.55 This standard, which was based on SWIFT's existing proprietary language, included approximately 50 messages that were implemented in subsequent stages on the SWIFT network between 1984 and 1997. ${ }^{56}$ SWIFT was then mandated by ISO to maintain the existing message set. But despite all the efforts to create an international message set to service the whole of the community, ISO 7775 was eventually unsuccessful in becoming the single primary standard in the securities industry.

One of the key limitations was that ISO 7775 was principally developed by custodian banks and did not support the entire end-to-end cycle of securities transactions, thus leaving out important areas of the trading cycle such 
as pre-trade information flows. This is where standards work reveals deeper governmental dynamics; in the case of securities, the question of what gets included in standards development and what gets left out highlighted broader issues about whether SWIFT membership should remain bank-only or open up to a broader constituency. Having lobbied for - and been excluded from SWIFT membership - the securities industry felt let down by SWIFT standards. Jamie Shay, former Head of Standards at SWIFT, recalls:

we were sometimes accused in standards of developing messages that people couldn't use ... and that is what happened in securities ... there was a difference in opinion as to what needed to be in the messages and there was a feeling that we [SWIFT] were developing messages without really consulting that side of the business, because we created these messages by talking to banks, when in fact "buys" and "sells", etc. are done by brokers and asset managers. ${ }^{57}$

The SWIFT network was the key platform for the transmission of ISO 7775-based instructions. But since securities firms were not admitted to the network ${ }^{58}$ many remained unconvinced that they should adopt a proprietary standard developed by a private cooperative. ${ }^{59}$ Finally, the proprietary SWIFT syntax used by ISO 7775 was considered costly to implement due to the scarcity of software vendors capable of developing specialist applications and commercial software. In response to these issues, other standards initiatives emerged to fill the gaps and complement the missing areas that SWIFT could not cover, with FIX protocol being the most notable in this regard. ${ }^{60}$

Around the mid-1990s, even further limitations of ISO 7775 emerged. While the securities sector was moving rapidly, approval procedures within ISO to amend standards and deal with their shortcomings took a long time usually around 18 months. Furthermore, additional technical issues like the poor syntax of the messages, confusion around the business meanings of fields, lack of message interaction (arising from stand-alone development that did not take into account relationships with other messages), and limitations placed on field tags (restricted to 99 options) made things even harder for ISO 7775 users. ${ }^{61}$ As a result, the securities community pushed ISO to form a working group that would release a fundamentally new standard to address these issues (instead of undertaking major revisions to the existing ISO 7775) that would protect the exist investments related to ISO 7775 messages as much as possible. ${ }^{62}$ The result of this initiative was ISO 15022 which was prepared by ISO/TC68/SC4 and issued in March 1999.63 Unlike ISO 7775, the ISO 15022 standard did not contain the specifications for the 
various messages implemented, but provided detailed information on a pre-agreed syntax and design rules according to which the actual messages would be developed. ${ }^{64}$ Separating the messages from the standard allowed for quicker turnaround times in the development and maintenance of messages which were placed under the responsibility of SWIFT, acting as a RA, without the need for ISO's further approval.

The leading innovation of ISO 15022 was its business-oriented approach to defining messages. It introduced a data field dictionary (DFD) containing names and definitions for each business element. The semantics of the message (which corresponds roughly to the "vocabulary" of the language) represents the information that is structured into the message text and ensures that the meaning of the business terms used is consistent across the financial services sector. These definitions were syntax-independent and transferable, and ISO 15022 outlined detailed rules about how they would be physically represented in a standardized message. ${ }^{65}$ A complete catalogue of the developed messages was compiled, including all the details of their scope and the business elements used. ISO 15022 also allowed for interactions with other standards such as EDIFACT ${ }^{66}$ whose syntax was accepted by the new standard. The above developments allowed for more automation which in turn helped to support further STP possibilities for all the relevant securities transactions.

Although these major improvements were incorporated within ISO 15022 , the rapid globalization of markets and the emergence of novel network technologies meant that things were about to change again and, this time, sooner than anticipated. Even before the initial release of ISO 15022, SWIFT worked closely with other standards-setting bodies, such as UN/ CEFACT, ${ }^{67}$ in order to further rationalize the development of standards and increase the business focus. The aim was to develop standards capable of better integration with a wider range of business transaction chains based on a deeper understanding of the end-to-end business process. ${ }^{68}$ The emergence and widespread acceptance of the eXtensible Markup Language (XML) throughout the financial services provided significant assistance in developing this much anticipated standardization approach while simultaneously offering a technically attractive solution (see Box 3.2 for more details). In 1999, the SWIFT Board of Directors endorsed the adoption of XML as the technology format to produce new message standards. ${ }^{69}$ This decision coincided with SWIFT's plans to move to its IP-based SWIFTNet platform. Being an open standard and already a major trend in financial services, XML was deemed to be the better choice compared to a complex re-engineering of the existing FIN syntax.

To coordinate the move to XML, and avoid having multiple unrelated XML-standards initiatives, the securities industry brought together an 


\section{Box 3.2 XML}

eXtensible Markup Language (XML) was developed in 1998 under the sponsorship of the World Wide Web Consortium (W3C) to capture the capabilities and extensibility of SGML and the simplicity of HTML. XML has been extensively used in various industries and is now one of the most popular syntaxes for electronically encoding documents on the internet. Its popularity means technical knowledge about XML can be easily used in multiple contexts. ${ }^{1}$ XML's success lies in two underlying characteristics of its design: first, it offers a formal way to express the structure of a document or message (the sequence of the fields and their format) which makes the language easy for computers to process. Second, XML also uses customized

Table 3.2 XML versus SWIFT proprietary syntax ${ }^{1}$

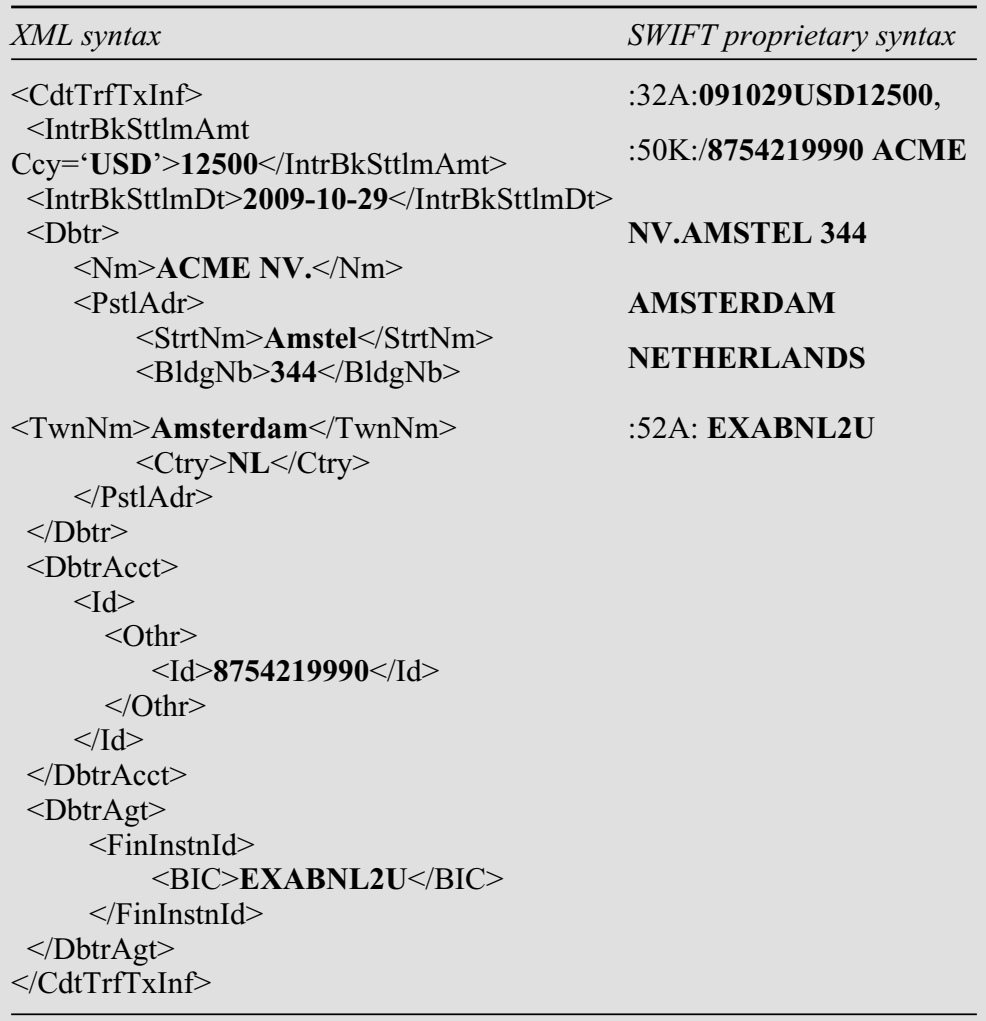

1. Example taken from SWIFT Standards team, ISO 20022 for Dummies, 6-8. 
"self-explaining" to clarify the meaning of the information transmitted in each field and indicate the beginning and end of a message. ${ }^{2}$ These features give it a major advantage over the FIN proprietary language adopted by ISO 15022 and make it a "computer processable specification language" (see Table 3.2). ${ }^{3}$ In practice this means that the conventions regarding the structure of the message do not need to be explicitly inserted into the existing applications (a task that requires extensive manual programming) and can be "injected" with little cost and programming effort. ${ }^{4}$

\section{Notes}

1. Gottfried Leibbrandt, "The interoperability revolution," Journal of Payments Strategy and Systems, 2 (1) (2007): 95-106.

2. Ayesha Khanna, Straight-Through Processing for Financial Services (Burlington, MA: Elsevier, 2008): 76; Although XML can identify fields, it is not able to pass on specific meanings for each field. This is a disadvantage when there is much heterogeneity in the types of messages being communicated in the network and the same fields can have different meanings. Also, while XML is inherently flexible, once fields are defined then messages need to be formatted accordingly, leaving little room to include optional fields. This aspect can be both good and bad as highly standardized messages reduce errors significantly but can also be characterized as "over-engineered" and inflexible (see Bob Hills, "Common message standards for electronic commerce in wholesale financial markets", Bank of England Quarterly Bulletin, August (2000): 274-85).

3. SWIFT, Simple XML: An Introduction to the SWIFT Community.

4. While XML has the potential to reduce the processing time and allow for more automation (as the instructions can be passed on mechanically to other parties in the network and be fed into supplementary applications and accounting systems), the size and complexity of the message can also play a role in this process. Looking at the example above, it is obvious that the selfdescribing XML syntax is substantially larger, as a text file, than the FIN one, a detail that, depending on the context, may count against it. This may not seem important in a payments or a settlement setting. However, it can have a significant impact in securities trading where time is critical and even microseconds count. For example, FIX uses short field tags in order to increase the speed of transmissions in trading (see Leibbrandt, "The Interoperability Revolution"): 96.

informal consortium early in 2000 led by international bodies such as GSTPA, Euroclear, and SWIFT, among others. Since these discussions originally concerned the securities community they were delegated to a working group (WG10) and were taken over once again by the SC4 
subcommittee of the ISO/TC68. The mission statement of WG10 was to "evolve ISO 15022 to permit migration of the securities industry to a standardized use of XML, guaranteeing interoperability across the industry..."70 Eventually, by the end of 2002, working and committee drafts were approved and were open to comments and voting from the entire ISO community. During its operations, WG10 also consulted other major industry and financial sector initiatives that had already adopted XML such as ebXML (E-Business XML), ${ }^{71}$ FIX, FpML, MDDL (Market Data Definition Language), and RIXML (Research Information Exchange Markup Language).

\section{Making ISO 20022 a universal standard}

WG10's commitment to building a durable unified standard scheme to service the entire supply chain and provide interoperability across wholesale financial markets and other industry sectors led committee members to rethink the $15022 \mathrm{XML}$ initiative. The call to ensure that "this time, these standards should be for all types of messages, not only for securities" prevailed "and the standard was moved up to TC68 level" to include all banking, securities and related financial services operations. ${ }^{72}$ This move resulted in the creation of ISO 20022, also known as UNIFI ${ }^{73}$ (UNIversal Financial Industry message scheme), which was published in 2004. Being a key contributor to ISO 15022 and to the discussions for the ISO $15022 \mathrm{XML}$, SWIFT maintained its position as the unique official RA for ISO 20022.74

ISO 20022 is not a traditional messaging standard; rather it is a multipart set of guidelines that "describes a common platform for the development of messages", 75 thus making it "a standard for standards". This approach represents a significant advance over ISO 15022. Not only is it consistent with the assimilation of "process methodology standardization" within $\mathrm{ISO}^{76}$ but it also demonstrates awareness that message syntax itself may vary over time. The ISO 20022 methodology for the creation and maintenance of message standards is based on the conception of three distinctive layers: first, the "business processes and concepts" layer entails all the definitions for the business process, including the roles of the actors involved and the information needed to complete the activity - the resulting business information model is usually represented in Unified Modelling Language (UML); second, the "logical message" layer presents all the information needed for a particular function of a transaction as message components and elements organized in a hierarchical structure; finally, the syntax layer "is the physical representation of the logical message" using XML as the primary syntax..$^{77}$ All the above subjects from all three different layers are stored in a common repository (similar to the ISO 15022 data field dictionary 
but considerably extended) allowing message components and structures to be identified and reused consistently in different messages across the financial services sector. ${ }^{78}$

The separation of the distinctive layers and the development of a central dictionary of business items are a core part of the new financial messaging standardization approach and come with a number of benefits. First of all, "business discussions are separated from the delivery of the standard messages" as modelling provides an abstract and technologically neutral description of the solution. ${ }^{79}$ Being independent from the syntax, the business model can remain valid no matter what the physical representation is or will be in the future, thus allowing users to express the logical message in a different syntax if they choose to. Most importantly however, thinking of standards from a multi-layered perspective helps to maintain a wider end-to-end view, potentially encompassing the global supply chain rather than providing a solution to a localized transaction, which can lead to fragmentation of the market.

The appointment of SWIFT as their collective coordinator provides considerable benefits for the financial community. Not only is SWIFT able to provide stability but they also play an important role by offering support to application and solution developers. They subsequently ensure that a record of objects produced by third parties is entered in the standards' repository where all the different layers of business processes, the logical messages, and their syntax are maintained.

\section{Standards convergence and the need for interoperability}

Even though the ISO 20022 approach promises significant advantages over MT message standards and could provide a foundation for interoperability, plans to discard the old FIN-based standards in favour of the MX (the new identifier for XML-based SWIFT standards) messages failed to materialize and were postponed indefinitely. The effectiveness of the migration from ISO 7775 to ISO 15022 was mainly due to pressure being put on the community through deadlines and penalties levied on users that continued to deploy ISO 7775. It was only after the migration had taken place that securities industry players recognized the value proposition of ISO 15022 in terms of STP. Despite the benefits and substantial STP capabilities relative to its predecessor (ISO 7775), ISO 15022 implementation was generally considered expensive and this is the reason why there was relatively little appetite in the securities industry for yet another migration (to ISO 20022). ${ }^{80}$ Recognizing that the changeover may be slow and contingent on business requirements that vary greatly across the financial services organizations, SWIFT has taken a more flexible and tactical approach toward MT/MX coexistence. Currently 
all three generations of standards - FIN proprietary, ISO 15022, and ISO 20022 - are being actively supported (independent of their syntax and detail of information) as long as they "adequately support the end-to-end business transaction at a particular service level." 81 Although longer-term sector-wide efficiencies are pushed further into the distance as a result, users currently have a wider choice of options depending on their needs for richer data and/ or compatibility with older applications and systems.

In many cases, ISO 20022 is treated as a unification tool where specialized middleware software applications translate the message outputs of one system and feed it to another in a way that it is recognizable. For many financial institutions, the short-term reality is that the cost of this process is lower than the migration of operations to an entirely new standard as long as the efficiencies are still present and a certain degree of STP can be achieved. The example in Figure 3.4 shows how an MT 103 customer credit transfer message can be translated into an MX Pacs.008.001.02 message using ISO 20022 and XML syntax. The mapping of messages between systems with the aid of technology is a common practice among financial institutions, since many of them still use their own formats to store and exchange information internally and then feed this information to the external format required to transmit their messages. This was also the case when the securities industry migrated from ISO 7775 to ISO 15022. Many firms still use the old standard internally (and externally with some of their clients) even though ISO 7775 became obsolete in $2001 .{ }^{82}$

The current need to support interoperability and preserve the coexistence of FIN and XML-based messages is actively discussed in the community and is often the subject of SWIFT publications and industry reports. ${ }^{84}$ As with previous standards, ISO 20022 will be of "limited use until others also use it" ${ }^{85}$ which means that it will need to achieve critical mass in order to increase its likelihood of widespread adoption. The adoption of ISO 20022 by various industry initiatives such as the Single Euro Payments Area (SEPA) or TARGET2-Securities, as well as other potential regulations and directives of the European Commission or the Financial Action Task Force (FATF), may help boost its rate of diffusion. All the above could serve the long-term vision to converge to "a single industry standard achieved through interoperability of existing standards and, ultimately, common syntax." 86

The issues of coexistence and interoperability extend beyond the relatively narrow topic of MT/MX standards. SWIFT's mission to drive standards convergence and harmonize market practice inside and outside the financial services sector is materialized by preserving "interoperability and consistency between standards developed by different organisations." 87 While ISO 7775 was predominantly concerned with the standardization of message syntax used on the SWIFT network, ISO 15022 (based on 


\begin{tabular}{|c|c|c|}
\hline & MT 103 & Pacs.008.001.02 \\
\hline $\begin{array}{l}\text { Example 1: } \\
\text { identification } \\
\text { of the debtor } \\
\text { agent }\end{array}$ & $: 52 A: E X A B N L 2 U \leftarrow$ & $\begin{array}{l}<\text { DbtrAgt }> \\
\quad<\text { Finlnstnld }> \\
\longrightarrow<\text { BIC }>\text { EXABNL2U }</ \text { BIC }> \\
\quad<\text { Finlnstnld }> \\
<\text { DbbtrAgt }>\end{array}$ \\
\hline $\begin{array}{l}\text { Example 3: } \\
\text { name and } \\
\text { contact } \\
\text { details of } \\
\text { the debtor }\end{array}$ & $\begin{array}{l}: 50 \mathrm{~K}: / 8754219990 \\
\text { ACME NV. } \\
\text { AMSTEL344 } \\
\text { AMSTERDAM, } \\
\text { NETHERLANDS } \\
\text { :50K:/8754219990 } \\
\text { ACME NV. } \\
\text { AMSTEL344 } \\
\text { AMSTERDAM, } \\
\text { NETHERLANDS }\end{array}$ & 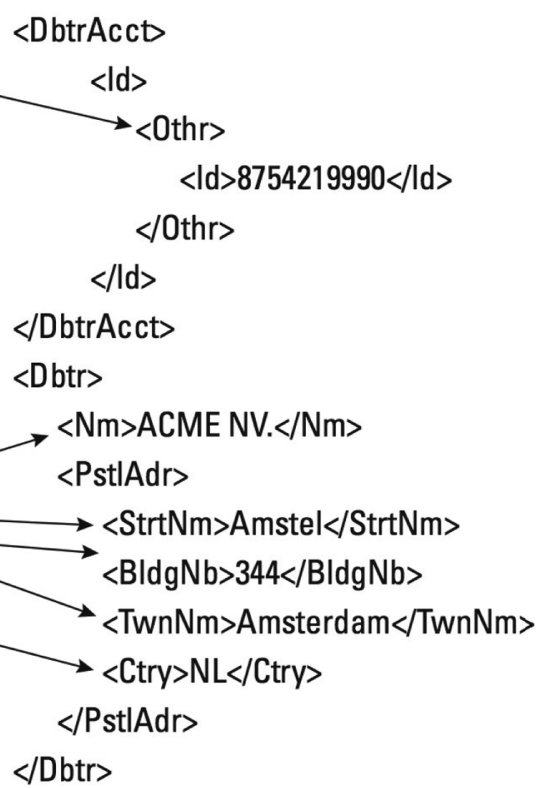 \\
\hline
\end{tabular}

Figure 3.4 Mapping a FIN MT 103 customer credit transfer on to an ISO 20022 XML-based message. ${ }^{83}$

Source: SWIFT.

SWIFT's proprietary messages) was a preliminary step away from this methodology and planted the seed for ISO 20022. Consequently, SWIFT generally dominated these standards. Aiming at the convergence of disparate standards throughout and even beyond the financial services, ISO 20022 was officially released and demanded a broader global governance model through cooperation and voluntary consensus. ${ }^{88}$ SWIFT's role in this is to promote and facilitate a common approach to standardization through the collaborative effort of user communities. For SWIFT to succeed, 
this approach has had to be defined and promoted at the highest level in the standardization field as well as being reinforced through the use of disciplined methodologies and tools. Hence, working closely with international standards-setting bodies such ISO and UN/CEFACT provided the right "neutral environment to coordinate and prioritize development" that would benefit members of the financial and other industries. ${ }^{89}$ SWIFT's determination to support cooperation and standards convergence is made explicit in a number of memorandums of understanding (MoU) and other formal agreements. ${ }^{90}$

One of the latest developments in the standards convergence front is that of the creation of the Standards Coordination Group in 2007. Being an assembly of the most notable standards setters in the field (FIX, FpML, SWIFT, XBRL, ISITC, and FISD), the group's objective is to generate an approach that accepts and leverages the diversity of the various standards that currently exist in the financial services sector, and puts them into "a broader framework without reinventing and creating redundant messages that increase implementation costs and cause confusion in the industry." 91 In other words, a common belief was established that "there are certain messages and certain protocols out there that better met the needs of different institutions." 92 As a result, a key outcome of the works of this group was the creation of an Investment Roadmap that provides a guideline on which message standards should be used for what type of operation (see Box 3.3). ${ }^{93}$

\section{Box 3.3 A Tale of Two Standards}

FIX Protocol Ltd (FPL) was founded in 1992 by Fidelity Investments and Salomon Brothers in New York City. As previously discussed, the lack of consultation and inaccessibility of the SWIFT network for securities firms initially provided the incentive for the FIX project. Of particular concern to securities firms was the time-critical nature of pre-trade and trade instructions which need to be transmitted and processed as quickly as possible. FPL thus created their own bespoke proprietary protocol of communication known as "tag=value" syntax (for example, a FIN-based ISO 15022 field describing the trade date for a security would appear in the form of "98A::TRAD//19980420", whereas its technical representation using the FIX protocol would be "75=19980420"). While the new messaging standard solved some of the issues securities firms were facing, it quickly became obvious that 
it was creating other problems. Having two different data exchange protocols for different parts of the trade lifecycle led to process fragmentation and decreased STP.

Table 3.3 Standards for securities trade lifecycle

\begin{tabular}{lllll}
\hline \multicolumn{2}{l}{ FRONT OFFICE } & BACK OFFICE & & \\
\hline $\begin{array}{l}\text { PRE-TRADE } \\
\rightarrow\end{array}$ & $\begin{array}{l}\text { TRADE } \\
\rightarrow\end{array}$ & $\begin{array}{l}\text { POST-TRADE/ } \\
\text { PRE- }\end{array}$ & SETTLEMENT & POST- \\
SETTLEMENT & $\rightarrow$ & SETTLEMENT \\
FIX & FIX & $\begin{array}{l}\text { SWIFT } \\
\text { (ISO 15022) }\end{array}$ & $\begin{array}{l}\text { SWIFT } \\
\text { (ISO 15022) }\end{array}$ & $\begin{array}{l}\text { SWIFT } \\
\text { (ISO 15022) }\end{array}$ \\
\hline
\end{tabular}

Aware of the tremendous opportunities that end-to-end automation could offer the sector, FPL and SWIFT issued a memorandum of understanding (MoU) on 6 July 2001, to coincide with discussions for the reorganization of ISO 15022 and the incorporation of XML syntax. The basis for this agreement was described as follows:

FPL believes that ISO 15022 XML will provide the glue between the pre-trade/trade (front office) and post-trade (back office) domains. The effort leverages FPL's experience and expertise in the pre-trade/trade domain and the work facilitated by SWIFT in the post-trade domain. Different parts of the trade life cycle are truly coming together to work through issues hindering effective STP. ${ }^{1}$

FPL's willingness to collaborate was influenced by two developments: first, the need for $\mathrm{T}+1$ for equity trade settlement, an initiative that was led by the Securities Industry Association (SIA); and, second, the adoption of ISO 15022 in XML by key players in the post-trade processing domain such as GSTPA and Omgeo. ${ }^{2}$ Following the agreement, FPL and SWIFT worked together and managed to reverse engineer many of the existing FIX messages (FIX 4.3 was the latest version at the time) against the ISO 15022 model and produce a set of interoperable messages for the pre-trade and trade domains.

In early 2005, however, FPL returned to producing its own FIX-based standards (creating an optimized version of FIXML 4.4) and informal discussions were held on the possibility of cutting ties with SWIFT, thus 
distancing themselves from the effort to improve interoperability and pursue a single standard in the sector. Soon after, in November 2005, FPL publicly announced their withdrawal from the memorandum of agreement with SWIFT. ${ }^{3}$ FPL stated that the adoption of FIX in the pretrade and trade areas had grown considerably, and that the creation of another standard to address this space "was redundant and did not serve the industry." It was suggested by some commentators that after gaining legitimacy from its relationship with SWIFT, FPL started to view SWIFT standards as competitors and chose to "send a clear message to the industry" by safeguarding "FIX Protocol as a long term strategic direction for the financial industry." The relationship between SWIFT and FPL resumed a few years later, in 2007, when as members of the Standards Coordination Group, they affirmed their commitment to ISO 20022.

\section{Notes}

1. FIX Protocol Ltd, FAQ re: ISO 15022 XML. Announcement, 6 July 2001.

2. Omgeo was founded in March 2001 as a joint venture between DTCC and Thomson Financial in order to provide post-trade solutions and products to the securities industry.

3. FPL press release, FPL and SWIFT Memorandum of Understanding $(M o U), 29$ November 2005.

4. FPL, FPL/SWIFT/ISO FAQ, 28 November 2005.

5. Ibid., 2.

\section{SWIFT's standards development and maintenance process}

From the beginning, the evolution of SWIFT standards has been driven by a community of users who seek to satisfy their demands for costsaving, increased volume, and reduced risk in order to meet the challenges arising from rapidly changing business conditions in the financial industry. As a result, user participation in the development and maintenance of new and existing standards has always been the key to effective standards development.

The governance structure of SWIFT has been used to support these efforts, as evidenced by the introduction of procedures for the development and implementation of standards in 1985 (broadly coinciding with the ISO 7775 implementation). At this time, SWIFT's user base consisted largely of banks with "a very homogenous business mix." 94 However, as the community grew and its members became more diverse, there was a need to reflect different business requirements. SWIFT's standards procedures were revised and an explicit standards policy emerged. This was presented in the 
form of a position paper following a meeting of the operations committee of the board of the directors in May $1994^{95}$ and was approved by the policy committee a month later. The guiding principles included in this proposed policy statement concerned the "collective benefit of its members" and specified SWIFT's role as an industry body that "will respond to the needs of its customers and the industry to initiate and implement message standards." 96 Two key principles supporting that manifesto were "universality," which highlighted SWIFT's long-term goal to create a single set of universally accepted standards, and "co-operation" which emphasized close partnership with the financial community while developing standards.

A more detailed document followed in September 1994 outlining a streamlined process for the development and implementation of standards. ${ }^{97}$ The goal was to shorten the standards development cycle so that delays in the implementation of standards by SWIFT would not fuel the emergence of competing standards bodies, which would raise costs and reduce efficiency for all concerned.

One of the shortcomings of the prior policy was over-reliance on various standards working groups (SWGs). It was claimed that their ad hoc meeting schedule slowed response times in the face of critical strategic requirements from industry members and produced irrelevant or inadequate modifications to existing standards. SWGs were primarily led by standards and IT specialists rather than business experts, which often resulted in the introduction of messages that did not meet with business requirements. It had also proven difficult for standards groups to bring representatives of all the industry sectors and geographic markets together. SWIFT's response was to allocate more responsibilities to the SWIFT standards department, a resource that was considered to be "under-utilised" ${ }^{98}$ As Gottfried Leibbrandt put it until then: "the standards department was one or two people... [O]nce a year they put everybody in front of a flip chart and decided which forms needed to be amended." 99 Under the new policy, SWIFT adopted a more systematic approach, giving the standards experts ownership of the business processes for which standards were being developed and encouraging them to analyze the business issues, thereby integrating SWIFT's standards processes with a market-driven strategy for its products and services. SWIFT hoped that by shifting key responsibilities from the SWGs to SWIFT's standards experts, the timeline for standards development could be significantly improved.

Having determined that "the standards development expertise present on a full-time basis in the Standards Department should be exploited to its maximum", 100 it was given responsibility for drawing up a "standards development plan" based on feedback from the marketing division. ${ }^{101}$ It then had the task of developing the standards documented in the plan which included: identification of MTs to be developed, modified or deleted; formation of 
business justifications for new MTs; identification of implementation timeframes and scenarios; identification of participants allowed to use the proposed MTs; arrangements for user visits and task forces; and soliciting comments and feedback from users on the standards proposals, etc. One of the key duties of the standards department was to collect issues and user requirements from business experts.

This new approach to standards development, as set out in BP 612 Standards Development and Implementation Procedures, marked not only the rise of the SWIFT standards department to more significant status within SWIFT, but also the emergence of SWIFT as a systematic standardization body coordinating and managing the needs of the financial services sector for the overall benefit of its community. As part of the reorganization, the standards development process was more closely defined along with the roles of the different departments and committees that contributed to the process. Finally, the guiding principles expressed in the new policy were aligned with SWIFT's mission as it was described in the Bylaws.

After the ER 616 Standards Policy and BP 612 Standards Development and Implementation Procedures documents laid the foundations for the development of the standardization process within SWIFT, several documents followed that revised the existing procedures in line with corresponding developments in the sector and the problems identified from previous approaches (see Table 3.4 for a comprehensive list). ${ }^{102} \mathrm{~A}$ few of the themes discussed in the various revisions were to: speed up standards development and implementation; focus on the end-to-end straight-through processing of financial transactions; improve communication with the industry; allow for business and market differences in more flexible standards development and implementation scenarios; protect members' investments in legacy systems in order to minimize the cost impact of standards changes; reorganize the roles and responsibilities of different actors in order to make the process more efficient; and ensure global consensus. ${ }^{103}$ As the collaboration with ISO evolved and the adoption of ISO 7775, ISO 15022, and ISO 20022 grew across the industry, revisions came to include new workflows describing the process for new ISO standards development and the interaction or synchronization points with the ISO registration bodies. ${ }^{104}$ Since the last Standards Development and Implementation Procedures document published in May 2007, subsequent revisions are being issued as part of the SWIFT User Handbook.

Today SWIFT is charged with developing and maintaining standards subject to approval from its board of directors. Once new standards and amendments have been approved, it is the responsibility of SWIFT to communicate these to the financial community through various channels 
Table 3.4 Key SWIFT standards-related documents

\begin{tabular}{|c|c|c|}
\hline Document number & Date of publication & Document title/description \\
\hline- & Circa 1985 & $\begin{array}{l}\text { Initial standards development } \\
\text { and implementation } \\
\text { procedures }\end{array}$ \\
\hline ER 616 & 13 May 1994 & Standards Policy \\
\hline BP 612 & 2 September 1994 & $\begin{array}{l}\text { Standards development } \\
\text { and implementation } \\
\text { procedures }\end{array}$ \\
\hline BP 647 & 10 November 1995 & Standards Reorganization \\
\hline BP 685 & 8 November 1996 & $\begin{array}{l}\text { Standards development } \\
\text { and implementation } \\
\text { procedures }\end{array}$ \\
\hline- & July 1999 & $\begin{array}{l}\text { Building standards for } \\
\text { tomorrow: A green paper on } \\
\text { SWIFT's goals in relation to } \\
\text { the next generation of } \\
\text { standards }\end{array}$ \\
\hline- & September 2000 & $\begin{array}{l}\text { SWIFT Standards: How } \\
\text { customers will benefit from } \\
\text { the new end-to-end standards } \\
\text { development }\end{array}$ \\
\hline BP 828 & 10 November 2000 & $\begin{array}{l}\text { Standards development } \\
\text { and implementation } \\
\text { process }\end{array}$ \\
\hline ER 868 & December 2001 & $\begin{array}{l}\text { Roll-out of SWIFT Standards } \\
\text { XML messages }\end{array}$ \\
\hline BP $828(\mathrm{R})$ & 22 February 2002 & $\begin{array}{l}\text { Standards development } \\
\text { and implementation } \\
\text { process, Revision } 1+ \\
\text { Annexes }\end{array}$ \\
\hline ER 909 & June 2003 & $\begin{array}{l}\text { SWIFT Standards - } \\
\text { intellectual property } \\
\text { rights policy }\end{array}$ \\
\hline BP $828(\mathrm{R} 2)$ & 25 May 2006 & $\begin{array}{l}\text { Standards development } \\
\text { and implementation } \\
\text { process, Revision } 2+ \\
\text { Annexes }\end{array}$ \\
\hline BP 828 (R3) & 25 May 2007 & $\begin{array}{l}\text { Standards development } \\
\text { and implementation } \\
\text { process, Revision } 3+ \\
\text { Annexes }\end{array}$ \\
\hline
\end{tabular}

Note: "ER" = SWIFT Executive Report and "BP" = SWIFT Board Paper. Overall an Executive Report looks for feedback by asking specific questions about a proposal and is usually produced by a SWIFT employee, while a Board Paper can only be produced by a Board Member and may serve different purposes. 
such as SWIFT publications, industry events, and user or national member groups. MT and MX development and maintenance processes are separately defined but, in general, any request to develop or maintain a standard originates either from an identified business opportunity or from the overall market demand and the specific business needs of the community.

\section{MT standards development and maintenance}

In the case of the MT messages, the portfolio is well defined since the SWIFT community has used these for many years. For that reason there is very limited activity with regard to the creation of new messages, but messages do pass through annual maintenance cycles. Being a marketdriven process, any request for maintenance would typically originate by user group chairpersons who manage individual user and member bids, representatives of market practice groups and infrastructures, members of closed user groups, or from within SWIFT. The SWIFT standards department collects change requests, analyzes them, and prepares the relevant documentation, including proposal documents and high-level information reports. These proposal documents are then submitted to the members of the relevant maintenance working group prior to its meeting. ${ }^{105}$ Working groups are composed of experts in the business area under discussion who are generally also required to have a sound knowledge of the SWIFT and ISO messages. Depending again on the message category, each user group chairman from the top ten countries which are anticipated to use the message and generate traffic will often nominate a key candidate (as well as a secondary) to join the working group in order to ensure global governance and wide representation from the industry. It is the responsibility of the SWIFT Standards team to approve the nomination and monitor the contribution of working group members to make sure that there is balanced representation and expertise between countries and communities based on what messages are being reviewed. ${ }^{106}$

Following the consultation with the maintenance working group, proposals are validated or rejected, in which case the process usually terminates unless there is an opportunity for appeal. After the decisions are endorsed by the SWIFT board of directors they are forwarded to the user community for country vote. The national user groups of each member country then return their vote for each of the proposals within five to six weeks. The results of the vote are ratified by the board and the standards department distributes the updated "high-level information document" which "provides an overview of the changes that were accepted by the 
working groups and approved by the country vote to the UGCs". 107 This document is also the basis for the formation of the Standards Release Guide and the Message Format Validation Rules that describe in more detail the effect the changes will have on the actual message formats. Before the messages are published in the Standards MT Message Reference Guide and the SWIFT User Handbook, the customers and vendors conduct tests to ensure that their interfaces and applications are ready for the standards implementation. In addition to this, training dates are also set to ensure familiarity with the new messages.

The overall maintenance process takes around 18 months and follows a strict timeline along which key dates for each step of the procedure are identified and closely monitored. A similar process is followed for the development of new FIN MT messages. However this usually takes two years to conclude and entails further consultations with the responsible development working group.

\section{MX standards development and maintenance}

MX standards follow the ISO 20022 methodology and hence their development and maintenance can be quite different from the process for MT standards. The ISO 20022 standards process uses UML to capture definitions for business areas, business transactions, message flows, and messages in a syntax-independent format that is not affected by any particular technology or protocol.108 In addition, MX messages are currently deployed on the SWIFT network in closed user groups. In practice, this means that users are required to opt in to use a new message, but most importantly, this arrangement ensures that the development of messages meets the demands of initial users ("pilots") without affecting the wider community.

When SWIFT seeks to develop a new ISO 20022 message set, it submits a "business justification" to be approved by the ISO 20022 registration management group following earlier support from the board of directors. ${ }^{109}$ With help from the pilot groups, SWIFT then develops and tests the new or enhanced messages based on the requirements that have been gathered. This takes place independently of the ISO 20022 submission and approval. The steps involved are: origination (market demands and business case identified); project initiation and requirements formulation (business model layer following the ISO 20022 methodology is outlined); message development (assessing the logical message layer in a test environment); piloting (on the SWIFT network); and packaging (putting together the documentation and implementing the standard). When this process concludes, SWIFT forwards the 
candidate messages to the ISO 20022 RA (in this case itself) for technical quality review prior to submission to the relevant ISO 20022 standards evaluation group, who are responsible for the business review and approval. ${ }^{110}$ SWIFT then works closely with the standards evaluation group to identify and apply any required changes, and finally resubmits the messages to the ISO 20022 RA for conclusive approval and registration. ${ }^{111}$

SWIFT's mission as the RA for ISO 20022 "is to ensure compliance of developed Repository items with the approved technical specifications and to publish the Financial Repository on www.iso20022.org, on behalf of ISO." 112 It is common for SWIFT's role as a RA and its capacity to act as a standards organization that develops messages for the community of network users to be misunderstood. As a whole, SWIFT commits to making all MX messages subject to approval and registration by ISO (following the 20022 registration process set by the international body). However, as a standards organization in its own right, it also has the option of creating and implementing messages that are not ISO 20022 compliant. The latter means that SWIFT may deploy MX messages on the SWIFT network before they have been approved by ISO. It also means that SWIFT is at liberty to comply with the wishes of its user community if they indicate that they do not want to implement a new version of an ISO 20022 message. In that case, the maintenance of these standards follows the same process as the MTs.

Our description of the development process for MT and MX message standards highlights key characteristics that a new message standard should have in order to increase the possibility of being widely accepted. First of all, a robust standard must have "a strong business case" and satisfy a recognized requirement. ${ }^{113}$ While this may seem obvious, determining factors like the costs of implementation, resources required for maintenance, or the degree to which potential benefits are realizable in practice have often not been taken into consideration. In the past, this has contributed to unfavourable outcomes such as disagreements between prospective users or the development of standards that remained unused. Recent developments in standardization such as the adoption of ISO 20022 have provided a more business-oriented approach that moves SWIFT away from focusing purely on messages "towards business processes". 114

\section{Conclusion}

SWIFT standards have not only "industrialized" financial services by enabling STP, thus creating major cost-saving opportunities, they have also 
opened up spaces for further innovation in terms of process innovation, interoperability, and broader, more transformative forms of connectivity. This has been identified as one of SWIFT's most important achievements and part of its lasting contribution to global business.

SWIFT's history has been characterized by negotiation and compromise between stakeholders from the start. By definition, its role as a third party places it in relation to ongoing tensions. To understand further how these relationships have been worked out in practice, it is essential to study the changing membership arrangements and user base at SWIFT and in particular their impact on the growth of SWIFT over the years. SWIFT's dual role as both network provider and standards-setting body also calls upon us to further explore the development of the SWIFT network infrastructure and this is the topic of the next chapter.

\section{Notes}

1 Yawar Shah, Chairman of the Board, SWIFT, Sibos Plenary Speech, 15 September 2008, Vienna.

2 Jamie Shay (personal communication with Susan Scott and Markos Zachariadis [email], 8 June 2013).

3 Paul David and Shane Greenstein, "The economics of compatibility standards: an introduction to recent research", Economics of Innovation and New Technology, 1 (1) (1990): 4.

4 Transactional messages are the messages that are designed to undertake a particular business or administrative goal - e.g. money transfers between bank accounts, trading instructions between agents, orders between suppliers and other organizations, etc. (see Malcolm Hamer, "An introduction to structured transactional messages 1": http://www.isf-us.com/Structured-TransactionalMessage-Standards.pdf).

5 Unlike unstructured messages such as free text contained in an email, etc., structured messages adhere to a strict format based on predefined rules agreed between the sender and the receiver.

6 See David and Greenstein, "The economics of compatibility standards".

7 Even though STP as a term mainly refers to the streamlining of information flows in securities trading, it can also be applied in the payments field since this is also part of the trade lifecycle (see Ayesha Khanna, Straight-Through Processing for Financial Services (Burlington, MA: Elsevier, 2008); Wayne Huang, Yining Chen, and Jarrad Hee, "STP technology: an overview and a conceptual framework", Information and Management, 43 (3) (2006): 263-70).

8 Huang et al., "STP technology": 264.

9 Paul David, "Some new standards for the economics of standardization in the information age", in The Economics Policy and Technological Performance, eds. Partha Dasgupta and Paul Stoneman (Cambridge: Cambridge University Press, 1987); David and Greenstein, "The economics of compatibility standards". 
10 Alistair Milne and LeiLei Tang, "An economic analysis of the potential benefits and dis-benefits of faster payments clearing", Office of Fair Trading Report OFT795 (May 2005). Also see Huang et al., "STP technology".

11 Craig N. Murphy and JoAnne Yates, The International Organization for Standardization (ISO): Global Governance through Voluntary Consensus (New York: Routledge, 2009): 5-24.

12 David and Greenstein, "The economics of compatibility standards".

13 Ibid. See also Brian Arthur, "Competing technologies, increasing returns, and lock-in by historical events", The Economic Journal, 99 (394) (1989): 116-31.

14 Nicholas Economides and Charles Himmelberg, "Critical mass and network size with application to the US fax market", NYU Stern School of Business Working Paper EC-95-11(August 1995): 1-40.

15 These two types of standards (unsponsored and sponsored) are also known as the de facto standards because they are originated from market-mediated mechanisms (see Bob Hills "Common message standards for electronic commerce in wholesale financial markets", Bank of England Quarterly Bulletin, August (2000): 274-85; Gottfried Leibbrandt, "Payment systems and network effects". Unpublished Ph.D. dissertation, Maastricht University.

16 Gottfried Leibbrandt, "Payment systems and network effects": 30; see also Michael L. Katz and Carl Shapiro, "Network externalities, competition, and compatibility", American Economic Review, 75 (3) (1985): 424-40.

17 Farrell and Saloner compare three common mechanisms for achieving coordination for the development of compatibility standards. By constructing a simple model their research finds that it is more likely to achieve coordination through standardization-by-committee in spite of being slower than the other alternatives. For a detailed discussion, see Joseph Farrell and Garth Saloner, "Coordination through committees and markets", RAND Journal of Economics, 19 (2) (1988): 235-52. Finally, mandated standards (often referred to as standardization-by-government) are created by regulatory authorities like government bodies or other legislatures. See David and Greenstein, "The economics of compatibility standards"; Hills, "Common message standards": 274-85; Murphy and Yates, The International Organization.

18 Murphy and Yates, The International Organization: 10.

19 For an extensive list of organizations and industry bodies involved in message standardization, see Hills, "Common message standards": 276.

20 Paul Glaser, "Using technology for competitive advantage: the ATM experience at Citicorp", in Managing Innovation: Cases from the Financial Services Industries, eds. Bruce R. Guile and James B. Quinn (Washington, DC: National Academy Press, 1988): 108-14; Robert Kauffman and Yu-Ming Wang, "An exploratory econometric analysis of shared electronic banking network adoption", Journal of Strategic Information Systems, 3 (1) (1994): 61-76.

21 Financial Information eXchange (FIX) protocol is an open standard that was created "as a bilateral communications framework for equity trading" (see www.fixprotocol.org). A more detailed account on the relationship between FIX and SWIFT is illustrated in Box 3.3 of this chapter.

22 SWIFT Annual Report 1974. 
23 The role of standards developer emerged as part of the broader network project rather than as a motivation in itself. It is notable that the word "standards" is not part of SWIFT's name unlike other standards-setting bodies such as ISO and ANSI.

24 Société Internationale de Télécommunications Aéronautiques, known as SITA, was founded in 1949 as a member-owned cooperative society to provide a worldwide message switching network for international air carriers. SITA influenced SWIFT in two ways: first, during the Message Switching Project prior to the founding of SWIFT, the SRI legal working party studied its governance structure and used it as a key point of reference when formulating their recommendations; second, the BIC code is based upon the three digit airline city codes e.g. SBA: Santa Barbara.

25 Jamie Shay (personal communication with Susan Scott and Markos Zachariadis [email], 8 June 2013).

26 Unpublished document on SWIFT standards, Brussels, $c$. January 2001. Part of this document is incorporated into the SWIFT report by Jean-Marie Eloy and Frank Vandamme, Message Standards Evolution in the Securities Industry: From Paper-based to XML Communications, 2002.

27 Alec Nacamuli (interviewed by Susan Scott and Markos Zachariadis [in person], London, 17 January 2012); Bessel Kok (interviewed by Susan Scott [in person], Prague, 24 April 2012). Similar information could also be found in SWIFT internal documentation and other confidential Board papers accessed by the authors with kind permission from SWIFT.

28 Alec Nacamuli (interviewed by Susan Scott and Markos Zachariadis [in person], London, 17 January 2012).

29 Andre Bamat, "Editorial", ClearIT, 29 (September 2006): 3.

30 ETH University profile of Prof. Dr Max Engeli (Professor Emeritus): https:// www.bi.id.ethz.ch/personensuche/detail.do?pid=12FBD\&lang=EN

31 While SWIFT produces standards on a standardization-by-committee basis, the primary syntax and SWIFT language was developed in-house by Max Engeli and Erik Wennerholm (Bessel Kok (interviewed by Susan Scott [in person], Prague, 24 April 2012)). Alec Nacamuli also recalls: "we noticed that there was nothing from ISO which we could lift. There was no existing standard for international transactions. At that point, each country had their own standards but, there was no international standard, and so the decision was taken, well, let's go ahead, just design the standards and we can then fold them into ISO which is what eventually happened". (Interviewed by Susan Scott and Markos Zachariadis [in person], London, 17 January 2012.)

32 Renato Polo (interviewed by Susan Scott [by telephone], 20 November 2009).

33 Jamie Shay (interviewed by Susan Scott and Markos Zachariadis [phone interview], 16 June 2013).

34 Ibid.

35 The MT 100 was a traditional customer payment message and one of the first financial messages developed by SWIFT. Twenty-five years after its development it remained the most heavily used message on the SWIFT network until it was replaced by MT 103 and MT 103+ in 2003. (For more details, see Nicola Boothby, MT103: Responding to the Market, November 2003 Standards Release by SWIFT.)

36 Image was taken from SWIFT Users' Handbook, September 2001 edition, FIN Service Description. 
37 For a comprehensive list with the names and purpose of all existing SWIFT Standards MT as well as their new XML version (SWIFT Standards MX), see: http://www.swift.com/resources/documents/standards_inventory_of_messages. pdf

38 The above representation was taken from the 10th anniversary general introductory brochure published in 1983 and it illustrates a payment order translated into an MT 100 message. The example payment is sent from Banco De Los Palos Verdes Mexico D.E. (SWIFT code: BAPVMXMMA) to Barclays Bank International London (SWIFT code: BARCGB22). The separate fields with the payment information are also clear.

39 See "The evolution of SWIFT standards and the relationship with ISO" section of the current chapter for more details.

40 An additional alphanumeric character could be added in the end of the number to specify additional options relating to the level of automation desired based on the corresponding machine utilized. In an interview, Chris Norton, a retired banker and former Chairman of the SWIFT (UK) ST Users Group, described this as follows: "The message text formats that were originally created fulfilled the requirements of both manual processing and automation. So in the original message text formats ... many of the field texts would have A, B, C, D and E options. A option would always be the extremely automatable option. In other words, the 57A would be the BIC. 57D would be a name and address. So banks could, if they wanted to automate, if they agreed with their correspondent that they would automate, then they could use the A option of these message text standards. And it would work both ways. And if a bank was not able to automate, it could use the D format" (interviewed by Susan Scott and Markos Zachariadis [in person], London, 22 July 2010).

41 The SWIFT proprietary language is one of various syntaxes employed in the financial services sector. Other prevalent protocols worth mentioning are: the FIX protocol; UN/EDIFACT (United Nations Electronic Data Interchange for Administration, Commerce and Transport) which is used mainly for communication purposes between banks and corporates; Comma Separated Values (CSV) and its variants, which were of the first to be used for data exchange purposes; and eXtensible Markup Language (XML), an advanced text format that uses customized $<$ tags $>$ to describe message fields and data. Alternative industry standards have employed XML-based protocols in order to be able to transmit data on many different platforms and through many applications. Such protocols are: the FpML (Financial products Markup Language) protocol, which was first published in 1999 to accommodate the growing Over-The-Counter (OTC) financial derivatives industry, and is currently used by various platforms, including DTCC (Depository Trust \& Clearing Corporation) and SwapsWire; and the GSTPA (Global StraightThrough Processing Association) protocol which provided post-settlement and pre-trade messages between broker-dealers, fund managers, and custodians (see Hills, "Common message standards"; Khanna, Straight-Through Processing: 69-89).

42 ISO International Standard 15022-1, first edition, 1 March 1999.

43 Hamer, "An introduction": 6.

44 The example was taken from SWIFT Users' Handbook, September 2001 edition, Message Structures. 
45 Information obtained from Barclays Group Archive (document: 80-4134); SWIFT BIC Policy Report, June 2009; ISO report on the ISO 9362:1994 (15 December 1994). See also note 24.

46 Renato Polo, memories from a former SWIFT user written for the LSE SWIFT research project in advance of his interview with Susan Scott [by telephone], 20 November 2009.

47 Evidence shows that in the beginning large international banks were quick to copy the SITA network and use the IATA airport codes to identify their branches. For instance, the department of a bank in Brussels would use "BRU" as their Branch Code: "The IATA codes were adopted ... partly because this was a good idea - the airport codes are short, and all the cities in which the banks have branches have airports, and therefore IATA codes - and partly because some of the programmers who worked on the SITA network formed the core of the new messaging software development teams in the banks". (See Hamer, "An introduction": 12.)

48 For example, SWIFT messages are limited by the need to conform to the fourline thirty-five character format institutionalized during the telex era (Frank Vandamme, former Head of Standards Initiatives, interviewed by Susan Scott and Markos Zachariadis [in person], Brussels, 7 May 2009).

49 Hills, "Common message standards": 279.

50 Nostro and vostro (from the Italian words, nostro and vostro, meaning 'ours' and 'yours' respectively) are accounting terms used to distinguish an account held for another entity from an account another entity holds. The entities in question are almost always, but need not be, banks.

51 Guildhall Library Manuscripts (GLM), Section M32326B, File No. 253, British Bankers' Association (BBA), private and confidential communication, 17 February 1978.

52 Another example of how outside initiatives were enfolded into SWIFT projects is the "Five Party Club" launched by Mesa banks in 1981. Open to other eligible ECU clearers, their "fully customized solution" was initially supported by key figures in the US but banks did not lend their support and the "message copy" concept underpinning it was quickly adopted by SWIFT (Polo, Memories).

53 Jean-Marie Eloy (interviewed by Susan Scott and Markos Zachariadis [in person], Brussels, 20 April 2012).

54 Information taken from unpublished SWIFT standards report (Brussels, c. January 2001); Eloy and Vandamme, Message Standards Evolution: 2.

55 ISO Technical Report 7775, second edition, 15 May 1997. This working group was a joint assembly between ISO and SWIFT and was considered as SWIFT's first attempt "to really embrace the ISO standards" (Jean-Marie Eloy (interviewed by Susan Scott and Markos Zachariadis [in person], La Hulpe, Belgium, 20 April 2012)).

56 These message types mainly covered the securities areas of post-trade, presettlement, settlement, reconciliation, corporate actions, and reporting.

57 Jamie Shay (interviewed by Susan Scott [phone interview], 9 March 2012).

58 In 1984, the general meeting of shareholders accepted the principle of participation by securities brokers (BRM 057) but it took until 4 May 1987 for the first categories of securities participants to be approved (BRM 080, BRM081, and BRM082). 
59 Sandy Bleich (interviewed by Susan Scott [phone interview], 26 March 2012).

60 Eloy and Vandamme, Message Standards Evolution; unpublished document on SWIFT standards; SWIFT Standards Report, November 2001.

61 Hills "Common message standards"; Leibbrandt, "Payment systems".

62 Eloy and Vandamme, "Message standards evolution".

63 Being a key person behind the original idea for the new standard, Jean-Marie Eloy, a standards expert (then Euroclear, now SWIFT), was appointed by ISO as the chairman of the committee responsible for the development of ISO 15022 (Jean-Marie Eloy (interviewed by Susan Scott and Markos Zachariadis [in person], Brussels, 20 April 2012); ISO International Standard 15022-1, first edition, 1 March 1999).

64 Because ISO 15022 was largely based on the 7775 syntax it was commonly referred to as "enhanced ISO 7775 syntax". The new standard addressed many of the technical shortcomings of ISO 7775 .

65 All business objects were uniquely identified, resolving any contradictions on meaning depending on the type of message, and thus "mapping" individual messages was no longer required. This helped to reduce narrative fields (fields that included unstructured information using lengthy blocks of text) and offered an opportunity to enhance STP in securities trading.

66 While EDIFACT was registered under the ISO 9735 standard, ISO 15022 described how this could be used in order to define a securities message.

$67 \mathrm{UN} / \mathrm{CEFACT}$ is the United Nations Centre for Trade Facilitation and Electronic Business, a UN centre that "supports activities dedicated to improving the ability of business, trade and administrative organizations, from developed, developing and transitional economies, to exchange products and relevant services effectively" (UN/CEFACT Mission Statement). UN/CEFACT is also the body that maintains and develops the EDIFACT standard.

68 See Eloy and Vandamme, "Message standards evolution": 5.

69 The decision was taken at a Board meeting before the Sibos conference in Munich, Germany (1999). At that time other standards-setting international organizations such as GSTPA and FIX had already adopted XML (see Clive Davidson, "SWIFT to use XML for next generation", Securities Technology Monitor, 20 September 1999).

70 See http://www.iso15022.org/

71 Sponsored by UN/CEFACT and OASIS (Organization for the Advancement of Structured Information Standards), ebXML is "a modular suite of specifications that enables enterprises of any size and in any geographical location to conduct business over the Internet" (see www.ebxml.org).

72 Jean-Marie Eloy (interviewed by Susan Scott and Markos Zachariadis [in person], Brussels, 20 April 2012).

73 The UNIFI acronym was given to ISO 20022 (after holding a contest) so that "it would be easier for people to remember." However, in 2008 the RMG voted to drop the name as SWIFT members and other financial services institutions were referring to the standard using its original name (ISO 20022) and so the number "stuck" (personal communication with Jamie Shay, June 2013).

74 A Registration Management Group (RMG) was also appointed by ISO to govern the overall process for the development and maintenance of messages. 
75 See http://www.iso20022.org/

76 Other examples are the ISO 9000 and ISO 14000 quality process standards.

77 SWIFT Standards team, ISO 20022 for Dummies.

78 Ibid., 15-17.

79 SWIFT, The SWIFT Standards Story.

80 While SWIFT has repeatedly disputed the argument of increased expenses by highlighting the value of injectionable message definitions integrated directly into the back-office applications and the fact that after the initial investment ongoing costs should be reduced due to syntax-independence, there is still a wide perception in the industry that the XML-based 20022 is more costly to implement and maintain than existing standards in the industry (Martine De Weirdt (interviewed by Susan Scott and Markos Zachariadis [in person], Brussels, 15 February 2012); "Demystifying Standards" (SWIFT Standards in collaboration with the financial community): 16. In addition, SWIFT revisited its price structure to accommodate the longer XML messages as part of ISO 20022 (SWIFT has traditionally charged every 325 characters as 1 message unit but there were also exceptions such as the statement) (personal communication with Jamie Shay, June 2013).

81 SWIFT, Simple Coexistence: Paving the Way to XML.

82 John Sandman, "Ghost messages linger in the SWIFT machine", Securities Technology Monitor, 11 October 2004; SWIFT Standards team, ISO 20022 for Dummies: 28.

83 SWIFT Standards team, ISO 20022 for Dummies: 29.

84 SWIFT Standards team, ISO 20022 for Dummies; SWIFT, Simple Coexistence.

85 SWIFT, "Demystifying standards".

86 SWIFT, The SWIFT Standards Story.

87 Ibid., 17.

88 Jim Northey and Joshua Derrick, "ISO 20022 Financial Messaging Standard: neither a Tower of Babel nor an Esperando", Global Trading, 15 March 2009.

89 SWIFT, The SWIFT Standards Story: 17.

90 During the mid-1990s, close collaboration with UN/CEFACT led to the creation of a limited number of EDIFACT-aware messages (MTs 105, 106, and 121) to cater for specific communication needs (see SWIFT Information Report IR 347, 7 June 2004). In October 2003 a MoU between the Interactive Financial eXchange (IFX) Forum, the Open Applications Group, Inc. (OAGi), SWIFT, and the Treasury Workstation Integration Standards Team (TWIST) outlined the terms of cooperation in the area of the content and use of a core payment kernel XML transaction. In June 2004, as part of SWIFT's involvement in ISO/TC68 for the development of ISO 20022, it took part in an agreement between ISO and UN/ CEFACT to investigate a common message standardization framework for the financial services sector. Last but not least, as part of the ISO 15022 initiative and the move to XML, FPL and SWIFT also signed a MoU in 2001 in order to improve interoperability and move toward a unified standard for securities trading.

91 SWIFT, Standards Investment Roadmap, September 2010. XBRL stands for eXtensible Business Reporting Language, an open standard for exchanging business information; ISITC is the International Securities Association for Institutional Trade Communication that supports STP; and FISD is the Financial Information Services Division of the Software \& Information Industry Association (SIIA) that provides a forum for the exchange of ideas on the distribution, management, administration, and use of market data. 
92 Jamie Shay (interviewed by Susan Scott [phone interview], 9 March 2012).

93 SWIFT, Standards Investment Roadmap.

94 SWIFT Board paper number BP 612, Standards Development and Implementation Procedures, 2 September 1994.

95 SWIFT Executive report number ER 616, Standards Policy, 13 May 1994.

96 Ibid., 2.

97 SWIFT Board paper number BP 612. This proposal was approved by the Operations Committee a few days later (28 September 1994).

98 Ibid., 4.

99 Gottfried Leibbrandt (interviewed by Susan Scott and Markos Zachariadis [in person], La Hulpe, Belgium, 21 December 2011). His role at the time of the interview was Head of Marketing. Leibbrandt joined SWIFT from McKinsey in 2005 to work on the SWIFT2010 strategy plan and then was appointed Head of Standards soon after its completion.

100 SWIFT Board paper number BP 612: 4.

101 The standards development plan was approved by the Operations Committee which monitored the overall process and also determined which categories of participants are allowed to use which message types. In addition, the role of the Policy Committee was to approve the company strategy and the overall standards policy (see SWIFT Board paper number BP 612).

102 Table 3.4 includes some of the key documents that revolutionized the process for the development and maintenance of SWIFT standards over the years. Following the latest revision of the BP828 in 2007, a standards development and implementation process was published and maintained as part of the SWIFT User Handbook online.

103 For example, see SWIFT Board paper number BP 685, Standards Development and Implementation Procedures, 8 November 1996; SWIFT Board paper number BP 828, Standards Development and Implementation Process, 10 November 2000.

104 SWIFT Board paper number BP 828 (R3), Standards Development and Implementation Process, revision 3, 25 May 2007.

105 Not all message categories have a MWG which meets regularly. In that case a group needs to be formed and a meeting to be scheduled.

106 Working Groups are reviewed every two years based on traffic volumes. The SWIFT Standards team can suggest a replacement of a WG member based on the quality and expertise of members. Members of a working group are reimbursed their travel and accommodation expenses for meetings organized at SWIFT's head office. This is a significant difference in comparison to other standards setting bodies, like ISO, which relies on its members' expenses to fund similar operations (see SWIFT User Handbook, MT Development and Maintenance Processes, 13 May 2011).

107 Ibid., 21-2.

108 SWIFT User Handbook, Standards MX Development and Maintenance Processes, 29 April 2011.

109 It should be clear that any potential user of messages can submit a Business Justification to the ISO RMG and must go through the same process SWIFT does. It is the responsibility of all organizations to develop the model and messages themselves, using the repository/dictionary provided by ISO and the RA. In some instances SWIFT will accept Business Justifications and Change Requests and also make the changes but this is on a consultancy basis and not 
94 SWIFT standards

part of the RA responsibility. In the case of message maintenance a 'Change Request' will need to be submitted instead.

110 At this stage the SEG may request changes to the message formats in order to make them more applicable to the wider market.

111 SWIFT User Handbook, Standards MX Development.

112 See www.iso20022.org for detailed information on the role of the Registration Authority.

113 SWIFT, "Demystifying standards": 5.

114 Ibid. 


\section{Development of the SWIFT network}

- The SWIFT network and technology

- SWIFT II

- SWIFTNet

- The evolution of SWIFT membership and network diffusion

On 31 May 2011, SWIFT broke the 20 million messages per day threshold for the first time since its network "went live" in 1977. Today SWIFT has more than 10,000 live users in 212 countries who exchange on average 4.5 billion messages between them on an annual basis. Though the aggregate value being transmitted through these messages is not publicly disclosed, it is believed that the average daily amount exceeds 7.7 trillion US\$, ${ }^{1}$ nearly half of US GDP, or three times UK GDP. These figures provide insight into the scale of the SWIFT network and its significance for international trade and financial markets around the world.

In this chapter we explore the development of SWIFT's messaging network infrastructure and the evolution of SWIFT membership and network diffusion. We begin by looking in detail at the development of the SWIFT system in order to understand the technological footprint from which it built its capacity to act as the key infrastructure for international payments responsible for facilitating cross-border operations. However, as previously discussed, it was not the technology alone that established SWIFT's core position but rather the achievement of critical mass. We therefore move on to discuss the process and pattern of SWIFT network diffusion after its launch in 1977. In so doing, we discuss key developments in the evolution of its membership and user base including its expansion from a "banks-only club" to an international infrastructure that connects more than 10,000 financial institutions (and corporates) around the globe.

\section{The SWIFT network and technology}

Following the founding of SWIFT in 1973, Burroughs Corp. was chosen to be its primary technology provider. ${ }^{2}$ Burroughs installed two switching 
centres in Brussels and Amsterdam, which were linked by telephone lines to data concentrators in 14 countries, and from there to the terminals of the member banks. ${ }^{3}$ Each switching centre connected with half of the "send/ receive points" and with the other switching centre. The anticipated result was that "most messages transmitted on the [SWIFT] network would be delivered anywhere in the system within a minute of being entered." 4 The completion of the installation and subsequent launch of the network were expected in March 1976. After numerous postponements due to debugging problems with the equipment, ${ }^{5}$ the system went live on 9 May 1977, connecting an initial group of 25 Belgian and French banks, ${ }^{6}$ as well as Barclays Bank in the UK. ${ }^{7}$ Other countries followed in subsequent tranches: Denmark, Italy, and Switzerland in June; the UK, Luxemburg, the Netherlands, Finland, Germany, Austria, Norway, and Sweden during July to August; and the US and Canada in September 1977. It was anticipated that by the end of the year about 400 banks would be connected to the system of the cooperative, which by this stage had reached more than 500 members.

The initial network architecture was based on a 3270 protocol that supported 3270 data streams ${ }^{8}$ between the source and the destination. These were usually sent over a "family" of plain Binary Synchronous Communication (BSC) protocols that had been originally developed by IBM during the 1960s to support batch communications between systems. The network, which became known as "SWIFT I", was fully redundant and was running on 9,600 Bps, leased, international circuits. ${ }^{9}$ Figure 4.1 illustrates the architecture of the SWIFT network in 1977, showing the first switching centres (stars), the country concentrators (circles), as well as the primary and back-up circuits (regular and dotted lines respectively).

Despite the significant technical and processual advances of SWIFT in comparison to the telex, its launch revealed residual operational issues and some banks complained that they were "not getting appropriate responses." 10 Although the telecommunications functionality was of a high standard, problems arose because each bank was attaching multiple, different forms of interface to the network. While SWIFT had commissioned the development of a bespoke computer-based terminal (CBT) which came to be known as the SWIFT Interface Device, or SID (see Box 4.1), the system allowed users to connect to the facilities using various types of interfaces, including telegraph and telex. ${ }^{11}$ The positive side of this was that no additional costs or changes to the operating procedures were required in order to connect to the SWIFT network, but there were significant disadvantages too. Operators had to enter payment instructions and other financial messages following the formatting requirements of SWIFT, otherwise the machine would log off the network and a new connection had to be established. The problem 


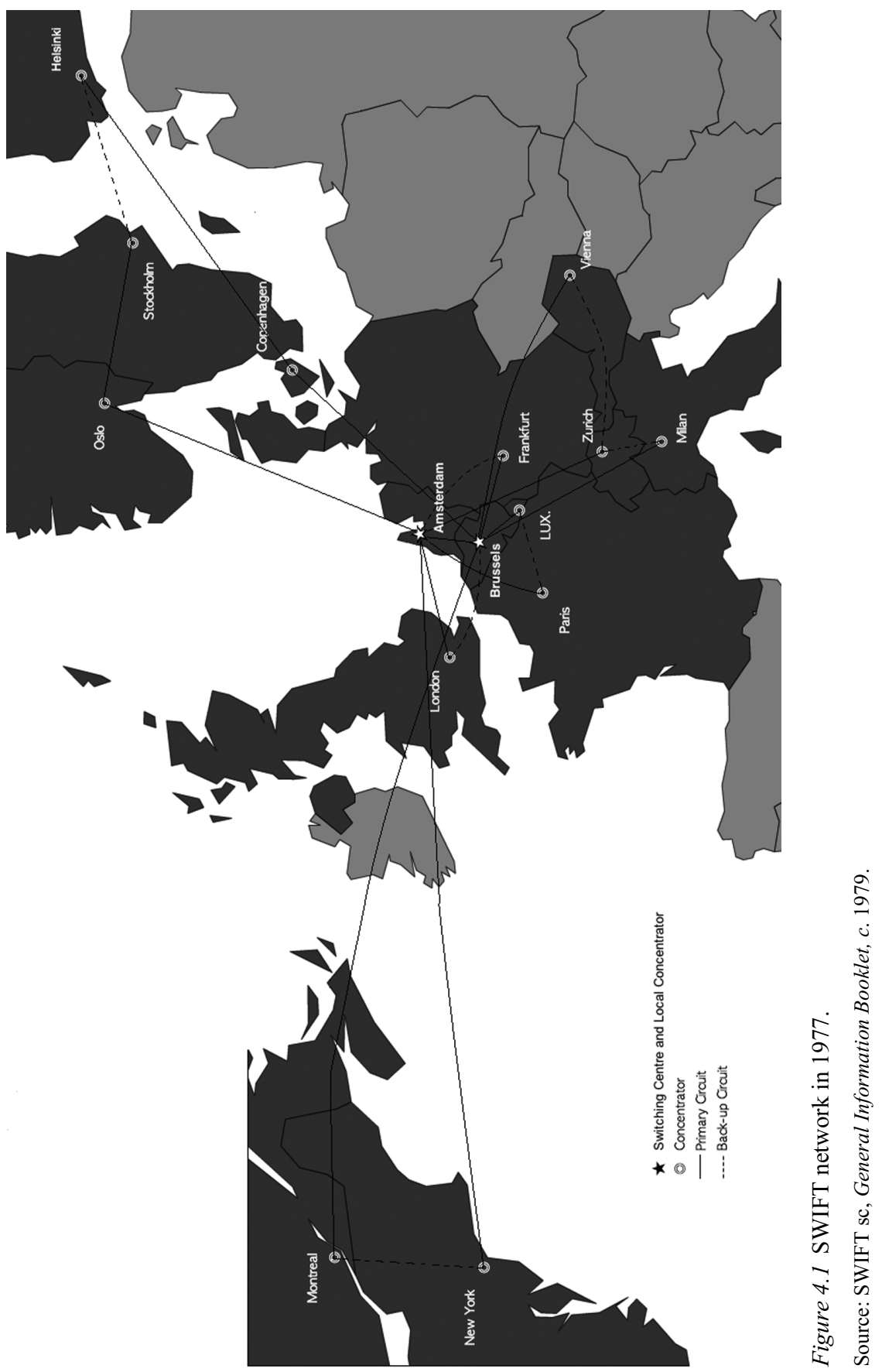




\section{Box 4.1 SWIFT Interface Device ${ }^{1}$}

The SID, which was "more of a standard than a product", ${ }^{2}$ was initially developed in collaboration with Burroughs Corp., General Automation, and Singer Business Machines (the computer division of the Singer sewing machine company). ${ }^{3}$ Of the three, Singer was responsible for the development of the SID software that would run on Burroughs' machines. At the time, the company was managed by Mr G. Cogar (CEO), Mr Komish in New York, and Mr Stitz in Brussels (VP of Singer Business Machines) who had established a diverse portfolio of computing projects, including banking systems for Société Générale de Banque (SGB) and Kredietbank as well as retail systems for Carrefour. Singer managed to win the contract over competitive quotes from IBM and others and worked on the project from 1973 to 1976. The team consisted of 13 software engineers directed by Arthur Borsei, a recipient of PhDs from UCLA and University of Rome, who had worked on the UNIVAC project and in the field of nuclear physics on the use of ferromagnetic thin fields to build faster memory for software, as well as the NASA Apollo project. Based in a building in Place Rogier, Brussels, he was charged with producing the "SWIFT, Singer SID operating system, a terminal multi-minicomputer system for worldwide multi-banking telecommunication network". In choosing the vendor, SWIFT put particular emphasis on the technical requirements for transfer speed and capacity, but made timeframe for delivery its priority. Borsei recalls: "They wanted it fast ... we passed the acceptance test, the others asked for more time." The SID software that Singer developed had to be written in proprietary computer language in order to connect to a special Burroughs' telecom package used by the pilot banks involved in the early stage of the SWIFT network. Borsei and his team produced the SID software for the Burroughs' system at two banks: SGB (Belgium branch), and the AMRO Bank of Holland. Following the completion of the final acceptance test (9 July 1976), SWIFT took the software and performed an operational readiness testing (12-16 July 1976). After the SGB SID software was generated and installed on 19 July 1976, SGB connected to the SWIFT concentrator and successfully passed the SWIFT bank connection test on 20 July 1976. AMRO followed the same process soon after. The telegram from Mr Coger (Singer New York) says: "Regarding SWIFT, a hearty round of applause and congratulations. We should make sure that the world 
knows about it. Regards, end of msg." Singer Business Machines was sold to International Computer Limited (ICL) in 1976, which in 2002 was renamed after its parent company, Fujitsu.

\section{Notes}

1. Information shared by Arthur Borsei (interviewed by Susan Scott and Markos Zachariadis [in person], Brussels, 20 December 2011).

2. Kevin Gidden (interviewed by Susan Scott and Markos Zachariadis [in person], London, 31 March 2009).

3. Information retrieved from (CBI 90), Burroughs Corp. records, Tray 21, Video No. M36. Soon after the initial bid SWIFT cooperated with several other vendors who supplied similar applications and decided to open the competition to the wider software market. The same source suggests that among the first movers were IBM, ARBAT, Olivetti, NCR, LMT, and Siemens.

was compounded by the slow speed of these machines which operated on a dial-up system that was not capable of maintaining a reliable link to the SWIFT concentrator.

A combination of operational risk issues, security concerns, and growing demand for a single standard connection for all members prompted a search for cheaper solutions that would be easier to implement. While the SID worked well for large banks that owned and maintained large mainframe computers, it was difficult to implement and relatively costly for smaller banks where telex was still used for some operations. To overcome these problems, SWIFT introduced the ST100 interface in 1981. This proved to be a significant stepping stone in achieving critical mass, as one of the SWIFT I implementation team members says: "It was the ST100 which brought on the members, because it was a relatively cheap, relatively simple to use closed computer system." 12 Eventually, when demand for interface devices began to outpace supply, SWIFT launched a wholly owned subsidiary called SWIFT Terminal Services SA (STS) in order to manage terminal and software sales. ${ }^{13}$ Following the success of the ST100, in 1983 STS announced the initiation of the next generation interface, the ST200. ${ }^{14}$ In addition to playing an important role in development, STS provided a 24-hour maintenance service and collaborated with specialized support groups alongside other vendors. STS implementation teams offered training and support for new connections and special emphasis was placed on integration with the existing or planned internal procedures. 
Despite the challenges faced by SWIFT and its users in the early stages of its development, this phase was characterized by those involved as one of optimism in which members on both sides of the Atlantic showed considerable willingness to engage in the cooperative effort needed to ensure that the system ran smoothly. Soon the network stabilized and as more countries went "live", traffic started to increase rapidly. By 19 February 1979, the volume of messages passing through the SWIFT network exceeded 120,000 per day..$^{15}$ As a result, plans for a third switching centre emerged in order to relieve the message load on the two initial hubs, and in February 1980, a new centre started its operations in the US. In the meantime, further concentrators were added to the network in Italy, the US, Denmark, and the UK. In addition, ten additional countries were linked for the first time in Europe and Asia, including Greece, Spain, Hong Kong, Singapore, and Japan, as well as various locations in Latin America including Argentina, Ecuador, Venezuela, and Mexico. ${ }^{16}$

Before adding new countries to the network SWIFT conducted an economic evaluation which was then assessed on a case-by-case basis according to a set of guidelines laying out the approval threshold. The policy stated that an analysis of revenue generation should be conducted "based on committed sent traffic figures for two years plus estimated sent traffic over the remaining three years of the planning period" and when this equalled or surpassed the "direct expenditure" for the network implementation then the country was eligible. ${ }^{17}$ Direct costs would usually include national site installations, national computer equipment, telecommunication cost to and from the country, travel cost to and from the country, and salaries of implementation staff.

By 1983, the SWIFT system was live in 52 countries and there was increasing demand to expand geographic coverage because it had become "desirable for banks in operating countries to also have smaller countries connected to the system." 18 However, the majority of the remaining countries and territories had difficulty in meeting the criteria laid down by the SWIFT Board. This is an example of where the cooperative's commitment to becoming a "global network" with worldwide coverage took precedent over straightforward commercial priorities. The SWIFT Board decided to use the surplus that had accumulated from its messaging services thus far to "subsidize the countries where break-even could not be reached" and thus encourage further network expansion. ${ }^{19}$ Figure 4.2 provides annual information on the adoption of SWIFT by countries and independent constitutional entities from 1977 to 2006 where the majority of countries worldwide had joined the network.

\section{SWIFT II}

Following this period of network expansion and corresponding increases in network traffic volumes (see Table 4.1), concerns about capacity and 


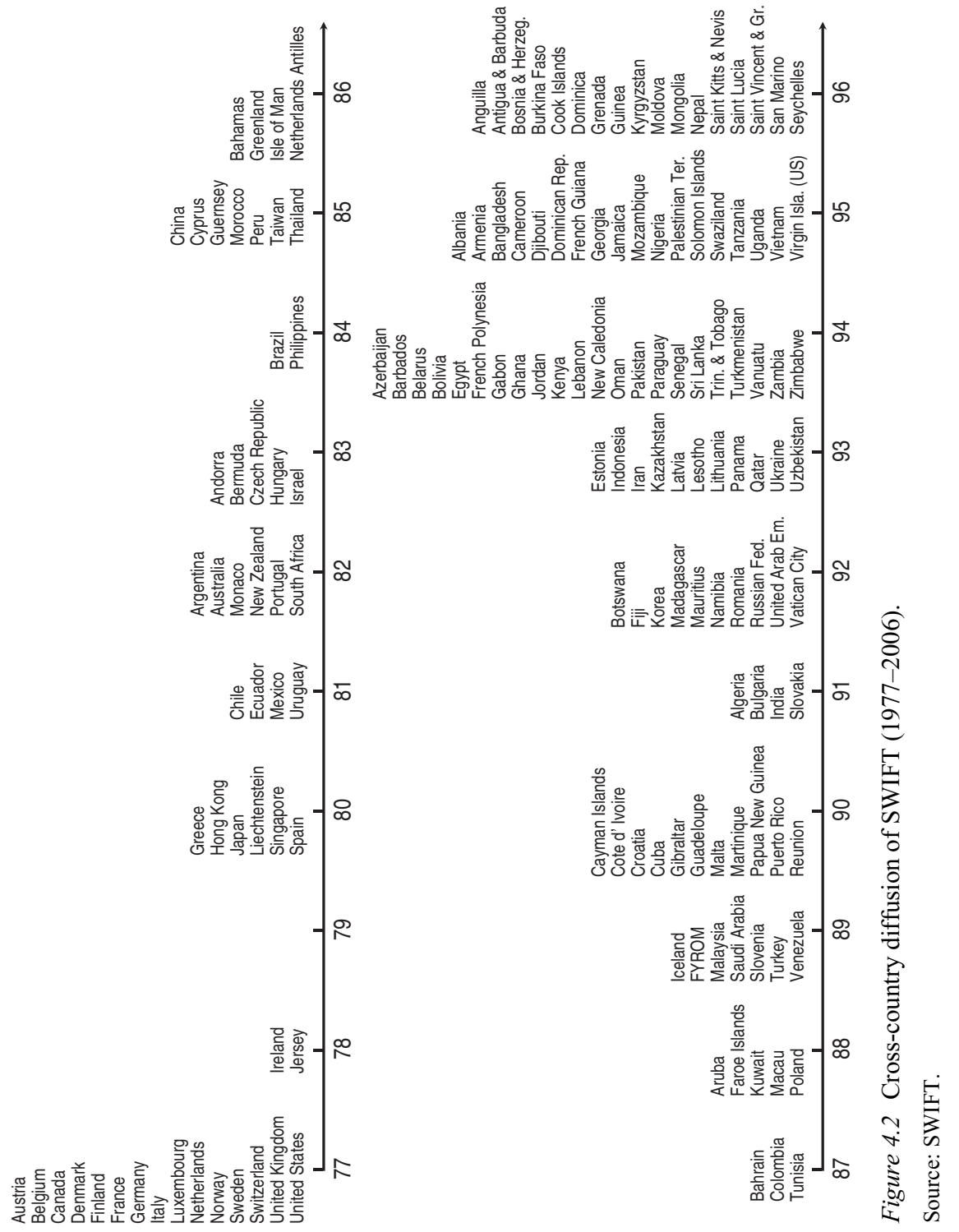




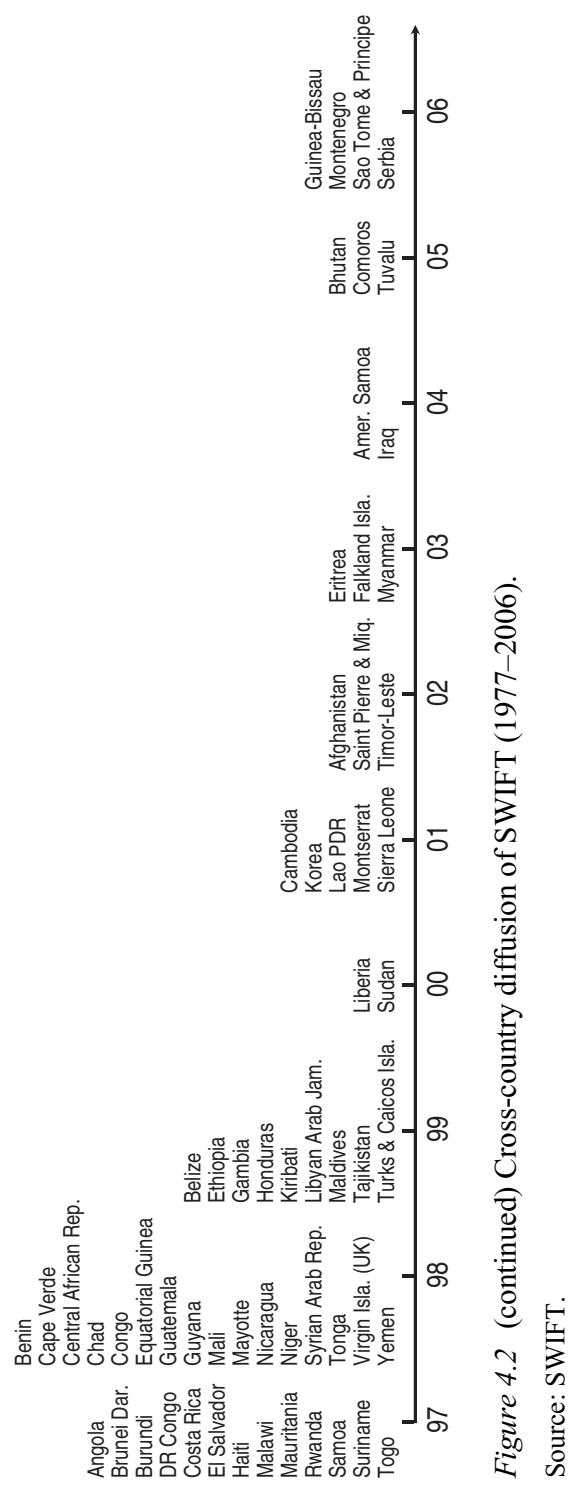


Table 4.1 SWIFT system traffic volumes (1977-1982)

\begin{tabular}{lc}
\hline Year & Daily traffic volume \\
\hline 1977 & 51,700 \\
1978 & 121,500 \\
1979 & 164,200 \\
1980 & 218,700 \\
1981 & 285,000 \\
1982 & 346,300 \\
\hline
\end{tabular}

Source: SWIFT Ten Year Anniversary Book.

network structure began to surface. Although a new switching centre had been installed in the US, the central-switch concept around which SWIFT I was designed imposed inevitable constraints in terms of volume. Anxiety about the capacity limitations of SWIFT I was exacerbated by the activities of major banks who, despite being members of the cooperative, continued to develop their own networks and thus their potential to divert interbank traffic through proprietary infrastructures. ${ }^{20}$ European PTTs (Post, Telegraph, and Telecom authorities) and other independent communication companies were also gradually increasing their share of the financial services sector market. ${ }^{21}$ As a result, SWIFT began to examine the possibility "of restructuring on the basis of a distributed network concept" setting up additional lines between national concentrators to relieve central switches (e.g. traffic from Zurich could be routed directly to London or the US without passing through Amsterdam, though national concentrators would have to be extended). This would both increase the capacity of the network as well as offer new services. ${ }^{22}$

Discussions about upgrading SWIFT I can be found in archive documents from the late 1970s and ideas for its successor were in development for some time. As the SWIFT II project began to form it became increasingly high profile with progress updates given to the community at Sibos each year. ${ }^{23}$ Unfortunately, progress was hampered by technical problems, including changes to hardware and software specifications as well as project management issues. This led to multiple postponements and doubts emerged as to whether it would be possible to complete the transition to "SWIFT II". ${ }^{24}$ The most significant challenge emerged when engineers decided to "drop a proprietary network scheme half-way through designing the net in favour of one based on X.25 packet-switching [network transport] protocols." 25 Initially SWIFT management had decided to use only Burroughs' proprietary network protocols to ensure compatibility with the Burroughs' computers used in SWIFT I but the increasing popularity of "packet switching," 26 which allowed "groups or packets of messages [to be] transmitted at high 
speeds between a series of regional switches," 27 motivated a shift in strategy. Packet-switching architecture would generally improve reliability because unidirectional traffic flows would be replaced by a multidirectional traffic pattern with the option to use different routes to reach the final destination of the message. It was also argued that the adoption of packet-switching protocol would better meet the demands of a multi-vendor environment.

Eventually, after many rounds of network and operational testing, 39 banks migrated to "full SWIFT II mode" by late $1990 .{ }^{28}$ Having delayed by more than three years, the enhanced X.25 system did not deliver its full potential right away. The early implementation phase was spent converting countries to the new network until Burroughs finished developing a software interface to facilitate the link between banks and the new infrastructure. ${ }^{29}$ Only then were banks able to realize the benefits of this phase of solutions development and use the 978 new functions that were incorporated into an additional one million lines of code. ${ }^{30}$

Despite the decision not to use Burroughs' proprietary communication protocol, SWIFT continued to use their mainframes as the basis for the new platform. ${ }^{31}$ The systems architecture that emerged used central control systems, slice processors (that would store and forward messages), and regional processors in order to handle and convert local protocols (see Figure 4.3). Northern Telecom Inc., ${ }^{32}$ a Canadian company, was commissioned to install around "60 DPN-100 digital packet switches in locations around the world over a three-year period". ${ }^{33}$ This new equipment would eventually replace the Burroughs' switches in SWIFT I which were nearly 15 years old. In SWIFT II, all the main operating centres would receive the traffic from the Northern Telecom X.25 protocol-based switches and route it to the new Unisys mainframes. Each of these regional processors would have the potential to be an operating centre, thus opening up the possibility for optional country-to-country routing. ${ }^{34}$

The upgrade and migration from the original SWIFT I platform to SWIFT II, known as the FIN network, were characterized by many as a technological "mess". In retrospect, an attempt to change the technology base, applications, and the protocols by which SWIFT communicated with customers in one move may have exceeded their project capability. On two occasions in 1991, SWIFT II became unavailable for a number of hours and, as described in Chapter 2, this resulted in a major overhaul in the approach taken to systems changes in the future. Despite the technological challenges relating to the network implementation, the new platform came with a number of benefits for its users and overcame many of the limitations of SWIFT I. As Peter Drummond, the executive Vice-President who oversaw the transition to the new platform, put it "... we need SWIFT II because we've got to manage greater capacities." 35 The original SWIFT 
system had accommodated increases in capacity from 250,000 messages per day to $1.3-1.5$ million messages per day by the time it was replaced. ${ }^{36}$ However, this was dependent upon the procurement and implementation of costly new switches. In contrast, the SWIFT II network was configurable and capacity could be increased by "plugging-in a new computer" 37 and from this point forward SWIFT's system capacity would be more scalable.

As the quest for new network solutions and communication technologies continued, SWIFT was already delivering benefits to its members beyond its core messaging service. Among the early advantages that SWIFT members realized were speed of messaging from automation, lower costs, increased volumes, more secure transactions, and standardization. Table 4.2 provides a description of the benefits of SWIFT membership during this period. SWIFT II also delivered additional benefits to network users beyond the increase in capacity. The X.25-based platform supported even faster speeds than SWIFT I, reaching up to $9.6 \mathrm{Kbit} / \mathrm{sec} .{ }^{38}$ The new architecture also allowed for the development of new services like Interbank File Transfers (IFT), the capacity to handle larger messages, longer storage periods of financial instructions, generation of reports and statistics, and delivery/non-delivery messages. ${ }^{39}$

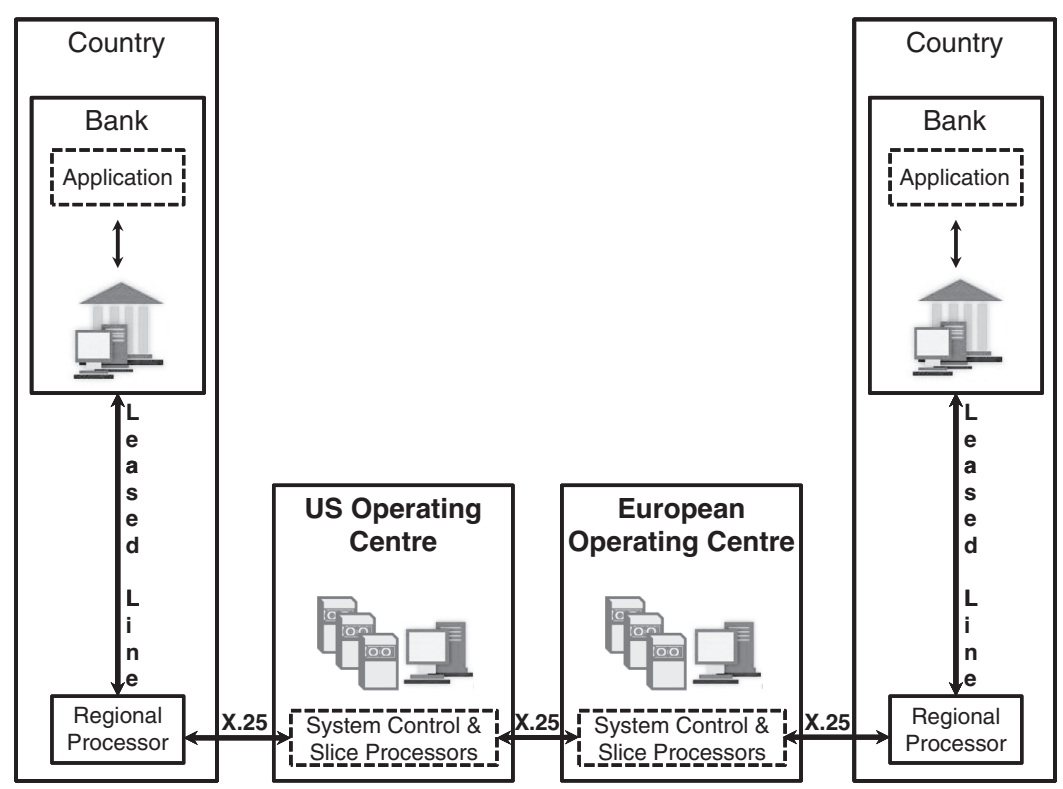

Figure 4.3 SWIFT II network infrastructure. 
Table 4.2 Benefits from the use of the SWIFT network in the early years

\begin{tabular}{|c|c|c|}
\hline Benefit & Description & Sources \\
\hline Speed & $\begin{array}{l}\text { Priority message transfers could take } \\
\text { well under one minute to reach their } \\
\text { destination, yet the main advantage } \\
\text { of SWIFT over its predecessors was } \\
\text { the automation of the standardized } \\
\text { authentication and data entry } \\
\text { processes that produced much of } \\
\text { the delay in payments. }\end{array}$ & Banking, July 1977 (48) \\
\hline Costs & $\begin{array}{l}\text { SWIFT messages were believed to be } \\
\text { considerably cheaper than traditional } \\
\text { telex and telegraph messages. The } \\
\text { estimated expense for sending a } \\
\text { letter of credit by telex was on } \\
\text { average } 13 \text { US dollars when a SWIFT } \\
\text { message would cost about } 50 \text { cents } \\
\text { (14 Belgian francs). Other estimations } \\
\text { accounted SWIFT messages to be five } \\
\text { times cheaper than sending a message } \\
\text { without SWIFT. Additional evidence } \\
\text { shows that SWIFT was responsible } \\
\text { for labour-force reductions. }\end{array}$ & $\begin{array}{l}\text { Boris Kozolchyk, "The } \\
\text { paperless letter of credit } \\
\text { and related documents } \\
\text { of title", Law and } \\
\text { Contemporary } \\
\text { Problems, 55 (3) (1992): } \\
\text { 39-101; Banking, July } \\
\text { 1977 (48); SWIFT } \\
\text { brochure, c. March } 1980 \\
\text { (BGA) }\end{array}$ \\
\hline Volume & $\begin{array}{l}\text { SWIFT network could manage a much } \\
\text { larger number of transactions. }\end{array}$ & Banking, July 1977 (48) \\
\hline Security & $\begin{array}{l}\text { The transition to SWIFT network } \\
\text { allowed for additional levels of } \\
\text { security in the coding and } \\
\text { authentication of messages between } \\
\text { banks. }\end{array}$ & $\begin{array}{l}\text { Banking, July } 1977(48) \text {; } \\
\text { Kozolchyk, "The } \\
\text { paperless letter of } \\
\text { credit", } 42\end{array}$ \\
\hline $\begin{array}{l}\text { Uniform } \\
\text { formats }\end{array}$ & $\begin{array}{l}\text { All the messages sent over the } \\
\text { network had to adhere to the strict } \\
\text { formats imposed by the system. }\end{array}$ & $\begin{array}{l}\text { SWIFT brochure, } c \text {. March } \\
1980 \text { (BGA) }\end{array}$ \\
\hline
\end{tabular}

Note: These are the primary benefits that were perceived from the member banks from using the SWIFT network. As the technology and the finance industry evolved, so did the benefits that the member banks and SWIFT users realized. In later years, benefits were perceived differently from bank to bank. For example larger banks began to view SWIFT more as a necessity and a commodity rather than a strategic innovation.

\section{SWIFTNet}

As technological developments and the needs of banks for more up-todate services rapidly increased, SWIFT had to keep pace and respond with new products and network upgrades. Consequently, in 1998, not too long after the full deployment of SWIFT II, the company officially announced their plans for a new TCP/IP network that would offer a series of new 
IP-based products and services. ${ }^{40}$ The new Secure Internet Protocol Network (SIPN) named SWIFTNet, which was built to replace the old X.25-based network, went live in 2001 (see Figure 4.4). In August 2002, the first SWIFTNet FIN message was sent over SWIFT's IP network and marked the official beginning of the users' migration to the new platform that was completed in 2004. The following year the X.25 network was officially dismantled. ${ }^{41}$

Probably the most important development to accompany the new SWIFTNet platform was the addition of enhanced market infrastructure services involving more advanced clearing and settlement instructions as well as links to support STP (straight-through processing) operations. Domestic market infrastructures such as Bundesbank's RTGSPlus system and the Bank of England's Enquiry Link were the first to fully move to SWIFTNet and use the newly developed messaging services.

In 2003 (30 years after the inauguration of SWIFT with 518 banks in 22 countries), SWIFT had 7,527 live users in 200 countries exchanging more than 2 billion messages per year. In a speech entitled "Thirty years of networking", the CEO of the company, Lenny Schrank, explained how SWIFT had grown over the preceding 30 years, far exceeding original expectations, building a "great community and a unique franchise". He also added that: 'SWIFT is not just a 'bank owned network,' it is 'a network of banks' and financial institutions." 42 What makes SWIFT's history notable, partly expressed through Schrank's words, is that an industry cooperative or "society" founded to reduce errors and increase efficiency in interbank payments became an unexpected network phenomenon. The notion of a "network effect" was not part of the consciousness of those involved in the original SWIFT project during the 1970s. Their focus was solely on creating an entity, a closed society, to bind members together in an organizational form that would employ standards designed to create efficiencies on transactions between the member banks.

SWIFT has since outsourced the development of its network, adopting a multi-vendor model that enables its secure IP network to "sit" on the infrastructure of four global network partners who provide a standard offering of managed IP-VPN services. ${ }^{43}$ Hence, users that seek to establish a direct connection to SWIFTNet make arrangements with one of its network partners. Connectivity to SWIFTNet demands dedicated interfaces to link to the users' applications, including messaging and communications packages. These software packages enable users to integrate applications with the services offered and are enhanced with a security layer (a version of Public Key Infrastructure). This ensures authenticity, integrity, and non-repudiation of emission and reception at the message level. SWIFT offers the requisite standards and rules for compatible interfaces to third-party vendors in order 


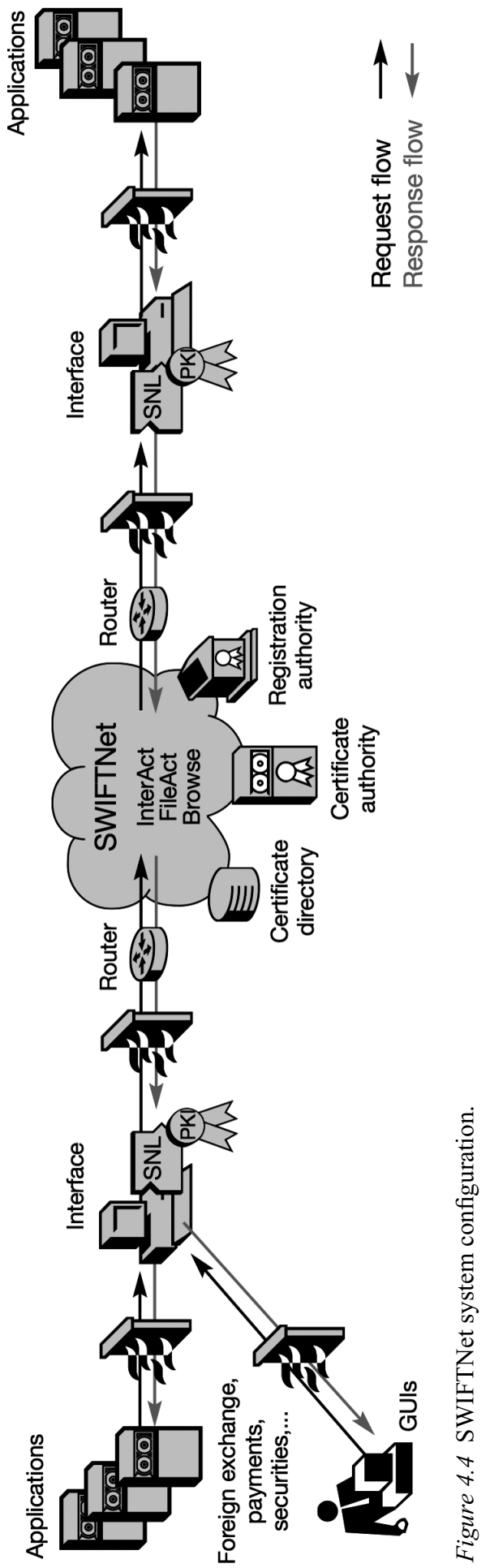


to facilitate the production of competitive products, and also provides interface products for the entire range of SWIFTNet services itself. Less costly solutions for indirect connectivity to SWIFTNet are also available. ${ }^{44}$ However, the cost of SWIFT is a small part of the banks' IT expenditure - if we are to understand the contests surrounding membership and network diffusion we need to consider the total cost of ownership. In other words, not only the direct savings produced by creating efficiencies in traditional correspondent banking flows and benefits from services offered on top of the SWIFT platform but additional value realized through interconnectivity with other infrastructures, accessing expertise, and influencing agendas.

\section{The evolution of SWIFT membership and network diffusion}

SWIFT network membership has been one of the most hotly debated topics since the founding of SWIFT in 1973, and one that continues to attract attention even today. This is largely because members of the SWIFT community are also shareholders of the cooperative and hence they can influence decision-making in the organization. As a result, network membership raises concerns about the balance of power within SWIFT's governance. Although SWIFT was conceptualized as a global initiative there was a notable presence of European banks among its original membership which meant that, despite the international nature of the markets for which they were competing, there were inevitable geopolitics. John Langdale notes that one of SWIFT's initial concerns was "the competitive advantage held by large US TNBs because of their sophisticated leased networks." ${ }^{45}$ For this reason, SWIFT was often perceived as a means of competing with these large intra-bank systems. ${ }^{46}$

This antagonism was also reflected in the early constitution of the board of directors of SWIFT. Eleven years after the founding of the organization Robert Moore of Chemical Bank became the first American banker to become chairman of the board at SWIFT. Despite the strategic significance of the move, Moore went on to reassure the SWIFT community that "there was a growing awareness at the board level that for the board to oversee company operations, the selection of chairman should not be based on political considerations." ${ }^{47}$ His promotion coincided with Charlie Reuterskiöld's elevation to President, which was seen as a move to balance any political influence within the organization. ${ }^{48}$

Soon, it became apparent that direct competition with US banks was not going to be the most defining feature influencing the design and development of SWIFT. Indeed, the interest of US banks in SWIFT has always been considerably tempered by the existence of their own federal systems such as FEDWIRE (owned and operated by the Federal Reserve 
Banks) and BANKWIRE (a private initiative), which met domestic demand for message transfers. Nevertheless, the deficiencies of the telex technology for cross-border payments meant that major US banks were keen to see the SWIFT network in operation. US banks were among the first to adopt SWIFT and they proved highly effective in realizing its benefits. 49

Another major source of controversy has been whether or not to extend SWIFT membership beyond the bank community. Accepting new types of members on to the network had been debated throughout the history of SWIFT. ${ }^{50}$ In 1987, SWIFT's member banks voted to expand the user base to include broker dealers, exchanges, central depositories, and clearing institutions. ${ }^{51}$ SWIFT initially started its operations in the securities sector via a collaboration with CEDEL - a leading bank-owned securities and depository system in bond clearing. Additional cooperation agreements were drawn up with the settlement system, Euroclear. All these developments along with SWIFT's efforts to introduce standards (new MTs) suitable for direct securities transactions between banks were regarded as important ways to inject more value-added services into the network to accommodate the emergence of new financial products. ${ }^{52}$

Nevertheless, other financial institutions did not find SWIFT so ready to extend membership. The efforts of international fund managers to become members of the society were blocked by vote..$^{53}$ After years of frustration they were accepted on to the network in 1992. This time it was the US banks that were "swimming against the tide" amid fears of losing business as fund managers were opting for other payment solutions, ${ }^{54}$ while in Europe there were fears concerning how fund managers would be defined and "what status they [would] have in the system". By the end of 1992, the membership of SWIFT had risen to 3,500 members.

Further complaints about the restrictions placed on membership were raised in the 1990s by triple A-rated corporations. They argued that SWIFT's ownership of both network and standards led to overemphasis on the interest of financial services companies at the expense of innovations that would benefit corporate treasuries, particularly in the area of standards development. In 1998, SWIFT acknowledged that they needed to make some changes in their network usage rules and created a special category of membership in order to accommodate corporate interests. The Member Administered - Closed User Group (MA-CUG), which allowed corporations to access the SWIFT network through member banks, was successfully launched in 2002 with the initial creation of 20 groups. ${ }^{55}$

Taking a historical perspective puts the evolution of network membership in context and helps us to identify events and influences that have affected growth and usage over time. Figure 4.5 presents some of the events 


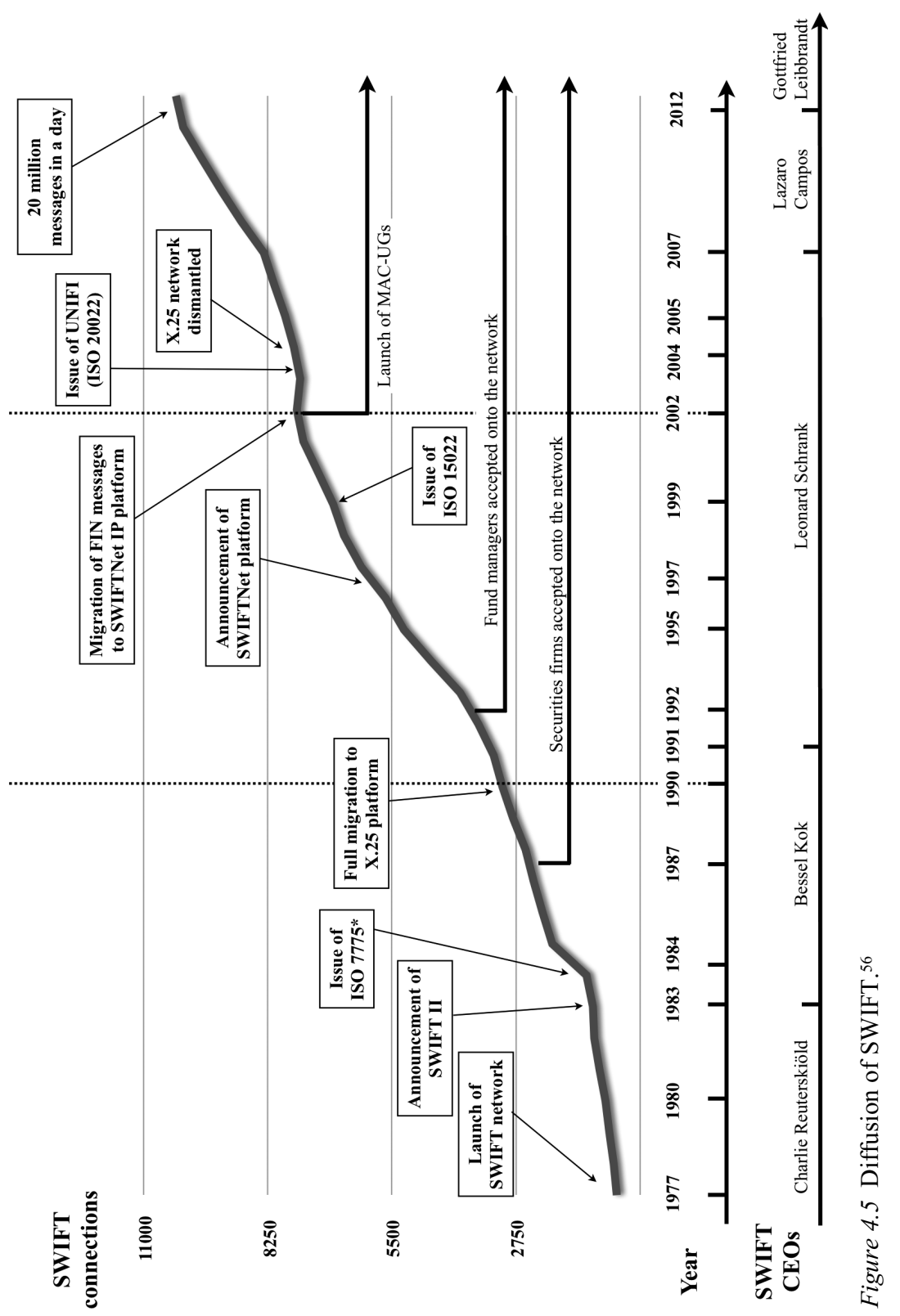




\section{Development of the SWIFT network}

that are believed to have played a decisive role in the ongoing development of SWIFT. These are mapped on to the diffusion curve of SWIFT since the beginning of its operation in 1977 until 2012 in order to draw a picture of the dynamic relations over the years. As can be seen from the figure, there have been three distinct influences on the immediate or long-term growth of SWIFT. Network upgrades have had an instantaneous effect on the capacity of the infrastructure supporting the additional number of users and transactions. This was particularly profound in the case of SWIFT II, the X.25 platform, whose development was announced in 1983 and was fully functional in 1990. Its deployment was deemed necessary in order to manage "greater capabilities" 57 and deal with the increasing client demands. Nathan Rosenberg, and Bronwyn Hall and Beethika Khan, categorize this effect as part of the "supply side," where improvements and technology upgrades are important determinants of the adoption of an innovation. ${ }^{58}$ In the case of SWIFTNet however, the story was different. Even though the announcement of the IP platform coincided with what seemed to be a period of expansion, the migration seemed to have a negative effect on the growth rates. This can be attributed to the somewhat increased cost of ownership that the new technology brought to its users as they had to upgrade their equipment and software to keep up with the latest developments. It might be the case that light users of SWIFT chose to leave the network as their connection was no longer cost effective. ${ }^{59}$

In parallel to the technological advancements, the development of new standards also played an important part in the expansion of the SWIFT user base. Their transmission over the network not only offered more interoperability benefits to its users but also introduced new products and services that did not exist before. In that respect, a broader range of solutions attracted more users that were keen to join the network. Finally, acceptance of new types of financial institutions (and corporates) on to the system is another factor that affected SWIFT growth since the beginning. Nevertheless, it was only through the combination of all the above that SWIFT achieved recognition and expanded in the financial services industry. For example, the introduction of new standards (like ISO 7775 initially and ISO 15022 later) attracted more securities firms once they were allowed on to the network (see discussion in Chapter 3). Consequently, the new firms pushed for further technology upgrades that were considered as necessary to satisfy their needs and the increasing volumes.

While our historical account of network evolution and diffusion provides key insights, there is still uncertainty about the precise processes and patterns characterizing SWIFT diffusion in different countries and regions. Exogenous factors are likely to have had an influence in the absolute number of adopters - for example, events like the bursting of the 
Table 4.3 Growth of SWIFT connections, countries, and annual traffic (1977-2012)

\begin{tabular}{|c|c|c|c|}
\hline \multicolumn{3}{|c|}{ Aggregate number of adopters } & \multirow{2}{*}{$\begin{array}{l}\text { Annual traffic } \\
\text { (thousands of } \\
\text { messages) }\end{array}$} \\
\hline Year & Firms & Countries & \\
\hline 1977 & 518 & 22 & 3,400 \\
\hline 1978 & 586 & 25 & 21,600 \\
\hline 1979 & 683 & 30 & 34,500 \\
\hline 1980 & 768 & 36 & 46,900 \\
\hline 1981 & 900 & 40 & 62,500 \\
\hline 1982 & 1,017 & 44 & 79,900 \\
\hline 1983 & 1,046 & 52 & 104,100 \\
\hline 1984 & 1,188 & 54 & 129,900 \\
\hline 1985 & 1,946 & 58 & 157,220 \\
\hline 1986 & 2,161 & 61 & 192,010 \\
\hline 1987 & 2,360 & 64 & 222,300 \\
\hline 1988 & 2,537 & 76 & 255,111 \\
\hline 1989 & 2,814 & 78 & 296,070 \\
\hline 1990 & 3,049 & 83 & 332,895 \\
\hline 1991 & 3,243 & 87 & 365,159 \\
\hline 1992 & 3,582 & 94 & 405,541 \\
\hline 1993 & 3,986 & 106 & 457,000 \\
\hline 1994 & 4,625 & 126 & 518,000 \\
\hline 1995 & 5,229 & 137 & 603,000 \\
\hline 1996 & 5,632 & 151 & 688,000 \\
\hline 1997 & 6,176 & 164 & 812,000 \\
\hline 1998 & 6,557 & 178 & 937,000 \\
\hline 1999 & 6,797 & 189 & $1,059,000$ \\
\hline 2000 & 7,125 & 192 & $1,274,000$ \\
\hline 2001 & 7,457 & 196 & $1,534,000$ \\
\hline 2002 & 7,601 & 198 & $1,817,000$ \\
\hline 2003 & 7,527 & 200 & $2,047,000$ \\
\hline 2004 & 7,667 & 202 & $2,299,000$ \\
\hline 2005 & 7,863 & 204 & $2,518,000$ \\
\hline 2006 & 8,105 & 207 & $2,865,000$ \\
\hline 2007 & 8,332 & 208 & $3,501,000$ \\
\hline 2008 & 8,830 & 209 & $3,855,000$ \\
\hline 2009 & 9,281 & 209 & $3,760,000$ \\
\hline 2010 & 9,705 & 209 & $4,031,935$ \\
\hline 2011 & 10,118 & 210 & $4,431,099$ \\
\hline 2012 & 10,279 & 212 & $4,589,109$ \\
\hline
\end{tabular}

Source: SWIFT sc.

"dot-com bubble" in 2000 and the ensuing two-year market decline or the $9 / 11$ terrorist attacks. ${ }^{60}$ Identifying network effects has the potential to provide additional insight into the role and contribution of market infrastructures to the economy. Recent research has produced some interesting findings in this regard and established an agenda for further research. 
For example, Markos Zachariadis' analysis of adoption and usage data not only uncovers evidence to support the existence of network externalities but also finds that SWIFT adoption positively impacts firm performance. Specifically, Zachariadis found that for every additional SWIFT adopter, there is a disproportionally larger increase in network usage (more than the average expected increase), thus emphasizing positive externalities and collective benefits and value added for all users in the network. ${ }^{61}$

Overall, SWIFT network adoption has grown steadily over the years, from its implementation in 1977 up until today (see Table 4.3 for a detailed breakdown based on countries, live users, and network usage).

\section{Conclusions}

In this chapter we explored the evolution of SWIFT's network infrastructure and membership growth in the context of ongoing technological developments. Its standards, products, and services have to be constantly updated, as so does its technology. As discussed above, SWIFT II introduced a second-generation system that represented a substantial development on the original network. Apart from greater processing power, the new system also provided flexibility and feasibility to expand into new services. Since 2004, and after several technological modifications, the SWIFT network has fully migrated to its IP-based platform, which opened the door to the development of further business solutions. Such upgrades in technology as well as messaging standards are sometimes perceived as an additional burden for SWIFT users who are reluctant for the cost of SWIFT adoption to increase. As a result, the society is constantly under pressure to meet expectations and offer new connectivity solutions or services to address concerns and meet its objective in operating and maintaining a global network.

The significant growth of SWIFT's network and membership as well as its organizational progress haven't gone unchallenged. Political, regulatory, and other issues posed considerable threats to its development by risking its status as a neutral infrastructure that serves the global financial community. In the next chapter we examine a number of these issues more closely in order to better understand debate across the industry and beyond.

\section{Notes}

1 The figure is based on 2002 estimates by Michael Brindle and Raymond Cox, eds., Law of Bank Payments (London: Sweet \& Maxwell, 2004): 101. 
2 Burroughs Corporation was one of the largest American manufacturers of mainframe computers and information systems solutions at this time. In September 1986, Burroughs acquired Sperry Corporation to form a new company named Unisys (see also Chapter 1).

3 According to information retrieved from the Charles Babbage Institute (CBI) (Archive, Burroughs Corp. (Ascent ion 90), press releases 1947-1987 (90:72, Box 1, Folder 17, 7 March 1974)), the initial value of the equipment was more than 6 million US\$, and included two dual central processor B 3700 computer systems, four data communications processors, and 14 data concentrators.

4 CBI Archive, 90:72, Box 1, Folder 17, 7 March 1974.

5 "New SWIFT network gives banks an instantaneous link worldwide", Banking, 69 (7) (1977): 48, briefly discusses the issues that delayed start up on several occasions, and pushed the cutover date to live operations back by about a year.

6 “SWIFT plans to start on May 9," Banking, May (1977).

7 Information retrieved from Barclays Group Archives (BGA) (HOC 138-77); internal communication from Barclays Bank, 3 May 1977. The same document suggests that the official starting date for the UK was set to be 18 July.

8 The 3,270 protocol was originally used by IBM 3270 terminals during the 1970 s (hence the name). These accepted large blocks of data (data-streams) from remote mainframe computers, and even though IBM stopped producing 3270 terminals, the protocol continued to exist and was commonly used as it reduced the amount of data transmitted and the number of interruptions to the mainframes (Cisco Systems, "Introduction" to Telnet 3270 Report).

9 George Ballester and Edmund Marcarelli, "The impact of global information technology on international investment managers and custodians", in Global Issues of Information Technology Management, eds S. Palvia, P. Palvia, and R. Zigli (Harrisburg, PA: Idea Group Publishing, 1992): 366.

10 "New SWIFT network", Banking: 48.

11 BGA, 80-4134, internal communication, June 1975.

12 Kevin Gidden (interviewed by Susan Scott and Markos Zachariadis, [in person], London, 31 March 2009).

13 SWIFT s.c. also owned another subsidiary called SWIFT Service Partners SA (SSP) which supplied SWIFT services to new securities participants. In 1992, under the leadership of the new CEO Leonard Schrank, both STS and SSP were merged back within their parent company SWIFT s.c. in order to reduce sales costs and achieve economies of scale while expanding the SWIFT network in more countries, especially the developing world.

14 The ST200 was based on Burroughs equipment and incorporated special software programmed by SWIFT. Its initial price was approximately $\$ 20,000$ for a single configuration. The price per workstation could be much lower for larger configurations - for example, approximately \$8,000 (Guildhall Library Manuscripts (GLM), Section, M32326B, File no. 253, ST200 product information, $c$. early 1983). Other popular models around that period where the MERVA from IBM, and FASTWIRE from Logica. Also, a limited version of Mini-SIDs was developed to accommodate smaller users.

15 GLM Section, M32326B, File no. 253, British Bankers Association (BBA), private and confidential communication, 23 February 1979. Up to then SWIFT had a theoretical capacity of 200,000 messages per day but there were concerns regarding its capability to deal with the transactions load in the near future. 


\section{Development of the SWIFT network}

16 Information retrieved from BGA, 80-3056-2: SWIFT brochure, $c$. March 1980. As part of its network expansion, SWIFT opened regional offices around the world starting from New York, and later on in Hong Kong, Singapore, Tokyo, and Buenos Aires (CBI 90, Burroughs Corp. records, Tray 21, Video No. M36).

17 SWIFT Executive report no. ER163 (Costing Techniques for Economic Evaluation of New Countries), 3 March 1981.

18 SWIFT Executive report no. ER217 (Amended Policy on Geographic Expansion), 9 September 1983.

19 SWIFT Executive report no. ER241 (Policy for Geographic Expansion (LossAvoidance Strategy)), 7 March 1984.

20 James Baker and Raj Aggarwal, "Evaluation of global electronic funds flow system: the Society for Worldwide Interbank Financial Telecommunications (SWIFT)", in Global Information Systems and Technology: Focus on the Organization and its Functional Areas, eds. Candace Deans and Kirk Karwan (Harrisburg, PA: Idea Group Publishing, 1994): 107-31.

21 Some good examples of such companies were GEISCO (General Electric Information Services Co.) and Reuters in the international arena, and the French SIT (System Interbancaire de Telecompensation), an automated cash transmission system in the national arena (Baker and Aggarwal, "Evaluation of global").

22 GLM, Section, M32326B, File no. 253, British Bankers' Association (BBA), private and confidential communication, 23 February 1979.

23 S. Newman, "SWIFT I will give way to SWIFT II, beginning in 1985; new telecommunication system will double capacity", The American Banker (1984): 13.

24 John Parry, "Bank communications system delayed; expansion of financial message link postponed another year", The American Banker, February (1987): 2-3.

25 Barton Crockett, "SWIFT2 completion adds needed capacity", Network World (1990): 27-30.

26 At the time, packet switching was considered a development in data transmission compared to circuit switching where an entire message is sent without the need to be reassembled upon arrival to its destination. With circuit switching a lot of the network capacity can be consumed to set up connections which are not used continuously. Circuit switching was also considered costly as PTT fees were charged based on the connection time rather than the data transferred which is the case with packet switching. Packet switching was largely established during the early 1980s with the most popular standard protocol suite X.25. More on the X.Series standards can be found through the International Telecommunication Union (ITU) at www.itu.int.

27 BGA, SWIFT “Company Plan”, 25 January 1979.

28 Baker and Aggarwal, "Evaluation of global:" 117.

29 "What will SWIFT II mean to your bank?", ABA Banking Journal (1986).

30 Baker and Aggarwal, "Evaluation of global".

31 Note that during this period Burroughs was acquired by Unisys Corp.

32 Today known as Nortel.

33 Wayne Eckerson, "SWIFT set to build global packet net", Network World (1989): 6.

34 "SWIFT II will open new doors", The Banker (1983).

35 Crockett, "SWIFT2 completion": 27.

36 "SWIFT II transition", ABA Banking Journal (1987): 112.

37 “What will SWIFT II mean?", ABA Banking Journal. 
38 Until that time the speed of the initial network could reach a maximum of $4.8 \mathrm{~K} \mathrm{bit} / \mathrm{sec}$.

39 For more details on the benefits delivered by SWIFT I and SWIFT II, see Baker and Aggarwal, "Evaluation of global"; Newman, "SWIFT I will give way": 13; "What will SWIFT II mean?", ABA Banking Journal.

40 Anthony Gandy, "SIBOS unveils the next generation: global financial payments organization SWIFT continues to expand, with the introduction of its next generation infrastructure, a move into securities and an involvement in e-commerce”, 148 (872) Banker (1998). See also SWIFT's User Handbook 2011 and information from www.swift.com (retrieved in March 2011).

41 Ibid.

42 SWIFT history: 2003 - "30 years of networking" (Leonard H. Scharnk, CEO, SWIFT) can be accessed at www.swift.com (retrieved in March 2011).

43 SWIFT report on High Values Payment Market Infrastructures (HVP MI), February 2009.

44 See Chapter 2 for more details on the different products and services provided by SWIFT.

45 John Langdale, "Electronic funds transfer and the internationalisation of the banking and finance industry", Geoforum, 16 (1) (1985): 6.

46 US Congress, Office of Technology Assessment, "Effects of information technology on financial services systems" (Washington, DC: US, OTA-CIT-202, September 1984).

47 Robert Garrson, "Americans gain top post, added clout in SWIFT; telecommunications group elects Chemical's Moore as chairman", The American Banker, April (1984).

48 Both these developments took place before a critical voting on procedures for amending the company's bylaws and the acceptance (or not) of stockbrokers to the network.

49 For more details on the economic impact of SWIFT adoption, see Susan Scott, John Van Reenen, and Markos Zachariadis, "The impact of the diffusion of a financial innovation on company performance: an analysis of SWIFT adoption", CEP Discussion Paper CEPDP0992, August 2010.

50 "Global custody: SWIFT busters strike out", The Banker, 142 (795) (1992): 44.

51 Securities have since proved to be a significant source of revenue for SWIFT. From the current FIN traffic about half ( 49.3 percent) is generated from payment messages which are still the dominant market on the SWIFT network but securities messages follow closely with a 44 percent share (Treasury and Trade account for 5.6 percent and 0.9 percent, respectively). Distribution by region is as follows: Europe, Middle East, and Africa 67.2 percent, Americas 20.4 percent; Asia Pacific 12.4 percent (see SWIFT report, SWIFT in Figures, April 2013).

52 "Future directions for SWIFT", The World of Banking, January (1983).

53 "The big US banks led the opposition", along with some German, French, and Japanese banks, but their resistance was expected to be reversed. Information obtained from "Global custody", The Banker: 1.

54 The "big" banks came to realize that they "can no longer push their proprietary networks on to investment managers as an alternative to SWIFT" ("SWIFT lets in fund managers", The Banker, 142 (1992): 1).

55 SWIFT Annual Report 2002.

56 Diffusion data are based on the number of SWIFT network live users since 1977. These were mainly acquired from SWIFT annual reports and online datasets. The figure is redrawn from Markos Zachariadis, "Diffusion and use of 


\section{Development of the SWIFT network}

financial telecommunication: an empirical analysis of SWIFT adoption": 12 (a copy of the full paper can be found at http://archive.nyu.edu/handle/2451/31404). Diffusion data are also presented in Table 4.3.

57 Crockett, "SWIFT2 completion": 27.

58 Nathan Rosenberg, "Factors affecting the diffusion of technology", Explorations in Economic History, 10 (1) (1972): 3-33; Bronwyn Hall and Beethika Khan, "Adoption of new technology", in New Economy Handbook, ed. Derek Jones (Amsterdam and London: Elsevier Academic Press, 2003): Chapter 10.

59 Around that time SWIFT went on to design new connectivity products that met the requirements of smaller banks and "lighter" users. An example of this movement was the development of the "Lite" solution.

60 That was the first year since the founding of SWIFT that the total amount of users decreased even slightly.

61 Zachariadis, "Diffusion and use of finanical telecommunication: an empirical analysis of SWIFT adoption", 1-44. Paper can be accessed here: http://archive. nyu.edu/handle/2451/31404 


\section{Current debates in historical perspective}

- Cooperative status and boundary management

- Data governance and the Terrorist Finance Tracking Program

- Geopolitics and exclusion of Iranian institutions

- Globalization, semi-globalization, and geopolitics

Over the years, SWIFT has crossed many social, political, and geographical boundaries and been surrounded by debates regarding the development of its standards and access to its network. Despite these challenges SWIFT remains a longstanding and important example of a cooperative network of competitors leveraging a member-owned infrastructure and the interoperability benefits that it generates. In this chapter, we review events that highlight the way in which global institutions such as SWIFT have to manage multiple constituencies and enter into negotiations with a wide range of organizations representing diverse interests, placing current debates in historical perspective. We begin by examining make-or-break tariff negotiations with state-owned Post, Telegraph, and Telecom authorities (PTT) which we use as the basis for a discussion about cooperative status and the challenges of organizational boundary management. In the second section, we describe SWIFT's involvement in the Terrorist Finance Tracking Program (TFTP) and discuss the issues of data governance that this raised. Next, we review the recent regulatory-mandated exclusion of Iranian institutions and briefly examine the pressures on SWIFT's standing as a global system. Finally, we put these events and their implications in the context of a broader discourse on globalization.

\section{Cooperative status and boundary management}

The cooperative status of SWIFT is a regular topic of debate among members of the financial services community, revisited on an almost cyclical basis every few years. Mixed into this ebb and flow are questions such as: 
Does Swift have sufficient resources and flexibility - and speed - to adapt to new technologies and competitive threats? Should Swift break its non-profit shackles in favour of some form of privatization, perhaps even a public stock offering? Will there even be a need for Swift in five to ten years? ${ }^{1}$

With its achievements as a pioneer of network connectivity behind it, members (often from its expanded membership categories) frequently ask: "What have you done for me lately?"2 SWIFT may have played a key role in transforming the back office of international banking and securities businesses but they ask, surely that is all in the past, what is next? (See Box 5.1)

\section{Box 5.1 Heidi Miller's speech at Sibos 2004}

The most widely cited example of critique by a SWIFT member is the plenary speech given by Heidi Miller (JP Morgan) at Sibos 2004 in Atlanta. Although industry commentators focus on her comments about SWIFT, in fact Miller begins by challenging her financial services colleagues: "The amount of customization in this industry and the lack of standardization across countries and across market infrastructures amazes me." She questions why parts of financial services are still highly "people and paper intensive" and says that:

As an industry, quite frankly, we are a very long way from STP... Constrained by regulatory and compliance requirements, by our own legacy investments, by the legacy investments of others, and by the glacial pace at which we banks tend to move. As an industry we are a very, very long way from "swift", please forgive the pun ... we support far too many redundant infrastructures and networks, too many proprietary standards, too many middleware platforms, too many legacy systems, too many products that should probably have been swept into the dustbin years ago... I am told that SWIFT became so successful because it replaced the old telex machines and helped us automate our back offices. SWIFT saved our industry billions of dollars but more importantly SWIFT made international payments faster, cheaper and more transparent for us and for our customers. Congratulations SWIFT, job well done. So, what next? To put it another way, what is today's telex equivalent that SWIFT can help me eliminate?... So the question for SWIFT is this: How will you help us 
create the new applications and business solutions to run over this wonderful new network, to leverage the awesome power and ingenuity of the incredible community that you represent? How will you help us get rid of all of these legacy infrastructures? How can you help our slow moving industry move faster to take full advantage of all the new possibilities? That is the challenge. ${ }^{1}$

Although it generally goes unremarked, her diagnosis of the problem is change management: "when we ask people to change they find it very frightening." In the ten years since Heidi Miller called for SWIFT to address the different proprietary bank interfaces by serving as a single window, it has developed a range of products and services to meet this need.

\section{Note}

1. Transcribed from SWIFT archive video of Heidi Miller's speech at Sibos, Atlanta, 2004.

This raises two further questions. How founded is the speculation about SWIFT's future? And where should a cooperative entity like SWIFT position itself in such a competitive sector? Although a definitive response to such questions is the preserve of SWIFT's members, we can outline the various points of discussion and explore historical case studies for insights from the past. Although technologically SWIFT could in theory be superseded, it is hard to justify abandoning a secure network with SWIFT's track record for reliability without knowing not only what will replace it but also what the long term will hold for any alternative entities. As we have seen in our chapter on the founding of SWIFT, successfully drawing together a consortium of banks and achieving critical mass is not a "given" for any network initiative. Replicating comparable confidence in data, network, standards, and finances would divert energy away from profitmaking activities.

In institutional terms, once SWIFT was accredited by regulators to connect to market infrastructures such as CREST, the likelihood that it will be replaced in the short to medium term was significantly reduced. SWIFT now connects to multiple market infrastructures thereby providing connectivity between the majority of the major institutions in international banking including central banks, exchanges, clearing and settlement organizations. While seeking an alternative for SWIFT is now rarely, if ever, debated, 
building on its foundations presents somewhat more fertile ground for speculation. Each time SWIFT expands its role, membership, or portfolio of products and services it necessarily creates tensions with commercial interests. Certain sections of its membership have told SWIFT that they should "Stick to your knitting!"4 in other words focus on the areas of its developed expertise - standardization and messaging - rather than try to create a charter around developing products in new areas. Others have vested interests that might be challenged should SWIFT extend its messaging and connectivity franchise into adjacent businesses.

"It's fair to say that everything we do upsets somebody somewhere: we level the playing field and once you do that you are likely to get in to trouble with someone", says Lázaro Campos philosophically. "The nature of a cooperative means that you are always seeking to do what your membership want you to do. The boundary surrounding SWIFT's remit is therefore not frozen", he says. "It changes over time." 5

What is seen by some as justifiable change over time is viewed as an identity crisis by others. But the history of both communication technology and financial services shows that innovation and establishing new value centres always involve challenging existing boundaries. In the case of SWIFT, this is well illustrated by the early contest with European PTT. The story of this clash of interests not only provides further insights into SWIFT's origins and an example of tensions of telecommunications access and pricing that continue to resonate in the internet era, it enables us to reflect on competitive dynamics and monopoly behaviour by incumbents in related sectors. As current SWIFT CEO Gottfried Leibbrandt commented: "SWIFT is not a bank - we are probably closest to a telecoms provider or technology company." 6

In the 1970s, as SWIFT moved closer to becoming operational, the PTTs, concerned that SWIFT threatened their telex revenues, attempted to impose volume-based line rental fees on SWIFT. Negotiations with the PTT's collective intermediary, the Conference of European Post and Telecommunications (CEPT), became the focus of a substantial amount of executive time. These negotiations were led by Bessel Kok, SWIFT's first Director of Finance. Recalling these events, Bessel Kok says:

The PPTs decided to bundle their forces against SWIFT through an organization called CEPT... And they decided, "We are going to be one front against SWIFT"... At first we only needed lines for testing purposes, so they had a couple years to think about how they were going to tariff SWIFT. They developed the idea that they would tariff volume, which was a completely new concern. It indicated that the PTTs did not see us as a client, but as a competitor... [CEPT] said 
"You're going to take our revenues away." We said, "Which revenues?" And they replied, "Telex". So, we were seen as the telex revenue eliminator... And we said "That's ridiculous! We're creating a new form of transport - the airplane - and you still want us to compensate you because we don't go by boat. You don't understand that computer based communication is the future - we want fixed rates. ${ }^{7}$

The move to restructure the tariff ${ }^{8}$ for SWIFT ran counter to the flat-rate pricing policy that the PTTs and CEPT had agreed for SITA (Société Internationale des Télécommunications Aéronautiques), a telecommunications network for the airline industry founded by major (mostly European) airlines in 1949. ${ }^{9}$ SITA had established a basis for this tariff by arguing that as an airline network the service they provided and the traffic they handled were safety critical. In contrast, Bessel Kok says, CEPT proposed charging SWIFT

a fraction of volumes. Every month we had to fill in a matrix detailing our traffic. How many messages were going from one country to another, so-called PTT statistical information, and they would send us a bill. And then, in 1976, Charlie [Reuterskiöld] had a great idea: "We will lodge a complaint at the European commission." ${ }^{10}$

SWIFT filed a complaint ${ }^{11}$ before the European Commission alleging abuse of dominant market position claiming that they were safety critical in the context of the financial services sector. After the complaint was filed, SWIFT and the PTTs reached agreement on a new method of price calculation. ${ }^{12} \mathrm{~A}$ formal EU ruling was not made but the complaint won sympathy for SWIFT and put pressure on CEPT to

at least keep the tariffs acceptable. It was difficult and a particularly European operation, the Americans did not have this problem. We really had to fight the PTTs, saying that they were protecting their monopolies and that they should open their eyes to the world. SWIFT is here to serve the development of international communication and they should not be so self-serving. ${ }^{13}$

The negotiations with CEPT highlight the movement from state-owned monopoly PPTs to private ownership of telecoms and adjacent businesses, providing insight into the role of regulators ${ }^{14}$ and the redrawing of business models. Thomas J. Ramsey cites the 1975 Community Policy for DataProcessing in which the EU Commission notes "... two contradictory trends" as the world enters "the era of distributed computing." The first trend involves the progressive creation of new opportunities for diversified 
and decentralized data-processing services. According to the Commission, this trend can continue only if the public authorities "create a framework of standards, procurement and aid which prevent monopolisation and assist this process of diversification." The second, "less attractive" trend, however, involves the progressive development by a single company of comprehensive systems and software services to meet virtually every data processing need, thereby "lock[ing] customers in for many years to come [and] severely limiting their freedom of choice." The latter trend would continue unless public authorities work to provide a favourable environment for alternative suppliers. ${ }^{15}$

As we have seen, SWIFT subsequently developed secure Internet Protocol (IP) for its communications, thus distancing themselves from these debates. However managing these boundaries with industry incumbents during their founding years marked a critical stepping stone in the establishment of a network business and global infrastructure. Discussing SWIFT's experience with the PTTs, Lázaro Campos said that the situation was: “... not atypical. We've seen it over and over again, where a customer needs to grow beyond what the existing providers can offer, and the existing providers don't see its value."16

Ironically, in the 1990s, SWIFT was itself the subject of a complaint concerning monopoly behaviour. ${ }^{17}$ La Poste applied for membership in 1994 but after having sought the advice of its French National User Group ${ }^{18}$ SWIFT turned it down on the basis that it was not a regular bank - i.e. regulated and carrying out the full range of banking functions. ${ }^{19}$ In 1996, La Poste complained to the European Commission, and in March 1997 the Commission initiated formal proceedings against SWIFT on the basis that SWIFT held a

dominant position of a monopolistic nature, since it is the only operator on the international networks for transferring payment messages and the only network to supply connections for banking establishments anywhere in the world. It therefore constitutes a basic infrastructure in its own right, since to refuse any entity access to such a network is tantamount to a de facto exclusion from the market for international transfers. ${ }^{20}$

The Commission further found that SWIFT had imposed "unjustified admissions criteria" and had applied those criteria in a discriminatory manner in the case of La Poste. ${ }^{21}$ SWIFT did not agree with these findings, but nonetheless provided a set of undertakings to the Commission to the effect that it would open admission to any institution that met the European Monetary Institute (EMI) criteria for admission to domestic payment 
systems. Based on these undertakings, the Commission considered its objections met, and the undertaking was published. ${ }^{22}$ SWIFT committed itself to creating a new category of non-shareholding financial institutions no later than its 1998 Annual General Meeting. In advance of the creation of the new category, SWIFT would give institutions meeting the EMI criteria non-discriminatory access to the SWIFT network through cooperation agreements. The Commission was to be informed of any disagreement between SWIFT's board and a national member group regarding an application for network access.

Although SWIFT originally represented a significant innovation in financial services, it has not been immune to the charge that it sometimes acts as an inhibitor to further change in the industry. Its members effectively dominate agenda-setting for the SWIFT network and its standards development. There have been phases, particularly when banks delayed expansion of membership, first to securities in the 1990s and then to corporates in the 2000s, when SWIFT was accused of stifling progress. Questions were raised about whether SWIFT's "standards development is meeting the requirements of all the constituents in the financial supply chain". ${ }^{23}$ To address this issue, SWIFT developed new categories of membership and began working more closely with the international standards bodies such as ISO.

Thus far, we have selected key "moments of interest" from the internal history of SWIFT - the PTT and LaPoste controversies, the change in membership over time, and the pressures on scope and innovation - to illustrate issues arising from its cooperative status and the challenges in managing boundaries. There is also value in considering a comparator organization to place this debate in the broader context of developments in the history of financial services and to this end we present a brief analysis of Visa, another (until recently) mutual organization in the sector. Visa facilitates electronic funds transfers throughout the world and was similarly founded as a cooperative. Its organizational form was originally designed to enable multiple, competing financial institutions to cooperate in the development of a payment service that none could have realistically provided alone in the late 1960s. ${ }^{24}$ Like SWIFT, Visa is a "high-reliability organization"25 that owns its network, sets standards, and designs the rules for operation. Until recently, Visa functioned as a non-profit membership association that developed and operates the legal, financial, and technological infrastructure necessary to facilitate the processing of payments involving multiple financial institutions. ${ }^{26}$ But even though SWIFT may share commonalities with Visa, it is also distinguished by key differences.

For example, early phases of development at SWIFT and Visa were marked by quite different experiences that patterned their governance and 
pricing strategies. The initial membership structure and governance of Visa reflected the need to overcome specific inter-organizational problems, such as non-cooperation of other financial institutions and fraud. In contrast to Visa's bumpy early years, SWIFT achieved momentum relatively straightforwardly partly due to the "burning platform" created by MARTI (see Chapter 1) and perhaps partly because it held to a more focused strategic aim supported by a bounded interest group - i.e. banks who wanted to achieve specific efficiencies and an agreed level of reliability. This shared vision meant that operational staffs belonging to SWIFT members were not only ready to implement it but also motivated to pursue follow-on programmes of change in transaction banking (process redesign, replacing internal standards with SWIFT standards) to further embed these goals. Visa had no such constituency and had to "engineer" consumer acceptance of descriptive billing if they were going to transform clearing and settlement. SWIFT had to work out pricing strategies with reluctant PTTs and proved to be ground-breaking in terms of both international regulation and multi-jurisdiction law, but these were external to issues of membership or governance.

Whereas banks rallied to SWIFT's cause, Visa became caught up in a cultural divide within American banking between the deposit and the consumer credit sides of the institutions. SWIFT appealed to the deposit side of the bank which arguably held more political sway, whereas Visa depended upon consumer credit departments who regarded it as a venture rather than a vital operational requirement. In the analysis of historian, David Stearns, ${ }^{27}$ this often made it difficult for CEO Dee Hock and the central Visa organization to convince banks to fund system development beyond fixing the immediate operational problems. While many banks were content to satisfice with electronic authorization and clearing, Dee Hock had further strategic ambition. The subsequent history of Visa's relationships with banks is marked by recurring power struggles in which it did not fare well. This hostility sometimes spilled over in comments made to SWIFT executives, such as: "You are our child and you cannot escape your parent" or "Don't do a Visa!"28 Jacques Cerveau recalls this as follows:

SWIFT suffered a little from Visa Syndrome, I would say. The banks saw Visa escaping from its creators. Visa was much more independent, running its own business with less regard for the interests of some banks. There is no doubt that when Swift was created its banks said, "Low profiles, guys, do your work in your corner and keep quiet." This was especially so among the American banks who were obsessed that Swift could take its own life. ${ }^{29}$ 
Perhaps the most significant difference between Visa and SWIFT is that organizations have a choice regarding their use of the former whereas the latter is a core infrastructure. SWIFT has become what sociologist Michel Callon terms an "obligatory passage point" 30 (i.e. if you want to participate in financial services you must join because there is no real alternative) for financial organizations around the world. SWIFT's standing as a trusted third party has grown over time and later adopters have signed up as much for the reputational value of membership as the benefits generated by the network effect created by widespread adoption. These benefits both surpass the initial goal of transaction efficiency and reinforce the value of basic connectivity. Fundamental to this is the further clarification that SWIFT has been charged by regulators to link up market infrastructures (payment systems, exchanges, and depositories).

SWIFT is also distinguished by its status as Registration Authority for the international standards body ISO (see Chapter 3). Although Visa has also been involved in standards development, SWIFT has a more formal network of standards setting. SWIFT's role as a standards repository is integral to its operation, creating a productive complementarity and fostering an extensive "community of practice". ${ }^{31}$ As banks extended their connectivity and straight-through-processing projects, SWIFT accumulated best practice documentation and made it available to members. It also supports community engagement through its annual Sibos conference (see Chapter 2).

To summarize, in comparison to Visa, SWIFT's early history was guided by a bounded and inclusive interest group with common aims, less competitive tension, and unforced momentum for a standardization agenda with a moving wall. Competition and conflicts of interest brought pressure to bear on Visa's cooperative governance, whereas SWIFT retained its status as trusted third party accountable to its members and to the industry generally. In 2006, Visa demutualized, staking out its own separate and profit-making mandate. While demutualization is currently not a burning issue for SWIFT, recent events, described in the next two sections, have implicated SWIFT in global affairs and generated debate concerning its status as a trusted third party.

\section{Data governance and the Terrorist Finance Tracking Program}

Access to communications has been a perennial source of tension between telecoms companies and the intelligence community. ${ }^{32}$ SWIFT, as a centre of communications for the financial services sector, has not been immune. For many years SWIFT was able to maintain a position as a secure third party contractually obligated to ensure confidentiality of data transmitted 
through its network. Then, in the 1990s, SWIFT was drawn into discussions about identifying and tracking illegal activity.

Lenny Schrank recalls that one of his first meetings after becoming CEO of SWIFT in 1992 was with Alexander (Alex) Karrer from the policy-making body Financial Action Task Force (FATF): ${ }^{33}$

At that time they were worried about drug money and money laundering, and wanted to work with SWIFT to improve our standards so that investigation would be easier. They wanted to work with myself and the Board rather than the members' user groups to tighten up on blank fields in payment standards and hoped that SWIFT would want to cooperate. This was when we first began to think the unthinkable: that maybe we have some data that the authorities would want, that SWIFT data would be revealed ... and what to do about it ... So we laid the basis in 1992 for how we deal with this ... no one thought about terrorism at that time.

The FATF were interested in SWIFT because a large volume of worldwide cross-border financial transactions pass through SWIFT and they wanted to explore the possibility of using that financial data (SWIFT messages) to trace illegal activities.

During the course of their discussions with the FATF in the 1990s, following an initial approach from the US government, ${ }^{34}$ SWIFT asserted that they were not allowed to disclose the content of SWIFT messages (bank data) to third parties and explained that data were only kept for a limited time. SWIFT nonetheless decided that it was appropriate to address broader concerns regarding the SWIFT message template, which at this time did not have a specific field to include originator's data. This field was subsequently included and made mandatory in the message standard, which means that its omission will cause the SWIFT system to reject the message. Except for changing the design of their message standard, SWIFT stood by its position to not enter into investigations with any third party concerning, for example, tax evasion or fraud. In this regard, they determined to distinguish themselves as a carrier of communications, not an information processor. In other words authorities should go directly to banks rather than asking SWIFT to access bank data. Via a SWIFT broadcast, banks were notified of this position, reinforced by a communication campaign reminding customers that the SWIFT network should not be used for illegal purposes and this was formally adopted as SWIFT policy in 1993. ${ }^{35}$

Lenny Schrank summed up the policy described above with the phrase: "We don't do subpoena" 36 and during these years an internal resolve crystalized to position SWIFT as a private organization subject to regulatory 
oversight. However, this stand would be tested by a watershed in global affairs. After the terrorist attacks on 11 September 2001, the US Government took a number of steps to investigate and track the flow of funds under the Terrorist Finance Tracking Program (TFTP). ${ }^{37}$ SWIFT was again approached by the US authorities and asked to cooperate. When SWIFT refused, citing its position that it is not allowed to provide bank data to third parties, the US Treasury issued subpoenas.

The writs that SWIFT received, ordering that the US Treasury be given access to facilitate traffic analysis as part of an anti-terrorist intelligence strategy, presented a situation that went beyond the parameters that had been rehearsed. Faced with an extreme scenario and legally enforceable subpoenas, SWIFT's legal team complied. Mindful of their obligations to members under other legal regimes, including the data protection laws applicable in the EU, SWIFT negotiated terms and signed a memorandum of understanding (MoU) with the US Treasury Department. ${ }^{38}$ The MoU included limitations on the Treasury's access to and use of data obtained from SWIFT, including requirements for a targeted request for limited purposes and an audited process. But neither the details of the US Government's use of legal compulsion to obtain information to track flows of suspected terrorist funds nor SWIFT's involvement in the programme were made public. ${ }^{39}$

On 23 June 2006, The New York Times and several other US newspapers published stories about SWIFT's disclosure of data to the Treasury. ${ }^{40}$ While the main point of these stories centres on civic interest, alerting the public to the US Government's access to bank customer data, SWIFT was caught up in the ensuing controversy over bank customer privacy. SWIFT quickly acknowledged a policy of cooperation with government authorities to prevent misuse of the financial system. ${ }^{41}$ The Belgian Data Privacy Commission and the EU data privacy advisory group, the Article 29 Working Party, then took up a review of SWIFT's compliance with the subpoenas. ${ }^{42}$ On 27 September, the Belgian Data Privacy Commission issued an advisory report concluding that in complying with the US subpoenas SWIFT had not fully complied with EU and Belgian data protection laws, ${ }^{43}$ and on 23 November, the Article 29 Working Party issued a similar non-binding opinion. ${ }^{44}$ SWIFT took strong issue with these findings which they argued were produced in haste after the TFTP had been made public based on an incomplete understanding of SWIFT's governance and operations. ${ }^{45}$

SWIFT's position was that, first of all, the subpoenas issued by the US Government were binding on it, so that there had been no choice about whether or not to comply. Secondly, SWIFT argued that as a data carrier and not a data processor they had not violated EU data protection laws. Thirdly, they argued that they had negotiated strong protections for the data given to the US Treasury. Overall, SWIFT noted that they were put in a 
very difficult position by the potential conflict of laws, and urged the US and European Union to reach an accommodation that would clarify the situation. ${ }^{46}$ Lázaro Campos, then SWIFT CEO, said:

We are explaining to our customers what we have done and the type of restrictions we have imposed. We've actually negotiated a very strict and elaborate scheme with the authorities - nobody has done that before. We make sure that only information relevant to on-going terrorism investigations is revealed; it is not for economic espionage, it is not for tax evasion. Many constraints have been put in place and we are sharing these with our customers. ${ }^{47}$

In early 2007, SWIFT undertook three specific operational initiatives to address the data-handling challenges that had emerged during the privacy controversy. These were: achieving Safe Harbor status for SWIFT's US operations, improving customer contract transparency, and developing systems alternatives for SWIFT's global messaging infrastructure. ${ }^{48}$ Safe Harbor status refers to meeting the requirements that have been agreed between the US Department of Commerce and the EU to provide a streamlined means for US organizations to comply with the EU Privacy Directive. ${ }^{49}$ During the course of the year, all three initiatives were completed. ${ }^{50}$ Of particular note, it was decided that the messaging infrastructure would be split into two different data zones, one for intra-European activity and located at European operating centres, and one for transatlantic or global activity located at operating centres in Europe and the US. In this way, purely intra-European messaging activity would never enter US jurisdiction. Also in 2007, the US Treasury sent to the Council of the European Union and to the European Commission a set of representations that described the controls and safeguards governing the handling, use, and dissemination of subpoenaed data under the TFTP. This set of representations, including a recommendation that there would be oversight by an "eminent European person", was accepted by the Council and the European Commission. ${ }^{51}$

In March 2008, French judge Jean-Louis Bruguière was appointed, as the "eminent European person", to review the procedures governing the handling, use, and dissemination of the SWIFT data subpoenaed by the US Treasury.52 Following his report, the EU issued an announcement in February 2009:53

Vice-President Barrot, in charge of Justice, Liberty and Security, presented today the findings to the European Parliament's Civil Liberties Committee and declared: "I am pleased to confirm that the United 
States Treasury Department has been vigilant from the outset in respecting the safeguards in the handling of personal data included in the TFTP Representations which we were able to negotiate with them back in 2007 and notably the strict counter terrorism purpose limitation. The TFTP has generated significant value in the fight against terrorism, notably in Europe."

The review focused particular attention on the core undertakings set out in the TFTP Representations, namely that SWIFT data are used exclusively for counter-terrorism purposes; that the Treasury ensures that subpoenas are narrowly focused; that searches against the TFTP database are targeted and designed to minimize extraction of data; that appropriate measures are in place to identify and delete data which are no longer considered necessary for the fight against terrorism; and that necessary physical and logical systems exist to ensure the security of subpoenaed data.

In the meantime, the Belgian Data Privacy Commission had reached a favourable conclusion (in December 2008) that SWIFT had taken appropriate steps to comply with Belgian data protection law. ${ }^{54}$ This report was informed by extensive discussions with SWIFT who undertook to explain the SWIFT system and the specific implications of its cooperative structure to them in detail. This second binding decision was much more elaborate and reversed many points in the Belgian Data Privacy Commission's initial opinion.

By January 2010, SWIFT had implemented the dual-zone messaging architecture agreed on in 2007.55 On 30 November 2010, the European Council of Ministers agreed an interim arrangement to allow continuing transfer of European data to the US. ${ }^{56}$ It was signed one day before the Treaty of Lisbon would have required European Parliament involvement prior to agreement. When the interim agreement was put before the European Parliament for consent in February 2011, it was turned down. ${ }^{57}$ In July of that year the US and the European Union entered into a revised EUUS Terrorist Finance Tracking Program (TFTP) Agreement. ${ }^{58}$ The new agreement incorporated a new role for Europol to review and control the transfer of data, an EU representative in the US to monitor data processing, a prohibition on data mining or the like, a right of redress for European citizens, and rules about data retention and deletion. ${ }^{59}$ The agreement came into effect on 1 August 2010.60

SWIFT's role as an active participant in the formulation of boundarycrossing multi-jurisdictional legislation and policy generally goes unremarked, yet it has made significant contributions to the global framework within which other organizations subsequently operate. When SWIFT was first founded many issues pertaining to the responsibility and liability for 
international transactions fell beyond the scope of existing national jurisdictional coverage and competence. Working with international agencies thus became necessary if SWIFT's operational development and integrity were to move forward. Whereas previous instances of global programmes of action have been generative and advanced SWIFT's broader mission, ${ }^{61}$ more recent calls for engagement have proved challenging, bringing it into conflict with its members, particularly with regard to its core values of infrastructure neutrality and customer confidentiality. Although many questions were asked by members at the height of the TFTP debate, perhaps the most potentially damaging was how SWIFT could reconcile its assurance of confidentiality with the decryption of messages by an external party without their knowledge. In addition to this, SWIFT's European-based members took particular offence to unknowingly becoming subject to a US subpoena when data protection legislation in EU/US jurisdictions was not aligned. The effort required to address these concerns and participate in the formulation of an international agreement was substantial.

The issues surrounding an event such as 9/11 are complex and perspectives on global security are deeply influenced by the entanglement of geographical commitment and sociopolitical experience. While many have greatly sympathized with any and all strategies that bring terrorism into check, others have needed considerable reassurance that SWIFT was acting in compliance with an internationally monitored programme rather than covertly colluding with the US Government. Throughout its history, SWIFT has worked hard to communicate a strong organizational narrative of neutrality and establish itself as the most trusted third party. It took due care to ensure that usage of data in the TFTP had oversight. Despite this a number of its members took the view that the trust they had in SWIFT did not necessarily extend to the US Government and its agencies, despite rigorous terms agreed with SWIFT.

Enforced compliance with the TFTP marks the beginning of a significant shift in terms of operational design, relationship with members, global strategy, and perspective for SWIFT. It also raises broader questions for international organizations, commercial news media, and privacy activists. Where does the appropriate balance between protecting the covert status of antiterrorist initiatives and upholding civil liberties lie? The intelligence value of the TFTP has reportedly been paralleled with the top-secret World War II code-breaking programme ENIGMA based in Bletchley Park, England which historians maintain shortened conflict by six months. ${ }^{62}$ But the intelligence staff at Bletchley intercepted and decoded a stream of messages sent by a known enemy whereas in contrast protagonists in the "war on terror" are distributed and their data are interwoven with that of others. The effectiveness of the TFTP is unlikely to be verified until the confidentiality of 
operations has been lifted and the impact of public disclosure by the media has been debated. In the meantime, and perhaps regardless of what is eventually known about the effectiveness of TFTP, it is fair to ask what is the role of the news media as whistle-blowers and guardians of civil liberties particularly in an age where they are under pressure from internet-based information sources and social media? Although calling for transparency seems noble, to quote the social anthropologist, Marilyn Strathern "in a social world where people are conscious of diverse interests ... appeal to a benevolent or moral visibility is all too easily shown to have a tyrannous side - there is nothing innocent about making the invisible visible." 63 Conversely, we also have to be conscious of how far governments will perpetuate a permanent state of emergency to justify an "anything goes" approach to data governance. ${ }^{64}$ What we can be sure about is that the TFTP has raised some difficult issues and will continue to be analyzed by practitioners and scholars alike. ${ }^{65}$

\section{Geopolitics and exclusion of Iranian institutions}

In a further example of SWIFT's entanglement with current issues and management of their position as a global institution, we turn to recent events in which they were called upon by the New York-based advocacy group United Against Nuclear Iran (UANI) to exclude Iranian institutions from their network. According to its website, UANI was founded in 2008 by US Ambassador Mark D. Wallace, the late US Ambassador Richard Holbrooke, former CIA Director Jim Woolsey, and Middle East expert Dennis Ross. Pursuant to its mission to prevent a nuclear Iran, UANI carries out what it calls private sanctions campaigns as well as legislative initiatives. ${ }^{66}$ On 30 January 2012, UANI launched what it called its SWIFT campaign with a letter to SWIFT. ${ }^{67}$

The letter alleged that "the global SWIFT system is used by Iran to finance its nuclear weapons program, to finance terrorist activities and to provide the financial support necessary to brutally repress its own people", citing SWIFT's 2010 annual report, which reported messaging traffic with 19 Iranian member banks and 25 Iranian connected institutions. UANI argued that SWIFT's role in the Iranian financial system violated US and European Union sanctions laws, in particular the US Comprehensive Iran Sanctions, Accountability and Divestment Act of 2010 ("CISADA"). ${ }^{68}$ On 2 February 2012, the US Senate Banking Committee passed legislation that would permit the imposition of sanctions on SWIFT if it continued to provide services to the Iranian financial institutions on its campaign list. ${ }^{69}$

SWIFT attracted media criticism from some quarters as this excerpt from The Wall Street Journal illustrates, arguing that SWIFT was: 
$\ldots$ one of the most critical access cards Iran still holds to the global financial system. SWIFT's annual report notes that 19 Iranian banks and 25 Iranian institutions use SWIFT, and that in 2010 they "sent $1,160,000$ messages and received 1,105,000 messages." Primary Iranian users of SWIFT's services include Banks Mellat, Sepah, Saderat, Post, and Iran's central bank - all of them designated by the U.S. Treasury as affiliates of Iran's Revolutionary Guards Corps, involved in aiding Iran's nuclear programs, or sponsoring terrorism. Under its own bylaws, SWIFT has the authority to expel any user of its products who "has adversely affected, or may adversely affect ... SWIFT's reputation, brand, or goodwill, for instance if the prospective or existing user is subject to sanctions." 70

SWIFT responded with a press release on 2 February, saying that it operated under regulatory oversight and was in compliance with all sanctions regulations:

SWIFT remains committed to maintaining its role as a neutral global financial communications network, as well as continuing to comply with all relevant sanctions laws in the jurisdictions in which it operates while also assisting financial institutions to do so. ${ }^{71}$

A few days later, SWIFT went further to give assurance that it understood the seriousness of the issues being raised by the Senate Banking Committee proposed legislation, that it was committed to "the global battle on terrorist financing", and that it was working with US and European Union governmental authorities, as well as G10 central banks, "to find the right multilateral legal framework which will enable SWIFT to address the issues." 72 By 17 February, SWIFT announced that it stood ready to implement whatever sanctions structure emerged from the ongoing discussions between the US and the EU. ${ }^{73}$

On 15 March, there was an EU Council decision that amended existing Iran sanctions to prohibit the provision of financial messaging services to identified sanctions institutions, followed up with a Council regulation on 23 March. ${ }^{74}$ Since "EU regulation is legally binding on the private sector" and in this instance "prohibits specialized financial messaging providers from offering its services to listed Iranian entities", 75 SWIFT complied confirming that it would cut off the sanctioned institutions. Lázaro Campos, the serving CEO of SWIFT, said "Disconnecting banks is an extraordinary and unprecedented step for SWIFT. It is a direct result of international and multilateral action to intensify financial sanctions against Iran." 76 
This resolution, whereby identified EU-sanctioned institutions were cut off from the SWIFT network, did not amount to the wholesale isolation of Iran sought by some in the US Congress. The US Iran Threat Reduction and Syria Human Rights Act of 2012, signed 10 August 2012, required the US Treasury to report on financial messaging services (such as SWIFT) on the basis that they might be doing business with Iran, and authorized but did not mandate the President to impose sanctions on such services under CISADA. The law effectively defers to the EU so long as its list of sanctioned institutions is "substantially similar" to the US list, which puts some pressure on the alignment of US and European Union sanctions policies toward Iran. ${ }^{77}$ When asked to comment on these events, current SWIFT CEO Gottfried Leibbrandt said:

As a result of European legislation, we disconnected 24 Iranian banks earlier this year. The US recently passed similar legislation mandating financial messaging networks to disconnect the Iranian banks on that list. For us this has been a watershed event because we have always maintained the position that we are like the internet -we connect everybody and we do not listen in on the conversation - and the banks have to make sure they comply with sanctions in terms of what they send over the network. ${ }^{78}$

After Iranian institutions were cut off from the SWIFT network in March 2012, two developments have called into question the use of denial of access to the SWIFT network as an "economic weapon". The first is the ability of Iranian organizations to challenge their status as sanctioned institutions on the EU list. ${ }^{79} \mathrm{~A}$ second is the ability of Iranian banks and other businesses to find other ways to move funds. ${ }^{80} \mathrm{~A}$ further remaining question is the consistency with which regulatory action such as this is applied - for example, whether other service providers will be called upon to take similar steps. ${ }^{81}$ As Blanche Petre, SWIFT General Council put it, "Denying access to SWIFT is for us not only an economic tool, but also a political one. In addition, the risks of reusing SWIFT for sanctions purposes (loss of neutrality, fragmentation and so on) should not be underestimated." 82

When studying SWIFT's governance, the term neutrality is regularly used in the sense of "levelling the playing field." While membership is restricted to specific classes of financial institutions the criteria used are publicly available and applications are checked by committee. Board representation is proportional and calculated by a standard formula. This is what SWIFT's Chairman, Yawar Shah, means when he says that "Neutrality is in SWIFT's DNA." But here we have a different cut through the notion of neutrality, one that is tied to the current phase of globalization in which risk, 


\section{6}

blame, and responsibility are distributed in ever more complicated ways. Whose responsibility is it if Iran develops nuclear capability? What is the role of information infrastructures in regulation and national political programmes? 83

Being identified as a global organization that is central to the operational integrity of the world does not lead to the comfortable "establishment" position that characterized the dignity of gentleman bankers in previous eras but rather entails the ongoing management of complex and unexpected risk. ${ }^{84}$ This catalogue of risk may present challenges to SWIFT's current membership, organizational form, and governance structure. SWIFT performs a critical function by providing worldwide payments services and it is in the interest of governments to protect this operational role and the integrity of the core infrastructure. Whereas regular in-sector debates focus on whether SWIFT can rise to the evolving needs of financial services, an open question has now been raised about whether it can maintain political integrity once it is drawn into sanctions. For example, do commercial organizations want to have an overt stake in these broader notions of risk and reward or the outcome of specific political usage? Continued use of sanctions might cause some commercial concerns to cede membership and reconsider participation in order to avoid becoming entangled in geopolitics that may limit their strategic opportunities in international business.

In 2012, former SWIFT CEO, Lázaro Campos, gave his perspective of what might follow from this highly pressurized moment of interest in which he felt:

Global organizations are now a species in extinction. I think that the extra-territorial nature of some of the legislation we're seeing in the US, and now increasingly in Europe, makes it almost impossible for global companies to continue to be global, because we end up being a tool for politicians. So I think this may be the end of the global organization. And it's not just about financial services, it's everybody... maybe the global company disappears to give way to structures, similar to the Internet, where you have local structures that actually coexist, or that have a common thread through DNS, through domain name arrangements that basically do the routing, and the interconnection in between the locals. And that maybe is the way of the future. But I think global organizations are going to have difficulties maintaining the value they deliver to the community, because they are going to be misused. ${ }^{85}$

Sanctions have changed the value proposition of SWIFT in a way that potentially transforms the nature of its mission and associated issues of trust, stakeholder perception of governance, strategic options, and the business 
model underpinning them. During his annual address to the assembled financial community at Sibos in the early 1990s, CEO Lenny Schrank would present SWIFT's increasing member rebates as a key performance indicator. His aim was to gain credibility by focusing on service quality, becoming more competitively priced, and improving the governance of the company ${ }^{86}$

In 1996, he announced that SWIFT would be repositioning itself from "a lowest-common-denominator utility for delivering payment messages" to the broader strategic priorities of "risk management and reduction; reengineering the back office; and assisting with the development of banking strategies for the 21st century." 87 SWIFT has engaged in many initiatives with lasting significance in all these areas (for example CLS, securities standards, IP network technology, infrastructure connectivity, and trade services). While these projects posed challenges of their own, particularly judging the shift to game-changing internet technologies, they characterize a time of "insurmountable opportunities" ${ }^{88}$ This historical reflection reminds us of the degree to which the complexity of achieving advances in each of these areas has amplified risk management and reduction as a priority, now not referring only to in-sector calculations of operational and market risk but also encompassing the dynamic broader political context. The question of how far this will influence SWIFT's identity and strategy as a global institution remains open but its management felt the challenges acutely as illustrated by this comment by Lázaro Campos:

On one side, the Western world wants the East to come in and join the system. But at the same time they're using, misusing the system to implement their own geopolitical objectives... We are going to have to choose. You're either a Western company with global ambitions. Or you are Eastern, or you are unaligned. If you are unaligned - you cannot be global anymore.

As noted in Chapter 1, SWIFT gained critical mass and global usage because it was the most diplomatic solution to a political situation. Indeed, assuming co-opetition as a modus operandi implies a long-term commitment to politicking. Except during its initial start-up phase, SWIFT's management portfolio has been diverse. Its many stakeholders each have a different perspective defined by their position, relationship, and dependency on SWIFT: standards body and ISO agent; global network with resilience responsibilities; convener for innovation projects; Sibos conference organizer; and regulator-mandated infrastructure. Indeed, one of the proposals put forward for the name of SWIFT's commemorative fortieth anniversary compilation was Kaleidoscope: a single entity embodying multiple perspectives. 
Over the years, despite charges of fragmentation that have been levelled, SWIFT has maintained coherence and created a "grand narrative" about itself as the world's foremost secure trusted third party. The issue of sanctions represents a challenge to this and puts pressure on SWIFT's identity in new and different ways that are still unfolding. Having noted some of the stakeholder concerns raised by sanctions, we should also note the opportunities and innovations that have emerged both from the process of negotiation and the environment that has been created, such as SWIFT's recent interest in further developing products and services for multiple authentication methods and sanctions screening.

To paraphrase the sociologist, John Law, "with such losses there are also gains and the hope is that giving up big narratives that seek to order the whole does not mean losing rigor but rather presents an opportunity to know something differently." 89 The nature of SWIFT's multiplicity (whether metaphorical kaleidoscope, rhizome, or puzzle) changes depending on the position from which the analysis is undertaken but one thing that stays the same is the world-making significance of both SWIFT and the issues with which it is currently wrestling for the next phase in the history of globalization. The complexities of the situation are summed up by Gottfried Leibbrandt as follows:

It is a difficult world we are entering into, because clearly sanctions are by nature divisive and our role is to serve the global community. And we are not alone - many of the global banks are facing the same issues. If the sanctions were backed by the UN it would be simpler than if they are backed by Europe and the US but without, say, Russia and China... If the sanctions remain limited in scope, then the impact should be minimal. But if we become the tool of choice for imposing sanctions on a whole series of countries, then we really are on a road we think is not conducive to the global banking system. ${ }^{90}$

\section{Globalization, semi-globalization, and geopolitics}

Robert Merton says that " $[t]$ he primary function of the financial system is to facilitate the allocation and deployment of economic resources, both spatially and across time, in an uncertain environment." 91 The discussion above illustrates that the need to develop strategies for managing risk during uncertain times has accelerated. As globalization has unfolded, we have become entangled in ever more complex relations. We have learned that while communication technologies have contributed to our sense of the world as a global society, termed "globality" 92 by sociologists, this does not 
imply that we live in a world without difference. The history of SWIFT traces the development of globalization in interesting ways from its foundation as a transnational cooperative society to international network and gradual institutionalization as a global service entity.

Many references made to SWIFT as the "plumbing" of financial services tend to overlook the nuances of its current position. However, in order to make the argument that SWIFT is a strategic entity we have to consider what we mean. If we define strategy as planned or premeditated calculation then, when viewed from a historical perspective, SWIFT has far exceeded any formal plans drawn up by its founders. As one of the participants of the original scoping study for SWIFT in the 1970s, Alec Nacamuli, says he "couldn't be happier"93 to know that his prediction for maximum message volumes of 300,000 per day has been overtaken (currently daily traffic is almost 20 million). ${ }^{94}$ Focused on an immediate problem and the initial technological challenge of implementing an international network, its founders could hardly have foreseen the network effect that SWIFT generated in the ensuing forty years. Nor was it apparent when standards groups began to gather and training programmes were formulated that SWIFT's developmental role would lead to its standards becoming so widely integrated in market practices.

In order to understand the potential positioning of SWIFT going forward we need to pause to consider the momentum of financial globalization. The particular dialectics at work put pressure on nations to make their institutions more like each other in ways that support the internationalization of business but at the same time evoke, if not provoke, the distinctiveness of nations. ${ }^{95}$ This has contradicted predictions that globalization would lead to the "flattening of the world" 96 in which differences between nations would be washed away and global homogenization would take its place. The volume of international business has risen, facilitated by global finance and ever-freer cross-border movement of goods and investments. But while national markets have been permeated by global brands, we have not witnessed the "MacDonaldization of the world." $"$ "It follows that while financial globalization has created some distinctive pressures for convergence, which mean we expect certain corporations to work in similar ways according to a shared interpretation and enforcement of rules, national policy makers still want to organize their national economies in ways that make sense to them in their local context. ${ }^{98}$

SWIFT is a contributor to international regulatory and legal frameworks as well as a repository for standards and practitioner "best practice". Thus it plays a role in making national institutions and professions more like each other. It has also maintained a strong local presence from the start, in many ways making its approach to international business management 
prototypically "glocal" 99 by threading its global structure with local representatives and user groups. Yet despite being well practised in managing an international community, Lázaro Campos says the 2000s "forced us to rethink what local meant." 100 Regionalization became an emerging characteristic. In 2007, then CEO Lázaro Campos told industry press:

I will regionalise everything that I can... I do not want any customer to be waiting for a headquarters decision. I am putting decision making as close to the customer as I can. And, in so doing, I am expecting the regions to be more active and effective at letting us know what customers really need. So, expect to see a good marriage between the development of global solutions and local flavour. ${ }^{101}$

This approach would seem to resonate with scholarly debates at this time around the notion of "semi-globalization."102 For example, citing data to support his argument, Pankaj Ghemawat suggests that businesses should develop strategies based on close study of multiple kinds of difference (cultural, administrative, geographic, and economic) between nations and the bridges that draw together economic regions. Certainly, as experts in developing international standards, SWIFT is well acquainted with the fact that business people tend to overestimate levels of cross-border integration.

Reflecting on this, in 2011, Gottfried Leibbrandt maintained that semiglobalization did not go far enough as a basis for building products and services:

We have found that many assumptions about geographical regions are Western inventions. For example, Asia is not a region, it is an area dominated by a number of very large countries that try to do things together. If these countries want to build connectivity, will they develop infrastructures themselves or use SWIFT? For us, the next logical step is to become relevant on a local basis. We are a cooperative, so that will include offering them a seat at the table. So this will not be a Western firm that goes East. This is a global firm. If we go to India, that means we become Indian. That has always been our philosophy. So we are currently working on how to do that. ${ }^{103}$

The extent to which the geopolitics in current global affairs and changes in representation on the Board will shift the centre of SWIFT's organizational gravity remain to be seen. Inevitably, much depends on the value propositions that can be formulated to support the strategic options ahead. Considerable effort is being made to identify distinctive products and services that turn the tensions and frictions characterizing this phase of 
globalization into opportunities. For example, SWIFT is trying to use its position at the core of the financial services community to help customers minimize the diversity of systems that they have to interact with by creating a single window approach to connectivity and standardization: "I connect to Swift, and Swift gives me the world ... using tools that give me the local world and the global world."'104

\section{Conclusion}

In this chapter, we examine selected "moments of interest" to explore the proposition that SWIFT's development and organizational progress is intertwined with the history of globalization. In the 1970s, the major technological challenge of the day was designing, developing, and implementing a private secure communication network capable of achieving global usage. This faced a significant institutional challenge when Post Telegraph and Telecom authorities attempted to impose prohibitive tariffs. SWIFT's negotiations with the PTTs illustrate the difficulties experienced by many network industries when trying to navigate between supporting diffusion in order to expand business and attempting to retain control over emerging value centres. Both the Terrorist Finance Tracking Program and the campaign by UANI to exclude Iranian institutions from the SWIFT system highlight the complicated way in which risk, blame, and responsibility are distributed in this phase of globalization. In our discussion, we draw attention to the complexity that surrounds contemporary global entities and provide examples of different ways in which one such institution, SWIFT, has attempted to position itself.

\section{Notes}

1 Andrew Copon and Jacqueline S. Gold, “Accelerating SWIFT", Institutional Investor, 35 (9) (2001): 141-4.

2 Examples of industry commentary on Heidi Miller's speech can be found in Chris Skinner, "Does SWIFT have a future?" The Banker, 1 September 2005; Frances Maguire, "Transformation is key", The Banker, 1 September 2005; Dan Barnes, "Is Swift living in the past?" The Banker, 1 October 2006.

3 There are alternatives to SWIFT (for example, IdenTrust, BT Radianz, and BT SettleNET) but they tend to operate in niche areas and do not have equivalent critical mass or global usage. More generally, the "Internet" is positioned as a potential competitor. However, while Lenny Schrank told journalists in 2001: "I can see a dozen scenarios that have us going out of business by 2010 . I really worry about the future of SWIFT" (Copon and Gold, "Accelerating SWIFT") by 2006, Lenny Schrank's assessment appeared to have shifted: "The internet is a stick with which to beat SWIFT rather than serious competition" ("Prospect of new boss gives SWIFT chance to accelerate" The Banker, 1 August 2005). One 
of the fundamental key differentiators between SWIFT and sending a message via the internet is that SWIFT accepts liability (see note 7 in the Introduction to this book).

4 Andrew Douglas (interviewed by Susan Scott and Markos Zachariadis [in person], London, 30 January 2012).

5 Lázaro Campos, "Swift answer to the detractors", The Banker, 1 September 2008.

6 "Swift - Q\&A - Gottfried Leibbrandt", The Banker, 1 October 2012 (see also Chapter 2).

7 Bessel Kok (interviewed by Susan Scott [in person], Prague, 24 April 2012).

8 According to the calculations that SWIFT presents in the EU complaint based on a 100 percent operational network (350,000 messages per day), the tariff proposed by SWIFT at 60 percent of a flat tariff plus a variable charge based on message volume resulted in an aggregate increment of 435 percent over the flat tariff (or 5.35x), ranging from 1.9x for Belgium to 21.99x for Great Britain. While SWIFT had estimated a cost of 0.70 Belgian francs per message, the tariff imposed a cost of 1.55 Belgian francs per intra-Europe message and 8.40 Belgian francs per trans-Atlantic message.

9 Notes about the history of SITA can be found on the SITA website (www.sita. aero/about-sita/what-we-do/sita-history).

10 Bessel Kok (interviewed by Susan Scott [in person], Prague, 24 April 2012).

11 The complaint is addressed to Monsieur E. Noël at the Secrétaire General de la Commission des Communautés Européennes from Bessel Kok (Finance Director) and Charles Reuterskiöld (General Manager). It cites the following PPTs assembled under the auspices of CEPT: La Régie des Télégraphes et des Téléphones (Belgique); Generaldirektoratet for Post-og Telegrafveesenet (Ministeriet for Offentlige Arbejden) (Danemark); Le Ministère des Postes et Télécommunications, Direction Générale des Télécommunications (France); Die Deutsche Bundespost (Der Bundesminister für das Post-und Fernmeldewesen) (République Fédérale Allemande); Ministero Poste e Telecommunicazioni (Italie); L'Administration des Poste et Télécommunications du Grand Duché de Luxembourg (G.D. de Luxembourg); Staats-bedriif der Posterijen Telegrafie en Telefonie (Pays-Bas); The British Post Office (Grande Bretagne); Das Bundesministorium für Verkehr, Generaldirektion für die Post- und Telegraphenverwaltung (Autriche); Ministère des Poste, Télégraphes et Téléphones de Finlande (Finlande); Televerkets Contralförvaltning (Suède); Direction Générale des Telecommunications de Norvège (Norvège); Entreprise des Poste, Téléphones et Télégraphes Suisses (Suisse). It begins by stating: "Nous avons l'honneur de presenter à l'article 3, para. 2, b) du Règlement n 17 du 6 février 1962, une demande à l'effet de faire constater par la Commission une infraction aux dispositions des articles 85 et 86 du Traité de Rome" ("SWIFT/PTT," accessed from the SWIFT legal archive, La Hulpe, Belgium).

12 See Faculty of Law, Centre de Recherche Information, Droit et Société, Université de Namur, Droit Européen et Droit Supranational, Communications Law, 170-1 (alexandrie.droit.fundp.ac.be/GEIDEFile/6776.pdf?Archive=1939 77991115\&File=6776_pdf); Eli Noam, Telecommunications in Europe (New York: Oxford University Press, 1992); William James Adams, ed., Singular Europe: Economy and Polity of the European Community after 1992 (Ann Arbor, MI: University of Michigan Press, 1992); Thomas J. Ramsay, "Europe responds to the challenge of the new information technologies: a teleinformatics 
strategy for the 1980s", Cornell International Law Journal, 14 (1981): 237-85; Joseph P. Markoski, "Telecommunications regulations as barriers to the transborder flow of information", Cornell International Law Journal, 14 (1981): 287-331.

13 Bessel Kok (interviewed by Susan Scott [in person], Prague, 24 April 2012).

14 "The European Commission's growing role in telecommunications followed two paths that can easily be at tension with each other: antimonopoly policy and industrial policy. The antimonopoly actions, in addition to the repeatedly mentioned British telex case, which involved the abuse of BT's dominant position by imposing restrictions on telex message-forwarding agencies, also soon included challenges to the following: the Bundespost's intent to extend its monopoly to cordless telephones; the extension of the Luxembourg broadcaster to telemarketing into neighbouring markets; the Bundespost's exclusive marketing and ownership of computer modems; the extension of the Belgian RTT monopoly to include medium-sized PBXs; excessively long-term leasing contracts for telephone equipment; and IBM's extension of its Systems Network Architecture for interconnecting computers and other equipment (requiring it to publish formats and protocols)... the PTTs' joint Managed Data Network Services project, and the price cartel in international telephone rates and in leased line tariff principles. An example of the E.C.'s successful action involved the pricing of international lines leased to SWIFT, the international interbank electronic transfer network. CEPT had repeatedly changed the rules applied to SWIFT with the aim of recouping revenue lost to telex service. SWIFT, not a meek organization itself, lodged a complaint with the commission charging a price cartel and abuse of individual and collective dominance. Negotiations then took place that ultimately resulted in the lowering of its rates" (Eli Noam, Telecommunications in Europe: 305-6).

15 Ramsay, "Europe responds". Ramsey cites Commission of the European Communities, Community Policy for Data-Processing, Doc. COM (75) 467 final 2 (1975).

16 Lázaro Campos (interviewed by Susan Scott and Markos Zachariadis [in person], La Hulpe, Belgium, 17 February 2012).

17 Official Journal of the European Commission, 97/C 335/03, Case No. IV/36.120-La Poste/SWIFT + GUF, 6 November, 1997.

18 SWIFT has made several attempts to produce a universal definition of a bank "without success... the concept of compliance with local laws and regulations" was therefore introduced which makes them reliant on input from National User Groups (personal email communication with Blanche Petre, 22 December 2013).

19 Brigit Gavin, The European Union and Globalisation: Towards Global Democratic Governance (Cheltenham and Northampton, MA: Edward Elgar, 2001): 132-3; see also Takis Tridimas, "Community agencies, competition law, and ECSB initiatives on securities clearing and settlement", in Yearbook of European Law 2009 (28) eds Piet Eeckhout and Takis Tridimas (Oxford: Clarendon Press, 2010): 216-307, 299.

20 European Commission, Report on Competition Policy (1997): 26.

21 Ibid.

22 Official Journal of the European Commission, 97/C 335/03, case no. IV/36.120-La Poste/SWIFT + GUF, 6 November 1997. 
23 "The evolution of global payments", Dialogue Magazine (SWIFT Publication, 2005) Q2: 20. The material in this section updates the content in our earlier journal article: Susan V. Scott and Markos Zachariadis, "Origins and development of SWIFT, 1973-2009”, Business History, 52, (3) (2012): 462-83.

24 Details on the history of Visa are from David L. Stearns, Electronic Value Exchange: Origins of the Visa Electronic Payment System (London: SpringerVerlag, 2011). We are grateful to David Stearns for his comments on a draft of Scott and Zachariadis, "Origins and development" written for a special issue of Business History on not-for-profit financial institutions.

25 Todd R. LaPorte and Paula M. Consolini, "Working in practice but not in theory: theoretical challenges of 'high-reliability organizations"', Journal of Public Administration Research and Theory, 1, (1) (1991): 19-48.

26 Stearns, Electronic Value Exchange.

27 Ibid.

28 Such comments were noted by both Bessel Kok and Alec Nacamuli in our interviews.

29 Jacques Cerveau (interviewed by Susan Scott [in person], Paris, 13 February 2012).

30 Michel Callon, "Elements of a sociology of translation: domestication of the scallops and the fishermen of St Brieuc Bay", in Power, Action and Belief: A New Sociology of Knowledge? ed. John Law (London: Routledge, 1986): 196233.

31 Jean Lave and Etienne Wenger, Situated Learning: Legitimate Peripheral Participation (Cambridge: University of Cambridge Press, 1991).

32 See Whitfield Diffie and Susan Landau, Privacy on the Line (Boston, MA: MIT Press, 2010).

33 "The Financial Action Task Force (FATF) is an inter-governmental body established in 1989 by the Ministers of its Member jurisdictions. The objectives of the FATF are to set standards and promote effective implementation of legal, regulatory and operational measures for combating money laundering, terrorist financing and other related threats to the integrity of the international financial system. The FATF is therefore a 'policy-making body' which works to generate the necessary political will to bring about national legislative and regulatory reforms in these areas" (see http://www.fatf-gafi.org/pages/aboutus/).

34 Details in this paragraph are from a personal email communication with Blanche Petre, 26 May 2013.

35 SWIFT archive, broadcast no. S1665, 30 July 1992: "Urgent. S.W.I.F.T. notification, general from: Chairman of the Board. S.W.I.F.T. S.C. Money Laundering Financial Action Task Force. As you will know many countries are involved in initiatives to prevent the utilisation of the banking system and financial institutions for the purpose of money laundering. They are also considering additional preventative efforts in this field. S.W.I.F.T. has now been asked by, and agreed, with the inter-governmental money laundering Financial Action Task Force to give following notice to all S.W.I.F.T. users and we would request you to follow this advice. Ensure when you send MT100 messages that: (A) Field 50 is completed with the name and address of the ordering customer or, when this is not possible, the account number, and (B) Field 59 is completed with the name, address and, where possible, the account number of the beneficiary customer. Eric C. Chilton. Chairman of the Board, S.W.I.F.T. S.C." This was subsequently followed up by a memo dated 30 October 1992 from CEO, Lenny Schrank to 
board members, national group chairpersons, and user group chairpersons asking them to ensure that "appropriate executives" in banks were "made aware of this important matter". The FATF company policy was documented in SWIFT board paper BP568 and approved at 106th board meeting held on 17/18 March 1993.

36 A subpoena is a mandatory request, with penalties for non-compliance, in the form of a writ or order from an authority (such as a court or government authority) for someone (or a company representative) to either appear in person and/or to provide data, documents, or information to that authority (see Black's Law Dictionary for further details). The quotation by Lenny Schrank is from our interview with him [in person] in La Hulpe, Belgium, 19 April 2012.

37 Information about the Terrorist Finance Tracking Program is available on the website of the US Treasury (US Department of the Treasury, Resource Center Terrorist Finance Tracking Program, www.treasury.gov/resource-center/terroristillicit-finance/Terrorist-Finance-Tracking/Pages/tftp.aspx) and on the website of the European Commission Home Affairs, Terrorist Finance Tracking Programme (ec.europa.eu/dgs/home-affairs/what-we-do/policies/crisis-and-terrorism/tftp/ index_en.htm).

38 SWIFT, private internal MOU.

39 As the dialogue with the FATF shows, SWIFT has had a longstanding commitment to working with authorities such as central banks, treasury departments, law enforcement agencies, and international organizations to combat the use of the financial system for illegal activities balanced with its position to protect data confidentiality. On their website, SWIFT states: "Given its importance in the financial community, SWIFT cooperates in good faith with authorities in the fight against illegal activities... Users are urged to take all reasonable steps to prevent any misuse of the SWIFT system... The conditions under which SWIFT complies with requests from authorities to produce data and informs its customers are set forth in the SWIFT Data Retrieval Policy... Due to the confidential nature of the contacts with authorities and due to non-disclosure or other legal requirements, SWIFT does not comment on them" (http://www.swift.com/ about_swift/legal/fighting_illegal_financial_activities?rdct=t).

40 Eric Lichtblau and James Risen, "Bank data is sifted by US in secret to block terror", The New York Times, 23 June 2006; Glenn R. Simpson, "US Treasury tracks financial data in secret program", The Wall Street Journal, 23 June 2006; Josh Meyer and Greg Miller, "Secret US program tracks global bank transfers", The Los Angeles Times, 23 June 2006; Barton Gellman, Paul Blustein, and Dafna Linzer, "Bank records secretly tapped", Washington Post, 23 June 2006.

41 SWIFT press release, 23 June 2006.

42 SWIFT press release, 25 August 2006.

43 Belgian Privacy Commission advisory opinion, 27 September 2006 (www. privacycommission.be/sites/privacycommission/files/documents/avis_ 37_2006_0.pdf).

44 Article 29, Working Party press release, 23 November 2006 (hec.europa.eu/justice/policies/privacy/news/docs/PR_Swift_Affair_23_11_06_en.pdf).

45 Personal email communication with Blanche Petre, 12 May 2013.

46 SWIFT press releases, 28 September, 4 October, 8 October, and 16 November 2006.

47 Barnes, "Is SWIFT living in the past?"

48 SWIFT press releases, 29 March and 15 June 2007. 
49 Information is available on the website of the US Department of Commerce (US Department of Commerce, Welcome to the U.S.-EU Safe Harbor, export.gov/ safeharbor/eu/eg_main_018365.asp).

50 SWIFT press releases, 15 June, 20 July, and 4 October 2007.

51 Official Journal of the European Union, C166, Vol. 50, 20 July 2007, Notices 2007/C 166/08-11.

52 SWIFT press release, 11 March 2008.

53 Europa press release, 17 February 2009 (europa.eu/rapid/press-release_IP-09264_en.htm\#fnB1).

54 SWIFT press release, 10 December 2008; see Belgian Privacy Commission decision, 9 December 2008 (www.privacycommission.be/sites/privacycommission/files/documents/swift_decision_en_09_12_2008.pdf).

55 SWIFT press release, 11 February 2010.

56 Simon Taylor, "EU agrees new bank data deal with the US", European Voice, 11 November 2010 (www.europeanvoice.com/article/2009/11/eu-agrees-newbank-data-deal-with-us/66563.aspx); Council Document 16110/2009 (eurocrim.jura.uni-tuebingen.de/cms/en/doc/1159.pdf); see also Eurocrim-Database, "Agreement between the European Union and the United States of America on the processing and transfer of Financial Messaging Data from the European Union to the United States for the purposes of the Terrorist Finance Tracking Program" (eurocrim.jura.uni-tuebingen.de/cms/en/vorgang/219/).

57 European Parliament press release, "SWIFT: European Parliament votes down agreement with the US", 11 February 2010 (www.europarl.europa.eu/sides/ getDoc.do?language=en\&type=IM-PRESS\&reference=20100209IPR68674,3); James Kanter, "Europe rejects US deal on bank data", The New York Times, 11 February 2010.

58 SWIFT press release, 8 July 2010; see also Official Journal of the European Union, L195, Vol. 53, 27 July 2010.

59 European Parliament press release, "Parliament examines SWIFT II agreement", 2 July 2010 (www.europarl.europa.eu/sides/getDoc.do?language=en\&type=IMPRESS\&reference=20100205BKG68527).

60 The agreement can be accessed on the website of the US Treasury (www.treasury.gov/resource-center/terrorist-illicit-finance/Terrorist-Finance-Tracking/ Documents/Final-TFTP-Agreement-Signed.pdf) and on the website of the European Commission Home Affairs on the Terrorist Finance Tracking Program (TFTP) (eur-lex.europa.eu/LexUriServ/LexUriServ.do?uri=OJ:L:2010:195:000 5:0014:EN:PDF).

61 For example, SWIFT found itself a key contributor to UNCITRAL (United Nations Commission on International Trade Law). In particular, SWIFT rules were referred to in the formulation of UNCITRAL model law on international credit transfer.

62 For a recent analysis of this intelligence operation, see Christopher Grey, Decoding Organization: Bletchley Park, Codebreaking and Organization Studies (Cambridge: Cambridge University Press, 2012).

63 Marilyn Strathern "The tyranny of transparency", British Educational Research Journal, 26, (3) (2000): 309-21.

64 See Richard A. Posner, Not a Suicide Pact: The Constitution in a Time of National Emergency (Oxford: Oxford University Press, 2006).

65 Further comment and analysis can be found in John R. Crook, "EU Parliament approves revised United States-European Union SWIFT agreement", The 
American Journal of International Law, 104, (4) (2010): 659-61; Marieke de Goede, "The SWIFT affair and the global politics of European security", JCMS: Journal of Common Market Studies, 50 (2) (2012): 214-30; Gloria González Fuster, Paul De Hert, and Serge Gutwirth, "SWIFT and the vulnerability of transatlantic data transfers", International Review of Law, Computers and Technology, 22, (1-2) (2008): 191-202; Erwin Jacobs, "SWIFT privacy: data processor becomes data controller", Journal of Internet Banking and Commerce, 12 (1) (2007): 1-5; Christian Kaunert, Sarah Leonard, and Alex MacKenzie, "The social construction of an EU interest in counter-terrorism: US influence and internal struggles in the cases of PNR and SWIFT", European Security, 21, (4) (2012): 474-96; Sylvia Kierkegaard, "US war on terror: EU SWIFT(ly) signs blank cheque on EU data", Computer Law and Security Review, 27, (5) (2011): 451-64; Joerg Monar, "The rejection of the EU-US SWIFT Interim Agreement by the European Parliament: a historic vote and its implications", European Foreign Affairs Review, 15 (2010): 143-51; Ariadna Ripoll Servent and Alex MacKenzie, "Is the EP still a data protection champion? The case of SWIFT", Perspectives on European Politics and Society, 12, (4) (2011): 390406; Ariadna Ripoll Servent and Alex MacKenzie, "The European Parliament as a 'norm taker'? EU-US relations after the SWIFT agreement", European Foreign Affairs Review, 17 (2/1) (2012): 71-86; Mara Wesseling, Marieke de Goede, and Louise Amoore, "Data wars beyond surveillance", Journal of Cultural Economy, 5, (1) (2012): 49-66.

66 United Against Nuclear Iran, mission statement (www.unitedagainstnucleariran.com/about/mission).

67 Details of the United Against Nuclear Iran Swift Campaign can be found at http://www.unitedagainstnucleariran.com/swift. The letter to Yawar Shah (Chairman of the Board of Directors) dated 30 January 2012 was copied to 115 other recipients including SWIFT executives, governors of central banks, settlement organizations, international financial organization (OECD, IMF, etc.), banking authorities, US Senators, US Representatives, and US Congressional committee members (e.g. Homeland Security, Foreign Relations, Foreign Affairs, Armed Services) (http://www.unitedagainstnucleariran.com/sites/ default/files/IBR\%20Correspondence/UANI_Letter_to_SWIFT_013012.pdf). The second letter to Board Members dated 31 January 2012 can be found at http://unitedagainstnucleariran.com/sites/default/files/IBR $\% 20$ Correspondence/UANI_Letter_to_SWIFT_Board-Members_013112.pdf. The letter was addressed to Stephen Zimmerman (UBS AG) and copied to 46 other recipients including SWIFT executives, payments executives at major banks, representatives from other financial services institutions (e.g. Clearstream), US Senators, US Representatives, and US Congressional committee members (e.g. Homeland Security, Foreign Relations, Foreign Affairs, Armed Services).

68 See US Department of the Treasury, CISADA: "The New US Sanctions on Iran" (www.treasury.gov/resource-center/sanctions/Programs/Documents/CISADA_ english.pdf); more generally, US Department of the Treasury, Resource Center Iran Sanctions (www.treasury.gov/resource-center/sanctions/Programs/Pages/ iran.aspx).

69 US Senate Committee on Banking, Housing and Urban Affairs, Johnson, Shelby Hail Committee Passage of Bipartisan Iran Sanctions Legislation (www.banking.senate. gov/public/index.cfm?FuseAction=Newsroom.PressReleases\&ContentRecord_ id=3ECF9A86-FB47-F18A-EE14-1AA86D4A8B07). See also Robert Menendez 
press release, "Menendez hails banking committee passage of Iran sanctions legislation", 2 February 2012 (www.menendez.senate.gov/newsroom/press/menendezhails-banking-committee-passage-of-iran-sanctions-legislation).

70 Anonymous, "Swift sanctions on Iran," Wall Street Journal, 1 February 2012.

71 SWIFT press release, 2 February 2013.

72 SWIFT press release, 5 February 2013.

73 SWIFT press release, 17 February 2013.

74 Council Decision 2012/152/CFSP of 15 March 2012 amending Decision 2010/413/CFSP concerning restrictive measures against Iran, Official Journal of the European Union, 77/18, 16 March 2012; Council Regulation (EU) No. 267/2012 of 23 March 2012 concerning restrictive measures against Iran and repealing Regulation (EU) No 96, Official Journal of the European Union, 88/1, 24 March 2012.

75 Personal email communication with Blanche Petre, 12 May 2013.

76 SWIFT press release, 15 March 2012. See also BBC, "Iran's banks to be blocked from global banking system”, 15 March 2012 (www.bbc.co.uk/news/business-17390456); US Department of the Treasury, Statement by Under Secretary David Cohen on "Action by the EU and Swift to terminate service for sanctioned Iranian banks", 15 March 2012 (www.treasury.gov/press-center/pressreleases/Pages/tg1451.aspx).

77 See PL 112-158 (http://www.gpo.gov/fdsys/pkg/PLAW-112publ158/html/ PLAW-112publ158.htm).

78 "Swift - Q\&A - Gottfried Leibbrandt."

79 Reuters, "EU Court rules for second time against Iran bank sanctions", 6 February 2013 (www.reuters.com/article/2013/02/06/us-iran-sanctions-euidUSBRE91514220130206); European Law Blog, "General Court rulings on Iranian banks threaten to torpedo EU's foreign policy ambitions" (europeanlawblog.eu/?p=1639); see European Court of Justice General Court cases T-494/10 (Bank Saderat Iran), 5 February 2013, T-496/10 (Bank Mellat), 29 January 2013.

80 US Department of the Treasury Office of Foreign Assets Control, "Advisory on the use of exchange houses and trading companies to evade US economic sanctions against Iran”, 10 January 2013 (http://www.treasury.gov/resource-center/ sanctions/Programs/Documents/20130110_iran_advisory_exchange_house. pdf); Leila Hatoum and Nicolas Parasie, "Iran banks said to be skirting cash ban”, The Wall Street Journal, 6 February 2013.

81 Personal email communication with Blanche Petre, 12 May 2013.

82 Ibid.

83 For further related discussion, see Jack Goldsmith and Tim Wu, Who Controls the Internet? (Oxford: Oxford University Press, 2008); see also Darryl S.L. Jarvis, ed., Infrastructure Regulation: What Works, Why and How Do We Know? Lessons from Asia and Beyond (Milton Keynes: Oxford University Press, 2011).

84 The exclusion of Iranian institutions is now brought to bear on other news stories about SWIFT. For example: "What would happen if the world's largest electronic payment system suddenly stopped working at a large number of financial institutions in your country? That happened last month when 19 Iranian banks and 25 affiliated institutions were disconnected in an unprecedented move from the SWIFT network... While the 'outage' in Iran was deliberate, at 0200 local New Zealand time Wednesday, the SWIFT payment system into that 
country suffered a technical 'glitch' that significantly impeded its use, various New Zealand news media reported. The importance of SWIFT to a country's financial institutions can't be overstated... it is 'the glue of the global banking system'... SWIFT is as important in New Zealand as it is in Iran" (Robert N. Charette, "Faulty cable delays thousands of SWIFT payments in New Zealand," Spectrum IEEE, 26 Apr 2012; http://spectrum.ieee.org/riskfactor/computing/it/ faulty-cable-impedes-swift-payments-in-new-zealand).

85 Lázaro Campos (interviewed by Susan Scott and Markos Zachariadis [in person], La Hulpe, Belgium, 17 February 2012).

86 Lenny Schrank quoted in Microsoft's OnWindows online magazine: “Ten years ago the system could have had improvements operationally, but today it operates at 'five nines' reliability and our customers take that for granted. Also, ten years ago our prices were high, but today the average price for a SWIFT message is 70 percent less and continues to be reduced. And in this era of cost control that's very important to our members" (http://www.onwindows.com/ Articles/Leonard-Schrank--Swift/82/Default.aspx).

87 Lenny Schrank quoted in article by Tom Groenfeldt, "CEO repositioning Swift as market-driven", American Banker, 9 October 1996.

88 Lenny Schrank (interviewed by Susan Scott and Markos Zachariadis [in person], La Hulpe, Belgium, 19 April 2012).

89 John Law, Aircraft Stories: Decentering the Object in Technoscience (Durham, NC: Duke University Press, 2002).

90 "Swift - Q\&A - Gottfried Leibbrandt."

91 Robert C. Merton, "Financial innovation and economic performance", Journal of Applied Corporate Finance, 4, (4) (1992): 12.

92 A classic text on globalization and globality is Roland Robertson, Globalization: Social Theory and Global Culture (Thousand Oaks, CA: Sage, 1992); see also Zygmunt Bauman, Globalization: The Human Consequences (Cambridge: Polity, 1998); Malcolm Waters, Globalization (London: Routledge, 2001); Anthony Giddens, Runaway World: How Globalization is Reshaping our Lives (Cambridge: Polity, 2002).

93 Alec Nacamuli (interviewed by Susan Scott [in person], London, 14 May 2012).

$94 \mathrm{See}$ http://www.swift.com/assets/swift_com/documents/about_swift/SIF_ 2013_04.pdf. For further traffic statistics, see http://www.swift.com/about_ swift/company_information/swift_in_figures.

95 See Rawi Abdelal, Capital Rules: The Construction of Global Finance (Boston, MA: Harvard University Press, 2007).

96 Thomas L. Friedman, The World is Flat: The Globalized World in the Twentyfirst Century (London: Penguin, 2007).

97 This expression refers to the move from traditional to rational forms of thought and in particular to the highly standard, rationalized production process that typifies the production of food in US McDonald's outlets. It has become a synonym for mind-numbing sameness. For an updated discussion, see George Ritzer, The McDonaldization of Society: 20th Anniversary Edition (Thousand Oaks, CA: Sage, 2012).

98 See Abdelal, Capital Rules.

99 See Robertson, Globalization: 186. A portmanteau word of global and local coined to convey an approach that attempts to simultaneously address the needs and interests of both communities. 
100 Lázaro Campos (interviewed by Susan Scott and Markos Zachariadis [in person], La Hulpe, Belgium, 17 February 2012).

101 Interview with Lázaro Campos, in Frances Maguire, "Relationship management at heart of Swift's new structure", The Banker, 1 October 2007. Maguire goes on to say "The organisation that $\mathrm{Mr}$ Campos oversees today is very different from the shared worldwide data processing and communications link established in 1973."

102 Pankaj Ghemawat, Redefining Global Strategy: Crossing Borders in a World where Differences Still Matter (Boston, MA: Harvard Business School Press, 2007). Ghemawat presents an analysis of data to support his argument that the real state of the world is one of semi-globalization rather than either zero or complete cross-border integration. He goes on to suggest that neither strategies of local customization nor total standardization will work. Instead he proposes strategies that focus on the differences that arise between national borders and the bridges that cross them.

103 Gottfried Leibbrandt (interviewed by Susan Scott and Markos Zachariadis [in person], La Hulpe, Belgium, 21 December 2011).

104 Lázaro Campos (interviewed by Susan Scott and Markos Zachariadis [in person], La Hulpe, Belgium, 17 February 2012). 


\section{Conclusion}

The Society for Worldwide Interbank Financial Telecommunication, SWIFT, has existed for 40 years. ${ }^{1}$ In this time, it has significantly reconfigured the core structure of transaction banking and securities businesses, becoming the most prominent standards body in the global banking community with standards that permeate every corner of international financial messaging. Anyone who has been involved in the transfer of an international cross-currency payment in business or with family and friends living abroad has benefited from SWIFT. Performing at 99.999 percent reliability (referred to as SWIFT's "Five Nines culture") the cooperative has provided remarkable dependability and efficiency in the financial services infrastructure, and produced - as noted in its signature storyline - "the world's most trusted third party secure network."

Conscious of security, SWIFT has remained elusive for much of its history. An internet search for SWIFT returns more results about the singer Taylor Swift than the cooperative society that lies at the core of the transactional world. As a consequence, SWIFT is largely taken for granted and simply referred to as "the plumbing". More recent generations of financial services professionals tend to dismiss the achievements embodied in its platform technology while conventional bankers wave away its efforts to build out into new products and services. The main purpose of this book has been to assemble an account of SWIFT's complex and multi-threaded organization and examine the complicated issues in which it is entangled. In drawing this material together, we hope to have contributed toward dispelling the common view that SWIFT is "just the back office" in financial services.

Returning to the metaphor of a kaleidoscope, we have seen that SWIFT has patterned practices and processes in financial services within a defined spectrum of possibility pivoting on a central mechanism - its cooperative organizational form. While governance provides SWIFT with definitional momentum this is inevitably intertwined with multiple other influences which interplay with its organizational experience. In the current phase of 


\section{Conclusion}

globalization the boundary between the internal organization and its external environment is negotiated rather than given. More recent events (TFTP, Iran sanctions) have vividly illustrated this, reaching to the core values of SWIFT's governance and standing as a global institution. As participants in our research project kept emphasizing, SWIFT has been drawn into other storylines that are still in the process of unfolding. Rather than treating SWIFT as a stand-alone organization, we have continually placed it in broader context in order to better understand its legacy and contribution. In our concluding comments, we pause to locate SWIFT in the trajectory of discourse on global governance as follows.

After World War II, it was thought that international organizations (such as the United Nations) would play a significant role in creating unified processes for addressing problems of global concern. As scholars of global governance have noted, this particular notion of international organization offered too much and delivered too little, becoming entangled in political controversies created by the end of colonial empire and the relative decline of the US. ${ }^{2}$ SWIFT represents a different genre of international cooperation reflecting the "search for a more feasible, less ambitious order focused on management, the acceptance of scarcity, and the avoidance of dependence on US power." 3 It is part of a generation of private mechanisms through which global governance is currently routed, stimulating an ethical debate about where the fundamental political units that rule our world lie. ${ }^{4}$ The issues are more complicated than they might at first appear: as discussed in Chapter 5, organizations like SWIFT find themselves being simultaneously used as the glue for capitalism and the stick with which instruments such as sanctions are enforced.

Global institutions are diverse but among the range of issues faced by SWIFT we can find traces of more general controversies that envelop private mechanisms placed in positions of high dependence. As discussed in Chapter 1, SWIFT emerged during an era when financial services formed "clubs" as a way of organizing collective action. Therefore although at the time of its founding the original voting and representation arrangements followed a "flatter" cooperative model (one vote per member regardless of volume or size), it nonetheless had the flavour of an autocracy (albeit offset by an ad hoc start-up organizational culture). Gradually access to membership was pried open, pricing formulas changed, rules governing appropriate use of surplus were tightened, and a more business-centred management descended. With it the multilateral and democratic lines along which its cooperative governance was first instituted were subtly reconfigured ushering in new forms of accountability. The spectrum of ways in which SWIFT's underlying governance has manifested suggests that a detailed historical examination of other global institutions is crucial. 
In SWIFT's history, themes emerge that characterize much of the discourse about global governance: speculation about the processes and relationships through which we can collectively act; concern about balance of powers; voluntary consensus; tough negotiation; anxiety about global uncertainty; data governance; and private legal action holding political issues at bay. All this takes place amid complicated, dynamic relationships between global, transnational, regional, and local interests. Close examination of organizations in SWIFT's position help us to identify the choices, ideas, assumptions, and mechanisms that define possibilities for global governance. In sum, such case studies contribute to our understanding of the global playbook and support the development of terms in which policymakers, scholars, and practitioners can debate the nature of the world's problems as well as the apparatus through which they are being worked out in practice.

We will have to wait and see whether SWIFT's resilience extends to its institutional identity as a "global" entity. However, we can be certain that SWIFT will see no respite from the effort required to manage ongoing debates about what it is and who controls it. From an academic perspective, we would say that this is an example of how structure is always underdetermined and contingent on other social, economic, and political agencies. In other words, the debates that surround SWIFT remind us all that "things could be different": relationships are not given but made. This is not to suggest that SWIFT sits passively in the midst of global affairs, far from it; as a defined and socially legitimate "organizational field" its financial services community is capable of participating in the construction of its own environment rather than simply responding to it. ${ }^{5} \mathrm{We}$ find grounds to support this in the various services and products that SWIFT is working on that recognize the changing "field of action" (sanctions checking, multiple authentication methods, ecology thinking, consumer grid projects, collaborative innovation).

SWIFT is an organization that spans a significant breadth of concerns and organizational interests which makes our representation of it necessarily fractional. Indeed, comprehensive coverage was not our aim; our interest in business history motivated a detailed engagement with distributed sources in order to establish a frame for understanding the content, conditions, and context of this study. We have attempted to find a balance across multiple forms of research material from archive documents, quantitative data sets, research interviews, and industry sources. The interviews enabled us to personalize the narrative of events but it is important to emphasize that producing an account of a global institution such as SWIFT with its extensive community of practice entails more than simply noting the roles of individuals. First, for a variety of practical reasons, we could not interview 


\section{4}

everyone of significance in a forty-year organizational study spanning so many different aspects of financial service. Second, the professionals involved are themselves enmeshed within - and produced through structures that are better understood by undertaking a broader analysis of organizational practice rather than focusing on individual careers. ${ }^{6}$

We have been selective rather than systematic in our use of academic literature because our primary purpose was to provide a detailed empirical understanding of SWIFT. We pursue a particular analytical strategy whereby, at appropriate junctures, we step back from an internal focus on SWIFT and connect particular points to academic discussions. In so doing, we highlight broader issues and themes that may be of wider interest. Our aim has been to interpret the material available to us in an informed manner in order to produce an independent analysis of a global institution that is useful to the lay public, students, policy-makers, and entry-level professionals. What did we not cover? Although we studied a substantial body of documentation, we did not spend time documenting the work of the National User groups nor did we attend committees or Board meetings. We were not able to attend Sibos or Innotribe ${ }^{7}$ events although we studied video and web-based material in-depth. Arguably these constitute some of the most important hubs of community engagement created by SWIFT and a detailed treatment of them by scholars undertaking further research in this area is more than deserved. Additional data-gathering in all these areas would no doubt have given us further insight into how SWIFT works and we acknowledge this as a limitation of the book.

What of the future? The history of SWIFT can be broadly divided into four periods: establishing the cooperative society and achieving critical mass; developing standards and growth in network traffic; expanding membership to securities, infrastructures, and corporate treasuries; and in the current era coming to terms with features of contemporary globalization such as regionalization, geopolitics, hyperconnectivity, and the network economy. Formulation of organizational strategy needs to be evidence based and, while the analysis of firm performance is now relatively routine, we are far from understanding how to construct the appropriate tools needed to assess the contribution of infrastructure to productivity and innovation. This is an area where further research is needed.

From a reputational perspective, few organizations can rest on prior performance to safeguard their standing and global institutions in particular have always needed to be especially conscious of proactive trustbuilding with stakeholders. Indeed, we would argue that there is an increasing need for the development of "active trust" which is "won rather than called upon" based on mutual learning, dialogue, and substantiation. As previously discussed, there have been sound security reasons why 
SWIFT has maintained an elusive presence in the past. However this is no longer sustainable in an internet age of dynamic boundary-crossing communication. In terms of communications, Sibos has become a fixture as a serious discussion platform for working through operational issues and a networking event where senior figures get business done. Recent outreach programs such as Innotribe and the establishment of the SWIFT Institute 8 research programme have done much to acknowledge the cooperative's position as a global nexus able to provide privileged access to knowledge and resources. By supporting the production of publicly available research, SWIFT has made important moves toward fulfilling a regulatory obligation that all financial services organizations are charged with: "Know Thyself".

Although the cooperative form will no doubt be debated again, there remains a role for "knowledge brokers" and demand for open spaces in which to develop projects. Individual for-profit companies may complain about the speed of progress but tend to balk at bringing initiatives designed to benefit a critical mass in-house. It is sometimes important, if not essential, for particular endeavours to be sequestered while the necessary stepping-stones are laid in order to develop services that hold shared interest. In this regard, the community of practice underpinning SWIFT plays an important role in enabling the flow of ideas, the culmination of which is often uncertain and sometimes overlooked but nonetheless vital.

SWIFT's position at the community core means that both successes and failures will always be subject to critique. No organization experiences an entirely smooth path but as Winston Churchill said, "Success is not final, failure is not fatal: it is the courage to continue that counts." In other words, outside the arena of war and violence, no one has ever died from a single failure. Rather, it is the failure to keep trying to exceed expectations that brings the probability of doom. Small defeats are integral to the learning process, learning is part of continuous improvement, and perhaps this is the only realistic approach to global governance.

\section{Notes}

1 SWIFT celebrated its 40th anniversary on 3 May 2013.

2 Timothy J. Sinclair, Global Governance (Cambridge: Polity, 2012): 29.

3 Ibid., 29.

4 For further reading on the global governance debates referred to here, see the following: Sinclair, Global Governance; Thomas G. Weiss, Global Governance. Why? What? Whither? (Cambridge: Polity, 2013); Rorden Wilkinson, ed., The Global Governance Reader (London: Routledge, 2005); Helmut Willke, Smart Governance: Governing the Global Knowledge Society (Chicago, IL: University of Chicago Press, 2007). 
5 This approach was inspired by Christopher Grey's organizational history of signals intelligence work during World War II in Decoding Organization: Bletchley Park, Codebreaking and Organization Studies (Cambridge: Cambridge University Press, 2012): 255.

6 Ibid., 246.

7 SWIFT's Innotribe is described as follows: "Innotribe is SWIFT's initiative to enable collaborative innovation in financial services. We facilitate mould-breaking conferences, an incubator program for new industry solutions and an annual, global start-up competition. The common thread? The enormous power of ideas. Read ours, share yours and join The Tribe." (http://innotribe.com/)

8 The SWIFT Institute was founded in April 2012. Its core objectives are to: "Extend understanding of current practice and future needs in global financial services, with a particular focus on transaction banking. Foster independent research by giving grants, access to research data and publication opportunities for approved projects. Act as a catalyst for bringing the SWIFT community and academics together to explore ideas, share knowledge, and extend mutual understanding. The primary focus of the SWIFT Institute is transaction banking, covering the following areas: Payments; Clearing \& Settlement; Cash Management; Trade Finance; Trust \& Securities." (http://www.swiftinstitute.org/about-us/) A further research resource that has been made available is the SWIFT Index - a range of proprietary fact-based indexes that can be used to derive an early indication of the short-term evolution of the Gross Domestic Product (GDP) for a country or group of countries (http://www.swift.com/swiftindex).

9 We have borrowed this quotation from the editorial of a special issue on not-forprofit financial institutions by Bernardo Bátiz-Lazo and Mark Billings, "New perspectives on not-for-profit financial institutions - organizational form, performance, and governance", Business History, 54 (3) (2012): 309-24. 


\section{Select bibliography}

Bernardo Bátiz-Lazo, J. Carles Maixé-Altés, and Paul Thomes, Technological Innovation in Retail Finance: International Historical Perspectives (New York, NY: Routledge, 2011). In this book the authors present an international survey analyzing how technologically enabled innovation changed retail finance. A resource for business historians, particularly those interested in the history of technology in financial organizations. Also valuable for those interested in the development of institutions other than commercial banks (i.e. not-for-profit) in regions outside the US. Provides insights into how technologies and organizations mutually shape each other.

Ken Beauchamp, A History of Telegraphy: Its Technology and Application (London: The Institution of Engineering and Technology, 2008). Beauchamp's work explores the growth of telegraphy over two centuries, examining the discoveries and inventiveness of the experimenters and engineers involved, the equipment they designed and built, and the organization, applications, and effects on society. Alexandros-Andreas Krytsis, ed., Financial Markets and Organizational Technologies: Systems Architectures, Practices and Risks in the Era of Deregulation (London: Palgrave Macmillan Studies in Banking and Financial Institutions, 2010). In this edited volume, the authors explore the organizational context of deregulation with an emphasis on the role of information systems and financial engineering in reinventing the business of banking. The aim of the book is to show the interconnectivity between financial and operational risks with global webs of organizational and technological complexity.

Craig N. Murphy and JoAnne Yates, The International Organization for Standardization (ISO): Global Governance through Voluntary Consensus (London: Routledge, 2009). Murphy and Yates approach the study of ISO from a global governance perspective. They present a systematic discussion on the history and development of the organization and focus on the impact this had on the wider economic infrastructure through "the way commerce is conducted".

Peter Norman, Plumbers and Visionaries: Securities Settlement and Europe's Financial Market (Chichester: Wiley, 2007). This book provides an account of the history and future of the securities settlement industry in Europe. Focusing on key events over the last forty years, it examines the challenges posed by 
cross-border settlement during an era when most financial infrastructures only operated within national frontiers. Provides key insights into the evolution of the global capital markets.

Dominique Rambure and Alec Nacamuli, Payment Systems: From the Salt Mines to the Board Room (Houndsmill: Palgrave Macmillan, 2008). This book provides a thorough guide to payment instruments, the architecture of payment systems, the risk management that they enable, and the stakeholders that they serve. Alec Nacamuli was part of SWIFT's founding team and together with his co-author he offers an expert view on the role of payment systems in global business strategy.

David L. Stearns, Electronic Value Exchange: Origins of the Visa Electronic Payment System (London: Springer-Verlag, 2011). Stearns provides a theoretically-grounded empirical study of the VISA payment system. He examines the history, governance, and evolution of the organization including technological aspects of the Visa system.

\section{Websites}

www.swift.com/ (the primary source of information on the Society for Worldwide Interbank Financial Telecommunication (SWIFT) for the community. This website is aimed predominantly at the clients and members of the society. It provides details on the company structure, its offerings, product support, training, events, etc.).

www.iso.org/iso/home.htm (this is the home page for the International Organization for Standardization).

http://www.iso20022.org/ (the official ISO 20022 website for the Universal financial industry message scheme. It provides detailed information about the standard including a full catalogue of the messages, financial repository, and process for the development and maintenance of standards. Being the Registration Authority for ISO 20022, SWIFT is "the guardian of the ISO 20022 Financial Repository and the www.iso20022.org website").

http://www.iso15022.org/ (the ISO 15022 website includes the Data Field Dictionary and catalogue of messages for the standard as well as administrative details on the registration and requests handled by SWIFT. A suitable resource for those interested in understanding better the standard-setting process and financial messaging standards in the field of securities).

www.fatf-gafi.org/ (useful source of information about the Financial Action Task Force (FATF), an inter-governmental body whose objectives are to set standards and promote effective implementation of legal, regulatory, and operational measures for combating money-laundering, terrorist financing, and other related threats to the integrity of the international financial system).

www.sita.aero/about-sita/what-we-do/sita-history

Some major SWIFT national member and user groups websites (in English):

http://www.swiftuk.org.uk/

http://eng.rosswift.ru/

http://www.swift-switzerland.ch/ 


\section{Index}

Note: references to endnotes are indicated by (n)

auditing of security 43

authority, organizational 48

availability $39-40$

back-up systems 41

Bank Identifier Code 66-7

banking, correspondent $8-10$; definition 8

banking telecommunications, history of 10-11

banks, central: role in payment lifecycle 34

banks: definition attempted 143(n); network projects $13-15,17-18$

Belgian Data Privacy Commission 129,131

Belgian law: mutual entities 29

board of directors 31

Borsei, Arthur (box) 98

boundaries, changing 122

boundary management 119-27

branch codes 90(n)

Brussels as headquarters 16

Burroughs Corporation 16, 38, 95-6, (box) 98, 115(n)

Business Identifier Code 66-7, 90(n)

CEPT, tariff negotiations with 122-3

Cerveau, Jacques 38, 52(n), 53(n)

chairpersons (table) 16

CISADA see Comprehensive Iran

Sanctions, Accountability and

Divestment Act closed user groups 110; service

levels 32

coexistence of standards 75

committees 31, (figure) 31

community: engagement $43-7$; ethos 48 competition: MARTI network 17-18; from US TNBs 109

Comprehensive Iran Sanctions, Accountability and Divestment Act (CISADA) 133, 147(n)

convergence of standards 75-7, 92(n) cooperation: and competition 19-20; informal 19

cooperative governance, importance of 8 cooperative organizations: role in sector change 2

cooperative society 29-33; decision to operate as $15,25(\mathrm{n})$

cooperative status 119-27

'co-opetition' 19-20, 26(n)

corporate entities: service levels 32

correspondent banking $8-10$;

definition 8

critical mass for society $17-19$

cross-border payments 35

culture: organizational 33 ; shift in (box) 41

customer confidentiality and TFTP 132 customer data, US Government access to 129

data disclosure 129-30, 145(n)

data governance $127-33$ 
data searches and counter-terrorism 131

debate at Sibos 46

design: Cerveau, Jacques, by 38 ;

history of 38

diffusion of SWIFT (figure) 111, (table) 113, 117(n)-118(n)

director nominations 31,49 (n)

disruptions to network (box) 40-1

dual-zone messaging infrastructure

$130,131,146(n)$

earnings 30

Engeli, Max 61, 88(n)

error detection 39

ethos statement 20

EU privacy directive 130

European Banks International Company (EBIC) 9-10, 21(n), 22(n)

European Commission: complaint on tariffs filed with 123, 142(n); initiates formal proceedings $124,143(\mathrm{n})$; role in telecommunications 143(n)

expansion, reactions to 122

eXtensible Markup Language (XML) see XML

finance and administration group 32

finance and founding 29-30

Financial Action Task Force (FATF) $128,144(n)$

financial messaging standards, and voluntary consensus 56-60

financial services, innovation in 3

First National City Bank: MARTI network 17-18; in Message Switching Project 17

'Five Nines' (system availability) 39-40, 41

FIX protocol 60, (box) 77-9, 87(n)

founding of society 16

future, possible roles in 120-1

global organizations' future questioned 136

globalization 149(n); history of 8-10, 21(n); and local presence 139, 149(n); and nations 139, 149(n) globalizing bank services 10-13 governance 29, 49(n); global 152, $153,155(n)$ headquarters: description of 28-9; location $15,16,25(\mathrm{n}), 29$

illegal activity, tracking 128-9 infrastructure 34-5; critical 43 Innotribe 156(n) innovation in financial services 3 integrity of messages 39,65 international business: causes of expansion 9

international finance: London's growth 9; restrictions post-World War II 9, 21(n)

International Organisation for Standardization 66 see also ISO international trade, expansion of 8-10 international transactions before 1900 11, 23(n)

'internet for financial services' 1 interoperability of standards 75 Iranian institutions, exclusion of 133-6; effectiveness queried 135, 148(n); disconnection 134, 135, 148(n); sanctions legislation 133, 147(n)-148(n); UANI campaign $133,147(\mathrm{n})$

ISO 7775 (securities messages) 68, 90(n); limitations 68-9

ISO 9362 (first standard) 66

ISO 15022 69-70, 91(n); evolution to ISO 2002273

ISO 20022 73-9; advantages 74; costs 74, 92(n); layers 73-4; message standards creation 73-4; new message development procedure 84-5, 93(n)-94(n); Registration Authority 85, 94(n); as universal standard 73-4 ISO, relationship of society with 66-73 IT operations group 32

Kraa, Johannes 14, 15

Large-Value Payment Systems (LVPS) 33-4, 50(n)

liability for loss $2,5(\mathrm{n})$

maintenance: MT standards 83-4; MX standards $84-5$; working group 83-4, 93(n)

marketing group 32 
MARTI network 17-18; ultimatum to banks 18, 26(n)

membership: evolution 109-14; expansion 20-1; external factors influencing 112-13, 118(n); numbers (table) 113

message flow 35-6; structure (figure) 36; Y-copy routing 36, (figure) 37

message structure 61-6; blocks 63-5; original design 61 ; syntax 63, 89(n)

Message Switching Project (MSP) 14; First National City Bank and 17, 24(n)

message template: originator's data field 128

message types 61-6; categories 62, 89(n), (figure) 62, (table) 63

messages: first 65-6; first generation 62-6; integrity 39,65 ; translation between standards 75 , (figure) 76 migration: to SWIFT II 101, 104; to SWIFTNet 106-7

Miller, Heidi: speech at Sibos 2004 (box) 120-1, 141(n)

money laundering 128

monopolistic position alleged by European Commission 124, 143(n)

MT 100 message 88(n); example of 65

MT standards maintenance 83-4

MX standards maintenance 84-5

network: analysis of adoption and usage data 114; benefits for users 105, (table) 106, 117(n); capacity limitations 101, 116(n); diffusion 109-14; disruptions (box) 40-1; distributed network concept 101 ; early expansion 100, 115(n), 116(n); eligibility of countries to join 100 , 116(n); growth over 30 years 107; hardware upgrade 104; interface devices 96, 99, 115(n); launch 96; outsourcing 107; packet-switching 101, 116(n); scalable capacity 105 ; subsidizing countries joining 100 , 116(n); technical design 16; traffic volumes 100, (table) 104; upgrades, effects of 112, 118(n)

non-supervised entities: service levels 32

'not for profit' description 30 operations management 41 originator's data field 128

oversight $43,53(\mathrm{n})$

payment: infrastructures 33-8; lifecycle 33, (table) 34; risk 33, 50(n); stages (table) 34; system processes (table) 34; systems 33-8, 49(n) privacy, customer 129, 130, 143(n) private communications network development 13, 23(n) product range expansion 28 'promise to pay' basis 33, 49(n) protocols, prevalent 89(n) PTTs, tariff negotiations with 122-3 public authorities and data-processing monopolies 123-4, 143(n)

real-time gross settlement (RTGS) 33, $50(\mathrm{n})$; message flow 36 redundancy 41 regionalization 140

Registration Authority: ISO 9362 66; ISO 15022 70; ISO 20022 73, $85,94(n)$

regulation, absence of 43

reliability of system $38-9$

research methods 153,154 responsibilities, balancing multiple 32 risk management and complexity 137 , 148(n)-149(n)

roles 30

routing of messages $35-6$

Safe Harbor status 130, 146(n) sanctions, possible consequences of 136,138

'Second Globalization' 10, 22(n)

Secure Internet Protocol Network (SIPN) 107

securities industry and standards 69, 90(n)

security 39 ; auditing process 43 ; data, of 2; evolution of 42, (figure) 42;

leading role in $42-3$; report, independent annual 43 semi-globalization 140, 150(n) service levels 32 settlement agents 34, 50(n) shareholders: eligibility 30-1, 32, 49(n); influence 109 


\section{Index}

shareholding structure $30-1$

Sibos 43-7, (table) 44, 53(n), 54(n); changing role 45 ; debate at 46 ; finances of 47; planning 46; role 47

Singer Business Machines (box) 98

SITA: CEPT's tariff for 123; network 60, 88(n)

society: change, charges of resisting 125, 144(n); ethos 20; future, roles in 154-5; governance options 15; headquarters location 15, 16, 29; history of 7-21; ISO, relationship with 66-73; perception of 151; workings of 29-33

society membership: closed user groups 110 ; extension $110,117(\mathrm{n})$; growth (figure) 110; international fund managers 110, 117(n); La Poste, application by 124, 143(n); new categories of 125

ST 100 interface 99

standards 28, 53-86; advantages of 65-6; automatic message processing 56 ; benefits of 59, 86(n), 87(n); classes of 59-60, 87(n); coexistence 75 ; competing 59, 60, 87(n); concurrent support 74-5; convergence 75-7; definition 56, 86(n); development 8; development and implementation procedure 79-80, 81; effect on business (box) 57-8; evolution of 66-73, 91(n); financial messaging 56-60; globalization, and 10, 62; interoperability $73,74,75$; membership affected by new 112; migration 101, 104, 106-7; policy 79-80, 81; professionals 61-2; proprietary $17-18,60-1,69$; rival $17-18,68$; securities industry 69 ; securities messages 68 ; transactional messaging 56-7, 86(n)

Standards Coordination Group 77, 92(n)

Standards Department 80-1 standards-related documents (table) $82,93(\mathrm{n})$

standards repository, role as 127 standards-setting organizations 59-60, 87(n) standards working groups (SWGs) 80, 93(n)

start-up funding 29-30

straight-through processing (STP) 56-7, 86(n)

strategic speculation 13, 23(n)

subpoenas issued by US Treasury $129,145(\mathrm{n})$

supervised financial institutions: service levels 32

SWIFT, alternative to 121,141 (n)

SWIFT I 96; network map (figure) 97

SWIFT II 101, 104-6, 116(n)

SWIFT Institute 156(n)

SWIFT Interface Device (SID) 96, (box) 98

SWIFT Services Partners SA (SSP) 115(n)

SWIFT Terminal Services SA (STS) 99

SWIFTNet 106-9

system: availability 39-40; change review process 41 ; design, history of 38 ; monitoring 42 ; reliability $38-9$; security see security

systemic risks 37

systemically important payment systems (SIPS) 33, 43, 53(n)

tariff 142(n); negotiations with CEPT 122-3, 142(n)

technologies 37 ; investment in 37 , $38,51(\mathrm{n})$

technology and the network 95-109

telecommunications in banking, history of $10-11$

telex: compatibility $60-1$; legacy 67 , 90(n); limitations 12-13; manual payments process 12 ; network founded 11; revenues for PTTs 123; security procedures $11-12,23(\mathrm{n})$

Terrorist Finance Tracking Programme 127-33, 145(n); revised EU-US Agreement 131, 146(n), 147(n) third party, trusted $1,3,32,33$, $47,127,132,151$; sanctions, and 138

third party vendors 107,109

tiger teams 42, 53(n)

tracking illegal activity 128-9 
traffic: growth (table) 113; influence of user numbers on 114; statistics 149(n)

transaction infrastructure services (table) 35

transactional messaging standards 56-7, 86(n)

transport network 1

UN/CEFACT 70, 90(n)

UNIFI (UNIversal Financial Industry) message scheme see ISO 20022
Visa, comparison with 125-7, 144(n) voluntary consensus and standards 56-60

Wall Street Journal criticises Iran's access 133-4

X.25 (packet-switching protocol) 101

XML (eXtensible Markup Language)

70-3; message example (box) 71

Y-copy routing 36, (figure) 37 


\section{Routledge Global Institutions Series}

83 The Society for Worldwide Interbank Financial Telecommunication (SWIFT) (2014)

Cooperative governance for network innovation, standards, and community

by Susan V. Scott (London School of Economics and Political Science) and Markos Zachariadis (University of Warwick)

82 The International Politics of Human Rights (2014)

Rallying to the R2P cause?

edited by Monica Serrano (Colegio de Mexico) and Thomas G. Weiss (The CUNY Graduate Center)

81 Private Foundations and Development Partnerships (2014)

American philanthropy and global development agendas

Michael Moran (Swinburne University of Technology)

80 Nongovernmental Development Organizations and the Poverty Reduction Agenda (2014)

The moral crusaders

by Jonathan J. Makuwira (Royal Melbourne Institute of Technology

University)

79 Corporate Social Responsibility (2014)

The role of business in sustainable development

by Oliver F. Williams (University of Notre Dame)

78 Reducing Armed Violence with NGO Governance (2014)

edited by Rodney Bruce Hall (Oxford University) 
77 Transformations in Trade Politics (2014)

Participatory trade politics in West Africa

Silke Trommer (Murdoch University)

76 Committing to the Court (2013)

Rules, politics, and the International Criminal Court

by Yvonne M. Dutton (Indiana University)

75 Global Institutions of Religion (2013)

Ancient movers, modern shakers

by Katherine Marshall (Georgetown University)

74 Crisis of Global Sustainability (2013)

by Tapio Kanninen

73 The Group of Twenty (G20) (2013)

by Andrew F. Cooper (University of Waterloo) and Ramesh Thakur (Australian National University)

72 Peacebuilding (2013)

From concept to commission

by Rob Jenkins (Hunter College, CUNY)

71 Human Rights and Humanitarian Norms, Strategic Framing, and Intervention (2013)

Lessons for the Responsibility to Protect

by Melissa Labonte (Fordham University)

70 Feminist Strategies in International Governance (2013)

edited by Gülay Caglar (Humboldt University, Berlin), Elisabeth Prügl (the Graduate Institute of International and Development Studies, Geneva), and Susanne Zwingel (the State University of New York, Potsdam)

69 The Migration Industry and the Commercialization of International Migration (2013) edited by Thomas Gammeltoft-Hansen (Danish Institute for International Studies) and Ninna Nyberg Sørensen (Danish Institute for International Studies)

68 Integrating Africa (2013)

Decolonization's legacies, sovereignty, and the African Union by Martin Welz (University of Konstanz) 
67 Trade, Poverty, Development (2013)

Getting beyond the WTO's Doha deadlock

edited by Rorden Wilkinson (University of Manchester) and

James Scott (University of Manchester)

66 The United Nations Industrial Development Organization (UNIDO) (2012)

Industrial solutions for a sustainable future

by Stephen Browne (FUNDS Project)

65 The Millennium Development Goals and Beyond (2012)

Global development after 2015

edited by Rorden Wilkinson (University of Manchester) and

David Hulme (University of Manchester)

64 International Organizations as Self-Directed Actors (2012)

A framework for analysis

edited by Joel E. Oestreich (Drexel University)

63 Maritime Piracy (2012)

by Robert Haywood (One Earth Future Foundation) and Roberta Spivak (One Earth Future Foundation)

62 United Nations High Commissioner for Refugees (UNHCR) (2nd edition, 2012)

by Gil Loescher (University of Oxford), Alexander Betts (University of Oxford), and James Milner (University of Toronto)

61 International Law, International Relations, and Global

Governance (2012)

by Charlotte Ku (University of Illinois)

60 Global Health Governance (2012)

by Sophie Harman (City University, London)

59 The Council of Europe (2012)

by Martyn Bond (University of London)

58 The Security Governance of Regional Organizations (2011)

edited by Emil J. Kirchner (University of Essex) and

Roberto Dominguez (Suffolk University) 
57 The United Nations Development Programme and System (2011) by Stephen Browne (FUNDS Project)

56 The South Asian Association for Regional Cooperation (2011) An emerging collaboration architecture by Lawrence Sáez (University of London)

55 The UN Human Rights Council (2011) by Bertrand G. Ramcharan (Geneva Graduate Institute of International and Development Studies)

54 Responsibility to Protect (2011) Cultural perspectives in the Global South edited by Rama Mani (University of Oxford) and Thomas G. Weiss (The CUNY Graduate Center)

53 The International Trade Centre (2011)

Promoting exports for development by Stephen Browne (FUNDS Project) and Sam Laird (University of Nottingham)

52 The Idea of World Government (2011)

From ancient times to the twenty-first century by James A. Yunker (Western Illinois University)

51 Humanitarianism Contested (2011)

Where angels fear to tread by Michael Barnett (George Washington University) and Thomas G. Weiss (The CUNY Graduate Center)

50 The Organization of American States (2011) Global governance away from the media by Monica Herz (Catholic University, Rio de Janeiro)

49 Non-Governmental Organizations in World Politics (2011) The construction of global governance by Peter Willetts (City University, London)

48 The Forum on China-Africa Cooperation (FOCAC) (2011) by Ian Taylor (University of St. Andrews) 
47 Global Think Tanks (2011)

Policy networks and governance

by James G. McGann (University of Pennsylvania) with

Richard Sabatini

46 United Nations Educational, Scientific and Cultural Organization (UNESCO) (2011)

Creating norms for a complex world

by J.P. Singh (Georgetown University)

45 The International Labour Organization (2011)

Coming in from the cold

by Steve Hughes (Newcastle University) and Nigel Haworth

(University of Auckland)

44 Global Poverty (2010)

How global governance is failing the poor

by David Hulme (University of Manchester)

43 Global Governance, Poverty, and Inequality (2010)

edited by Jennifer Clapp (University of Waterloo) and

Rorden Wilkinson (University of Manchester)

42 Multilateral Counter-Terrorism (2010)

The global politics of cooperation and contestation

by Peter Romaniuk (John Jay College of Criminal Justice, CUNY)

41 Governing Climate Change (2010)

by Peter Newell (University of East Anglia) and Harriet A. Bulkeley

(Durham University)

40 The UN Secretary-General and Secretariat (2nd edition, 2010)

by Leon Gordenker (Princeton University)

39 Preventive Human Rights Strategies (2010)

by Bertrand G. Ramcharan (Geneva Graduate Institute of

International and Development Studies)

38 African Economic Institutions (2010)

by Kwame Akonor (Seton Hall University) 
37 Global Institutions and the HIV/AIDS Epidemic (2010)

Responding to an international crisis

by Franklyn Lisk (University of Warwick)

36 Regional Security (2010)

The capacity of international organizations

by Rodrigo Tavares (United Nations University)

35 The Organisation for Economic Co-operation and Development (2009)

by Richard Woodward (University of Hull)

34 Transnational Organized Crime (2009)

by Frank Madsen (University of Cambridge)

33 The United Nations and Human Rights (2nd edition, 2009)

A guide for a new era

by Julie A. Mertus (American University)

32 The International Organization for Standardization (2009)

Global governance through voluntary consensus

by Craig N. Murphy (Wellesley College) and JoAnne Yates

(Massachusetts Institute of Technology)

31 Shaping the Humanitarian World (2009)

by Peter Walker (Tufts University) and Daniel G. Maxwell (Tufts University)

30 Global Food and Agricultural Institutions (2009)

by John Shaw

29 Institutions of the Global South (2009)

by Jacqueline Anne Braveboy-Wagner (City College of New York, CUNY)

28 International Judicial Institutions (2009)

The architecture of international justice at home and abroad

by Richard J. Goldstone (Retired Justice of the Constitutional Court of South Africa) and Adam M. Smith (Harvard University)

27 The International Olympic Committee (2009)

The governance of the Olympic system

by Jean-Loup Chappelet (IDHEAP Swiss Graduate School of Public

Administration) and Brenda Kübler-Mabbott 


\section{The World Health Organization (2009)}

by Kelley Lee (London School of Hygiene and Tropical Medicine)

\section{Internet Governance (2009)}

The new frontier of global institutions

by John Mathiason (Syracuse University)

24 Institutions of the Asia-Pacific (2009)

ASEAN, APEC, and beyond

by Mark Beeson (University of Birmingham)

\section{United Nations High Commissioner for Refugees} (UNHCR) (2008)

The politics and practice of refugee protection into the twenty-first century

by Gil Loescher (University of Oxford), Alexander Betts (University of Oxford), and James Milner (University of Toronto)

\section{Contemporary Human Rights Ideas (2008)}

by Bertrand G. Ramcharan (Geneva Graduate Institute of

International and Development Studies)

\section{The World Bank (2008)}

From reconstruction to development to equity

by Katherine Marshall (Georgetown University)

\section{The European Union (2008)}

by Clive Archer (Manchester Metropolitan University)

19 The African Union (2008)

Challenges of globalization, security, and governance

by Samuel M. Makinda (Murdoch University) and F. Wafula Okumu

(McMaster University)

18 Commonwealth (2008)

Inter- and non-state contributions to global governance

by Timothy M. Shaw (Royal Roads University)

\section{The World Trade Organization (2007)}

Law, economics, and politics

by Bernard M. Hoekman (World Bank) and Petros C. Mavroidis

(Columbia University) 
16 A Crisis of Global Institutions? (2007)

Multilateralism and international security

by Edward Newman (University of Birmingham)

15 UN Conference on Trade and Development (2007)

by Ian Taylor (University of St. Andrews) and Karen Smith (University of Stellenbosch)

14 The Organization for Security and Co-operation in Europe (2007) by David J. Galbreath (University of Aberdeen)

13 The International Committee of the Red Cross (2007)

A neutral humanitarian actor

by David P. Forsythe (University of Nebraska) and Barbara Ann Rieffer-Flanagan (Central Washington University)

12 The World Economic Forum (2007)

A multi-stakeholder approach to global governance

by Geoffrey Allen Pigman (Bennington College)

11 The Group of 7/8 (2007)

by Hugo Dobson (University of Sheffield)

10 The International Monetary Fund (2007)

Politics of conditional lending

by James Raymond Vreeland (Georgetown University)

9 The North Atlantic Treaty Organization (2007)

The enduring alliance

by Julian Lindley-French (Center for Applied Policy, University

of Munich)

8 The World Intellectual Property Organization (2006)

Resurgence and the development agenda

by Chris May (University of the West of England)

7 The UN Security Council (2006)

Practice and promise

by Edward C. Luck (Columbia University)

6 Global Environmental Institutions (2006)

by Elizabeth R. DeSombre (Wellesley College) 


\section{Internal Displacement (2006)}

Conceptualization and its consequences

by Thomas G. Weiss (The CUNY Graduate Center) and David A. Korn

4 The UN General Assembly (2005)

by M. J. Peterson (University of Massachusetts, Amherst)

3 United Nations Global Conferences (2005)

by Michael G. Schechter (Michigan State University)

2 The UN Secretary-General and Secretariat (2005)

by Leon Gordenker (Princeton University)

1 The United Nations and Human Rights (2005)

A guide for a new era

by Julie A. Mertus (American University)

Books currently under contract include:

\section{The Regional Development Banks}

Lending with a regional flavor

by Jonathan R. Strand (University of Nevada)

\section{Millennium Development Goals (MDGs)}

For a people-centered development agenda?

by Sakiko Fukada-Parr (The New School)

\section{UNICEF}

by Richard Jolly (University of Sussex)

\section{The Bank for International Settlements}

The politics of global financial supervision in the age of high finance by Kevin Ozgercin (SUNY College at Old Westbury)

\section{International Migration}

by Khalid Koser (Geneva Centre for Security Policy)

\section{Human Development}

by Richard Ponzio

The International Monetary Fund (2nd edition)

Politics of conditional lending

by James Raymond Vreeland (Georgetown University) 


\section{The UN Global Compact}

by Catia Gregoratti (Lund University)

\section{Institutions for Women's Rights}

by Charlotte Patton (York College, CUNY) and Carolyn Stephenson (University of Hawaii)

\section{International Aid}

by Paul Mosley (University of Sheffield)

\section{Global Consumer Policy}

by Karsten Ronit (University of Copenhagen)

\section{The Changing Political Map of Global Governance}

by Anthony Payne (University of Sheffield) and Stephen Robert Buzdugan (Manchester Metropolitan University)

\section{Coping with Nuclear Weapons}

by W. Pal Sidhu

\section{Twenty-First-Century Democracy Promotion in the Americas}

by Jorge Heine (The Centre for International Governance Innovation) and Brigitte Weiffen (University of Konstanz)

\section{EU Environmental Policy and Climate Change}

by Henrik Selin (Boston University) and Stacy VanDeveer (University of New Hampshire)

\section{Making Global Institutions Work}

Power, accountability and change

edited by Kate Brennan

\section{Global Governance and China}

The dragon's learning curve

edited by Scott Kennedy (Indiana University)

The Politics of Global Economic Surveillance

by Martin S. Edwards (Seton Hall University)

\section{Mercy and Mercenaries}

Humanitarian agencies and private security companies by Peter Hoffman (The New School) 
Regional Organizations in the Middle East

by James Worrall (University of Leeds)

\section{Reforming the UN Development System}

The politics of incrementalism

by Silke Weinlich (Duisburg-Essen University)

\section{Post-2015 UN Development}

Making change happen

Edited by Stephen Browne (FUNDS Project) and Thomas G. Weiss (CUNY Graduate Center)

For further information regarding the series, please contact:

Craig Fowlie, Publisher, Politics and International Studies

Taylor \& Francis

2 Park Square, Milton Park, Abingdon

Oxford OX14 4RN, UK

+44 (0)207842 $2057 \mathrm{Tel}$

+44 (0)207842 2302 Fax

Craig.Fowlie@tandf.co.uk

www.routledge.com

\section{Who Participates?}

States, bureaucracies, NGOs and global governance by Molly Anne Ruhlman

The United Nations as a Knowledge Organization by Nanette Svenson (Tulane University)

United Nations Centre on Transnational Corporations (UNCTC) by Khalil Hamdani and Lorraine Ruffing

\section{The International Criminal Court}

The Politics and practice of prosecuting atrocity crimes by Martin Mennecke (University of Copenhagen) 